\title{
Multi-Scale Mass Transfer Processes Controlling Natural Attenuation and Engineered Remediation: An IFRC Focused on Hanford's 300 Area Uranium Plume
}

January 2010 to January 2011

Annual Report to the

DOE Office of Science, Climate and Environmental Sciences Division

\section{Principal Investigator:}

John Zachara, PNNL

\section{Co-Principal Investigators:}

Bruce Bjornstad, PNNL John Christensen, LBNL Mark Conrad, LBNL Jim Fredrickson, PNNL Mark Freshley, PNNL Roy Haggerty, OSU Glenn Hammond, PNNL Doug Kent, USGS Allan Konopka, PNNL
Chongxuan Liu, PNNL Jim McKinley, PNNL Chris Murray, PNNL Mark Rockhold, PNNL Yoram Rubin, $U$ of CA, Berkeley Vince Vermeul, PNNL Roelof Versteeg, Sky Research Inc. Andy Ward, PNNL Chunmiao Zheng, $U$ of $A L$

\section{Peter Lichtner, LANL}




\title{
DISCLAIMER
}

This report was prepared as an account of work sponsored by an agency of the United States Government. Neither the United States Government nor any agency thereof, nor Battelle Memorial Institute, nor any of their employees, makes any warranty, express or implied, or assumes any legal liability or responsibility for the accuracy, completeness, or usefulness of any information, apparatus, product, or process disclosed, or represents that its use would not infringe privately owned rights. Reference herein to any specific commercial product, process, or service by trade name, trademark, manufacturer, or otherwise does not necessarily constitute or imply its endorsement, recommendation, or favoring by the United States Government or any agency thereof, or Battelle Memorial Institute. The views and opinions of authors expressed herein do not necessarily state or reflect those of the United States Government or any agency thereof.

\author{
PACIFIC NORTHWEST NATIONAL LABORATORY \\ operated by \\ BATTELLE \\ for the \\ UNITED STATES DEPARTMENT OF ENERGY \\ under Contract DE-AC05-76RL01830
}

Printed in the United States of America
Available to DOE and DOE contractors from the Office of Scientific and Technical Information,
P.O. Box 62, Oak Ridge, TN 37831-0062;
ph: (865) 576-8401
fax: $(865)$ 576-5728
email: reports@adonis.osti.gov

\begin{abstract}
Available to the public from the National Technical Information Service, U.S. Department of Commerce, 5285 Port Royal Rd., Springfield, VA 22161 ph: (800) 553-6847 fax: $(703) 605-6900$ email: orders@ntis.fedworld.gov online ordering: http://www.ntis.gov/ordering.htm
\end{abstract}

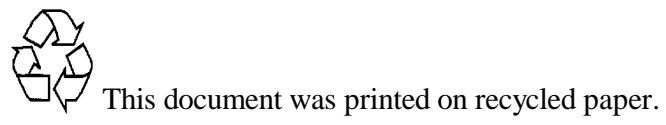




\section{Multi-Scale Mass Transfer Processes Controlling Natural Attenuation and Engineered Remediation: An IFRC Focused on Hanford's 300 Area Uranium Plume}

\section{January 2010 to January 2011}

Annual Report to the

DOE Office of Science, Climate and Environmental Sciences Division

J.M. Zachara, Principal Investigator

February 2011

Chemical \& Materials Sciences Division

Fundamental \& Computational Sciences Directorate

Pacific Northwest National Laboratory

Prepared for

the U.S. Department of Energy

under Contract DE AC05 76RL01830

Pacific Northwest National Laboratory

Richland, Washington 99352 
Multi-Scale Mass Transfer Processes Controlling Natural Attenuation and Engineered Remediation: An IFRC Focused on Hanford's 300 Area Uranium Plume

\section{Table of Contents}

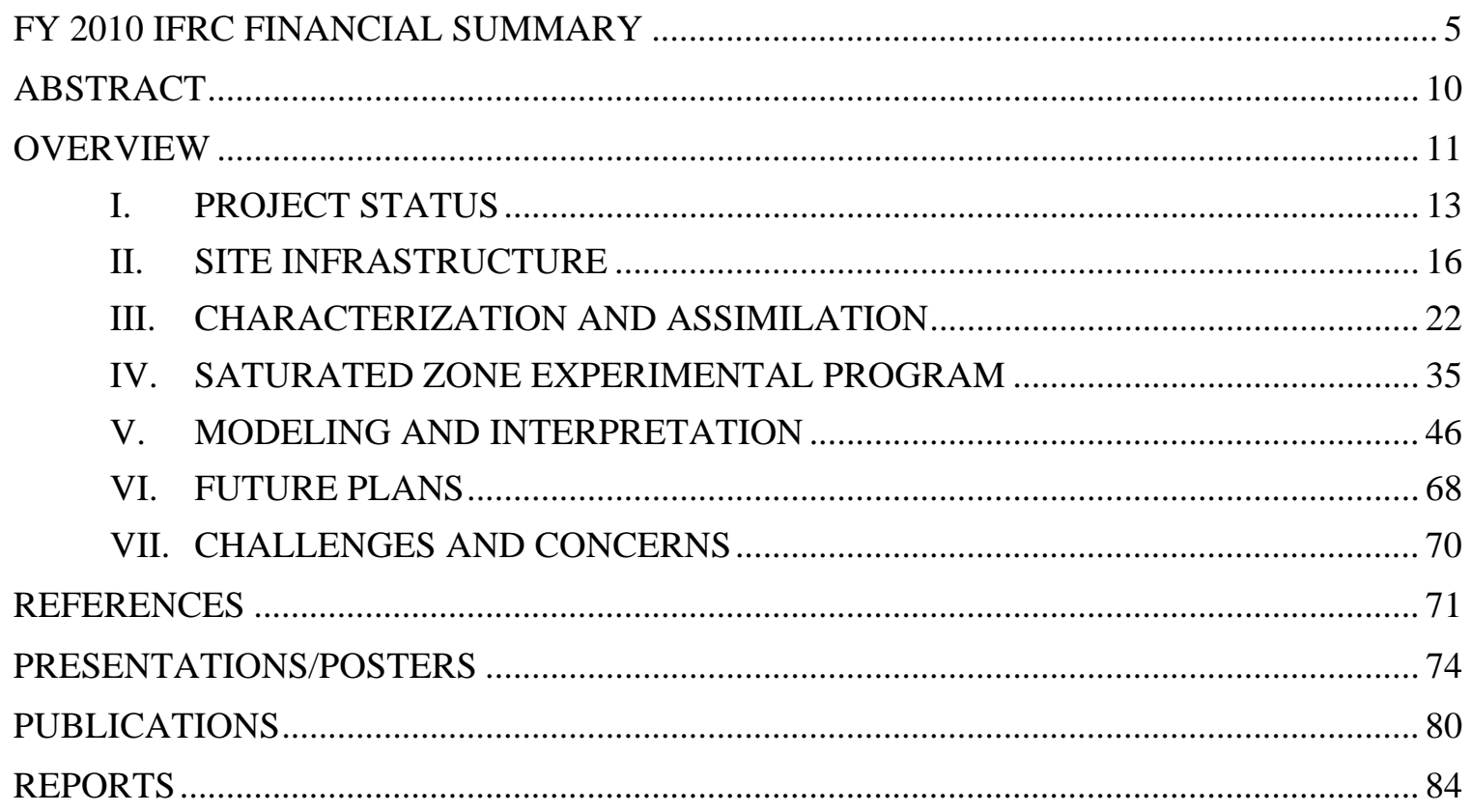




\begin{abstract}
The Integrated Field Research Challenge (IFRC) at the Hanford Site 300 Area uranium (U) plume addresses multi-scale mass transfer processes in a complex subsurface hydrogeologic setting where groundwater and riverwater interact. A series of forefront science questions on reactive mass transfer focus research. These questions relate to the effect of spatial heterogeneities; the importance of scale; coupled interactions between biogeochemical, hydrologic, and mass transfer processes; and measurements and approaches needed to characterize and model a mass-transfer dominated system. The project was initiated in February 2007, with CY 2007, CY 2008, and CY 2009 progress summarized in preceding reports. A project peer review was held in March 2010, and the IFRC project has responded to all suggestions and recommendations made in consequence by reviewers and SBR/DOE. These responses have included the development of "Modeling" and "Well-Field Mitigation" plans that are now posted on the Hanford IFRC web-site.
\end{abstract}

The site has 35 instrumented wells, and an extensive monitoring system. It includes a deep borehole for microbiologic and biogeochemical research that sampled the entire thickness of the unconfined $300 \mathrm{~A}$ aquifer. Significant, impactful progress has been made in CY 2010 including the quantification of wellbore flows in the fully screened wells and the testing of means to mitigate them; the development of site geostatistical models of hydrologic and geochemical properties including the distribution of $\mathrm{U}$; developing and parameterizing a reactive transport model of the smear zone that supplies contaminant $U$ to the groundwater plume; performance of a second passive experiment of the spring water table rise and fall event with a associated multi-point tracer test; performance of downhole biogeochemical experiments where colonization substrates and discrete water and gas samplers were deployed to the lower aquifer zone; and modeling of past injection experiments for model parameterization, deconvolution of well-bore flow effects, system understanding, and publication. We continued efforts to assimilate geophysical logging and 3D ERT characterization data into our site wide geophysical model, and have now implemented a new strategy for this activity to bypass an approach that was found unworkable.

An important focus of CY 2010 activities has been infrastructure modification to the IFRC site to eliminate vertical well bore flows in the fully screened wells. The mitigation procedure was carefully evaluated and is now being implementated. A new experimental campaign is planned for early spring 2011 that will utilize the modified well-field for a $U$ reactive transport experiment in the upper aquifer zone. Preliminary geophysical monitoring experiments of rainwater recharge in the vadose zone have been initiated with promising results, and a controlled infiltration experiment to evaluate $\mathrm{U}$ mobilization from the vadose zone is now under planning for the September 2011. The increasingly comprehensive field experimental results, along with the field and laboratory characterization, are leading to a new conceptual model of U(VI) flow and transport in the IFRC footprint and the 300 Area in general, and insights on the microbiological community and associated biogeochemical processes. 


\section{OVERVIEW}

\section{CY 2010 Accomplishments and Report Objective}

CY 2010 was a busy year for the Hanford IFRC team that was punctuated by a mid-term peer review in April 2010. While the outcome of the peer review was positive, a significant portion of the second half of the calendar year was spent devising a mitigation plan for vertical flows in IFRC wells. That troublesome situation is now under control and the IFRC team is looking forward to a busy spring experiment schedule focusing on the remediated well-field and the upper aquifer system. The following are important accomplishments for FY 2010.

- The behavior of non-reactive tracers and U(VI) in our preliminary U injection experiment performed in October 2009 indicated that vertical well bore flows were greatly complicating IFRC site monitoring data. A site wide study was consequently performed during November 2009 to February 2010 to monitor and quantify ambient vertical flows in all IFRC unscreened wells that lead to two publications.

- A modeling approach to explicitly account for the complex and varied effects of vertical wellbore flows was applied to monitoring data from one of our past IFRC transport experiments. The resulting simulations better matched the complex experimental data yielding an interesting manuscript that is now in press.

- An IFRC modeling plan and a well-field mitigation plan were developed in response to comments made at the Hanford IFRC peer review.

- A joint manuscript was initiated with the Rifle IFRC team to compare and contrast the behaviors of the U(VI) groundwater plumes at the two IFRC sites. The paper emphasizes their common hydrologic location in the groundwater-river interaction zone and the complex and dynamic process coupling that occurs. This activity was a recommended outcome of the March 2010 peer review.

- A comprehensive well-field remediation study was performed to ascertain the best approach to eliminate well-bore vertical flows in the fully screened IFRC wells. The study compared single packers, dual packers in sequence, and bentonite cementation. Bentonite cementation was the most effective solution.

- The data assimilation code, MAD, has been completed and it is being utilized to refine our hydrophysical model of the IFRC site, to quantify the uncertainty of key hydrologic parameters, and to integrate geophysical logging and characterization data of different forms. Several publications have already emerged from this activity with others in preparation.

- Significant progress has been made in developing a geochemical transport model of the dynamic water table zone that resupplies and sustains soluble U(VI) in the groundwater plume. This model is based on multi-scale experiments of smear zone sediments. It will be integrated with a geostatistical model of U(VI) concentration distribution in the extended smear zone for final deployment.

- A second passive monitoring experiment to evaluate U(VI) release from the deep vadose zone during the spring high river stage event was performed from April to July 2010. This experiment built on the findings of the 2009 experiment, and had a number of new and improved elements including a multi-point tracer test during the period of water table rise. The experiment was highly successful. It validated the vadose zone release model and captured a river water intrusion event that moved across site changing water composition and $U$ distribution. 
In the text that follows we will summarize: i.) project status; ii.) modifications to site infrastructure; iii.) progress on site characterization and data assimilation; iv.) select results of the saturated zone experimental program; v.) modeling activities for experiment analysis, interpretation, and experiment planning; vi.) future plans, and vii.) challenges and concerns. Our objective in this reporting is to provide significant and select highlights, rather than an exhaustive or detailed summary of activities and findings. A Hanford IFRC poster session at the SBR Annual Meeting in April 2011 will emphasize detailed scientific findings and future plans. 


\section{PROJECT STATUS}

Project activities in FY 2010 were primarily focused on: i.) preparing for and responding to comments from the March 2010 peer review, ii.) publishing results from site characterization and field experimental activities, and iii.) devising a mitigation approach for vertical well bore flows in IFRC fully screened wells. Our project status is summarized in Figure I-1. Overall, progress has been excellent as shown by completed activities in FY 2010 (e.g., blue), and this progress has translated into increased publication productivity (see PRESENTATIONS, POSTERS, and PUBLICATIONS).

A number of planned activities were deferred (green), including four different experiments for the saturated zone (e.g., multi-tracer/cold water, desorption injection, adsorption injection, and isotopic exchange). These activities were deferred to FY 2011 and beyond because of concern that vertical well-flows might compromise the quality of field experimental data. The funding for these activities was consequently re-directed to a comprehensive study of well bore flows in the IFRC well-field, and approaches to mitigate them. The findings of this study were reported to the SBR and FREC in October 2010 in the form of a "Well Field Mitigation Plan". This study was very successful, yielding two publications and documented methodology to fix the well-field hydraulic problem (bentonite pellets). That fix is now being implemented. Well-field mitigation will result in a monitoring system that samples the smear zone and the upper $1 \mathrm{~m}$ (high conductivity zone) of the saturated zone U(VI) plume. This dynamic zone is the region of both U(VI) resupply to the plume, and intrusion of river waters of dissimilar composition.

A short-coming to the well mitigation approach is that the lower third of our existing down-hole ERT monitoring system will be compromised by the bentonite seal. A "Geophysical Monitoring and Research Plan" was consequently drafted in late CY 2010 for internal project use to identify approaches for replacement of geophysical monitoring capabilities (and their cost), and to provide needed direction for future IFRC geophysical research and infrastructure investments. An important question was to identify scientific opportunities that would be inaccessible with the truncated geophysical monitoring system. Beyond the question of scientific opportunity, difficulties have been encountered in the quantitative assimilation of our current geophysical measurements into the IFRC site hydro-physical model, and a new scientific strategy for this activity was developed as the "Geophysics Plan" was being formulated. This new strategy for robust use of past geophysical measurements is now being implemented with encouraging initial results. We are now tracking this activity as a major project outcome because of its importance (Figure I-1).

IFRC plans for vadose zone research continue to evolve as different technical questions and issues arise for the $300 \mathrm{~A}$ (e.g., does infiltration occur through the contaminated vadose zone and does it impact groundwater quality?), and as results accrue from our very successful passive monitoring experiments of the deep vadose zone during water table rise and fall. Given soon to be rectified problems with the IFRC saturated zone monitoring array that have delayed our saturated zone experimental plan, development of the vadose zone site has been deferred pending the outcome of two exploratory activities. The first of these is an evaluation of our ability to: i.) monitor infiltration events through the vadose zone during "wet" winter months using a combination of multiple surface and downhole geophysical methods, and ii.) transform geophysical measurements into meaningful 
information on vadose zone water content and transport velocities. This "feasibility" experiment, planned with publication in mind, has now been underway for 1.5 months with encouraging results. We expect to utilize results from this monitoring experiment to plan a vadose zone infiltration/ $\mathrm{U}$ mobilization experiment for September 2011. The second exploratory activity is summer field testing of the ability to install multiple depth-piezometers between 5 and $8 \mathrm{~m}$ into the vadose and smear zones by direct push technology. The intent of these piezometers would be to monitor pore-water compositions at multiple depths and spatial locations, and the response of groundwater composition to surface infiltration events and water table rise and fall. If the testing is positive, peizometers will be installed at locations informed by site characterization and passive experiment results.

Hanford IFRC management is beginning to think of next year's (FY 2012) SBR IFRC proposal call in terms of shoring up major scientific accomplishments through FY 2011 field experimentation and publication, and identifying impactful follow-on science themes and approaches. 


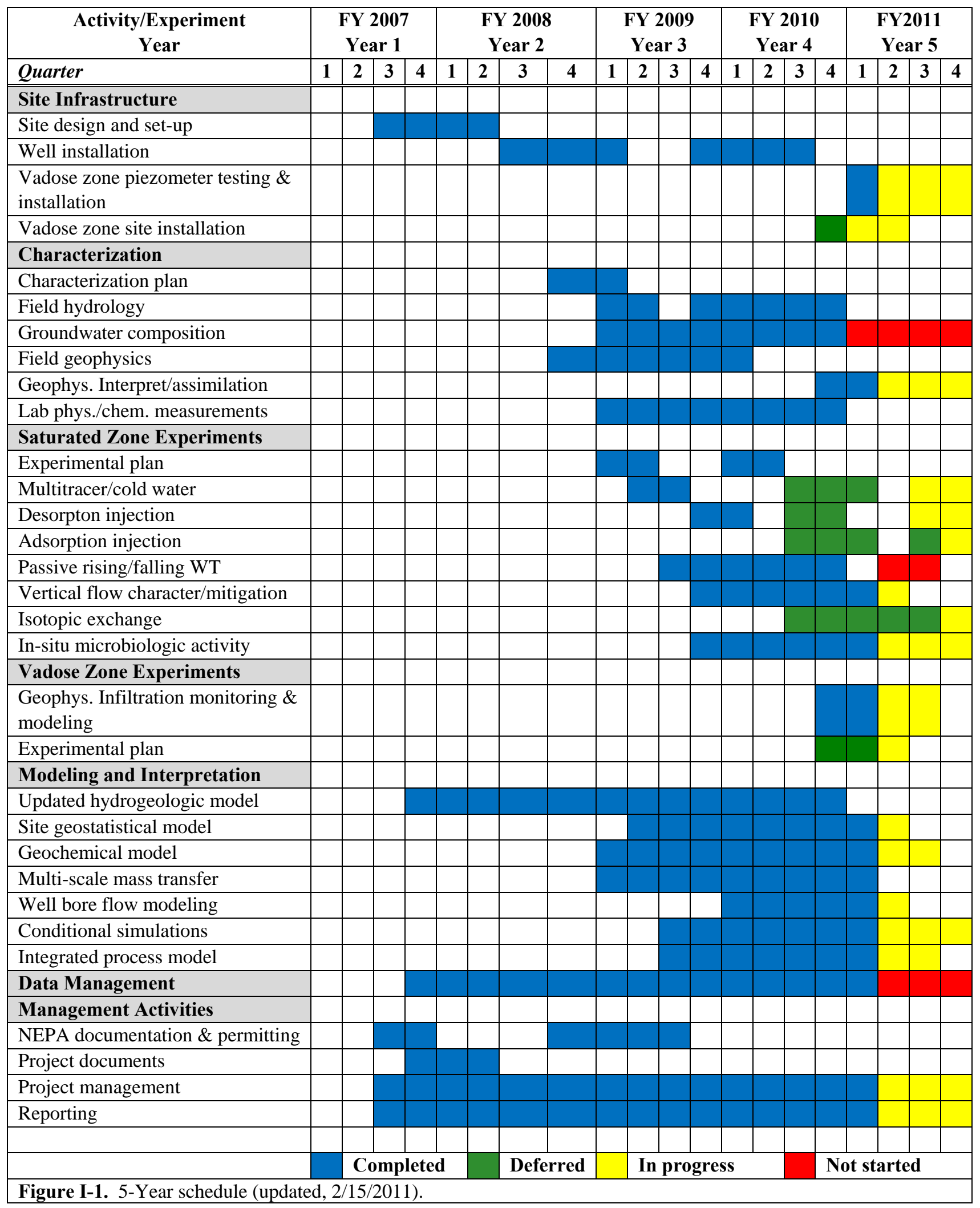




\section{SITE INFRASTRUCTURE}

\section{New, Shallow Monitoring Wells}

Three new shallow monitoring wells were installed in early March 2010 (Figure II-1). The wells were screened from 7.0-11.6 mbgs (meters below ground surface) to allow monitoring of the seasonally saturated smear zone (7.0-10.6 mbgs) and the upper $1 \mathrm{~m}$ of the saturated zone (10.6-11.6 mbgs). A primary use for these new wells is monitoring the release of sorbed U(VI) from the deep vadose zone during periods of high water table. Grab samples were collected every $0.5 \mathrm{~m}$ during borehole advance, and these were added to the IFRC sediment repository. The method of well completion was described in Bjornstad and Vermeul, 2009 (Drilling and Sampling Specifications for New FY 2010 Well Installations in the 300 A to Support PNNL's Integrated Field-Scale Subsurface Research Challenge Project) which is posted on the IFRC web-site.

\section{Well Remediation Activities}

As was discussed in Zachara et al., 2010 [HANFORD IFRC QUARTERLY REPORT, October 2010, Well Field Mitigation Plan], a series of well mitigation trials were conducted in well 399-2-21 to assess the effectiveness of various approaches for increasing hydraulic resistance within the wellbore, and thus minimizing the impacts of vertical wellbore flows on measured aqueous concentrations in wells. The mitigation trials in well 399-2-21 coincided with the Spring 2010 Passive Experiment, which included both daily monitoring of aqueous uranium concentrations in selected wells and a tracer injection and drift test conducted in an adjacent upper zone well. Following this field campaign, a second well mitigation trial was performed in well 399-2-22. A brief description of the approach used in these trails and an evaluation of monitoring results are provided below.

The well mitigation trials in Well 399-2-21, which were performed between June and November, 2010, included an evaluation of three successively more rigorous approaches for mitigating wellbore flow. Approaches tested included deployment of 1) a single 30-in long inflatable packer, 2) two 30-in inflatable packers in series, and 3) a bentonite plug installed over the full thickness of the lower and intermediate zones (i.e., $\sim$ bottom $2 / 3$ of the well screen). EBF and water-level measurements were made during the full trial period (Figure II-2) and U samples were collected into early September, approximately three weeks after installation of the bentonite plug (Figure II-3).

The initial single-packer installation was deployed when the Columbia River displayed its maximum yearly fluctuation. The packer significantly reduced the magnitude of wellbore flows as compared to data collected without a packer the year before (Figure II-4), but had little impact on the frequency and oscillation of flow that were controlled by river stage changes. Soon after this single packer experiment, a dual packer string was deployed and a simple tracer intercommunication test performed that verified solute exchange from the lower to the upper zone in presence of the two packers (Zachara et al., 2010). Immediately following the two week test with a dual packer string, the lower portion of well 2-21was filled with bentonite pellets, effectively sealing the wellbore from 40 to $56 \mathrm{ft}$ bgs. EBF monitoring and $\mathrm{U}$ sampling and analysis continued following deployment of the bentonite plug. The resulting EBF monitoring data (Figures II-2 and II-3) indicate that the bentonite plug provides an effective approach for mitigating vertical wellbore flows at the IFRC site. The initial interpretation of these data (Zachara et al., 2010), which concluded that the bentonite plug was ineffective, was impacted by spurious EBF data that resulted from a defect in the probe cable. Once this malfunction was identified and a new cable was 
deployed, it became clear that the EBF data collected between early August and October were suspect. An evaluation of subsequent EBF monitoring data using a new EBF cable indicated that the bentonite plug was indeed effective (see November, 2010 data period in Figure II-2, annotated as "new probe"). This assessment is consistent with the $\mathrm{U}$ data that was collected during the trial (Figure II-3), which shows a clear difference in $\mathrm{U}$ response between the dual-packer and bentonite plug deployment.

Following completion of the well mitigation trials in well 300-2-21, a similar field trial was performed in nearby well 399-2-22, another well that exhibited relatively large ambient wellbore flows. The same wellbore flow mitigation approaches were tested in this well, with similar results. Figure II-5 shows EBF and water-level elevation measurements thought the trial period, which includes an open wellbore (baseline), dual packer installation, single packer installation, and a bentonite plug. Wellbore flows are increasingly mitigated with each successive increase in seal effectiveness, with the bentonite plug installation indicating good seal performance. Figure II-6 shows the EBF data plotted in relation to vertical head difference measured in the adjacent three well cluster. The amplitude of the wellbore flow and head difference responses is not fully correlated throughout the baseline monitoring period, owing to the difficulty of accurately calculating these small head differences from available water-level measurements. However, it is clear that the frequency of flow direction reversal is very well correlated and thus provides a useful measure for comparison between the various trial periods. As indicated, vertical gradients are still highly variable during the bentonite plug monitoring period, with no corresponding indication of vertical wellbore flow.

\section{Upper Zone Hydrologic Characterization Approach}

Once wellbore flow mitigation activities are completed and all wells are reconfigured to limit communication (to the extent possible) to the upper portion of the aquifer (February 2011), additional hydrologic characterization of the well-field will be performed. This field testing campaign is needed to better quantify the bulk hydraulic conductivity, and its vertical distribution, within the upper aquifer. Previous hydraulic characterization activities were performed over the full aquifer thickness and because the lower zone was highly permeable and thus tended to dominate the response, hydraulic property estimates for the upper aquifer are somewhat uncertain.

Planned hydraulic tests include detailed ambient and dynamic EBF profiling over the upper interval and constant-rate injection testing. EBF profiles will be conducted at multiple water table elevations (i.e., up to three elevations for wells with sufficient screen length, two elevations for most wells) to provide for different scales of interrogation. Constant rate injection tests will be conducted in a subset of wells located throughout the well-field to obtain spatially distributed estimates of bulk hydraulic conductivity. 


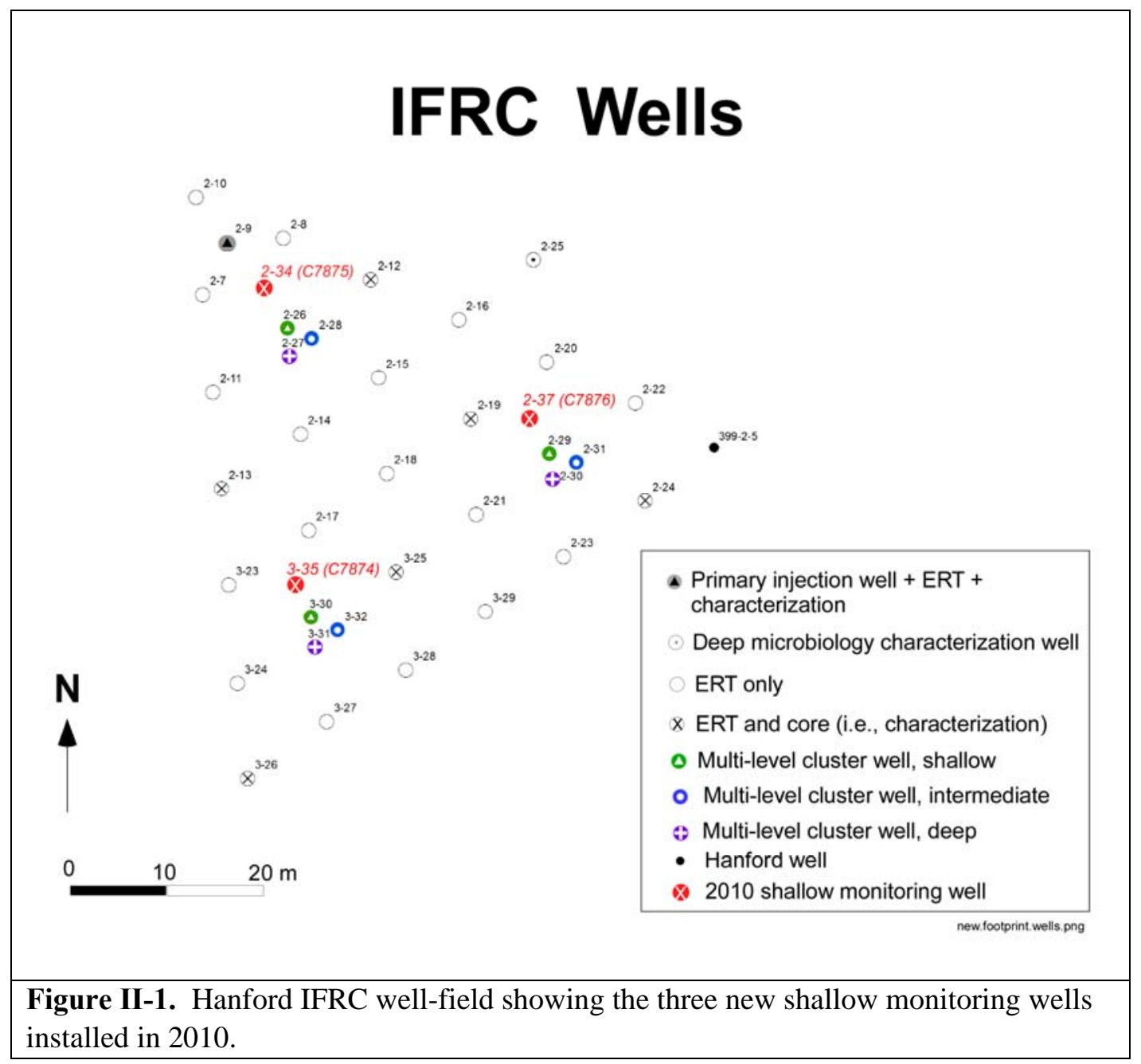




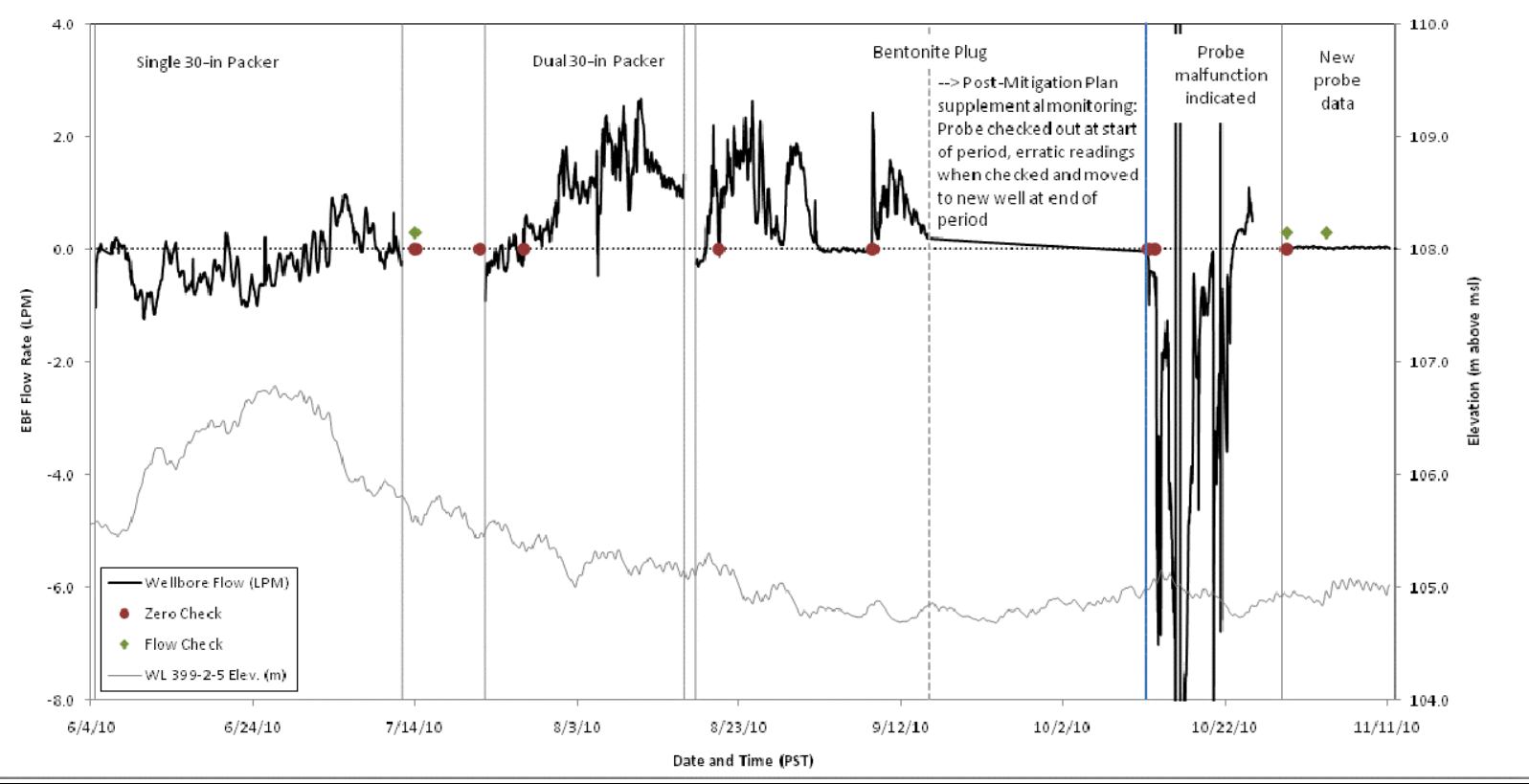

Figure II-2. Temporal trends in ambient vertical flows in test well 2-21 during the wellbore flow mitigation trials. Water-level elevation data are shown for comparison. EBF data collected from early August through October, when a defect in the probe cable was identified and the cable replaced, are spurious and should be disregarded.

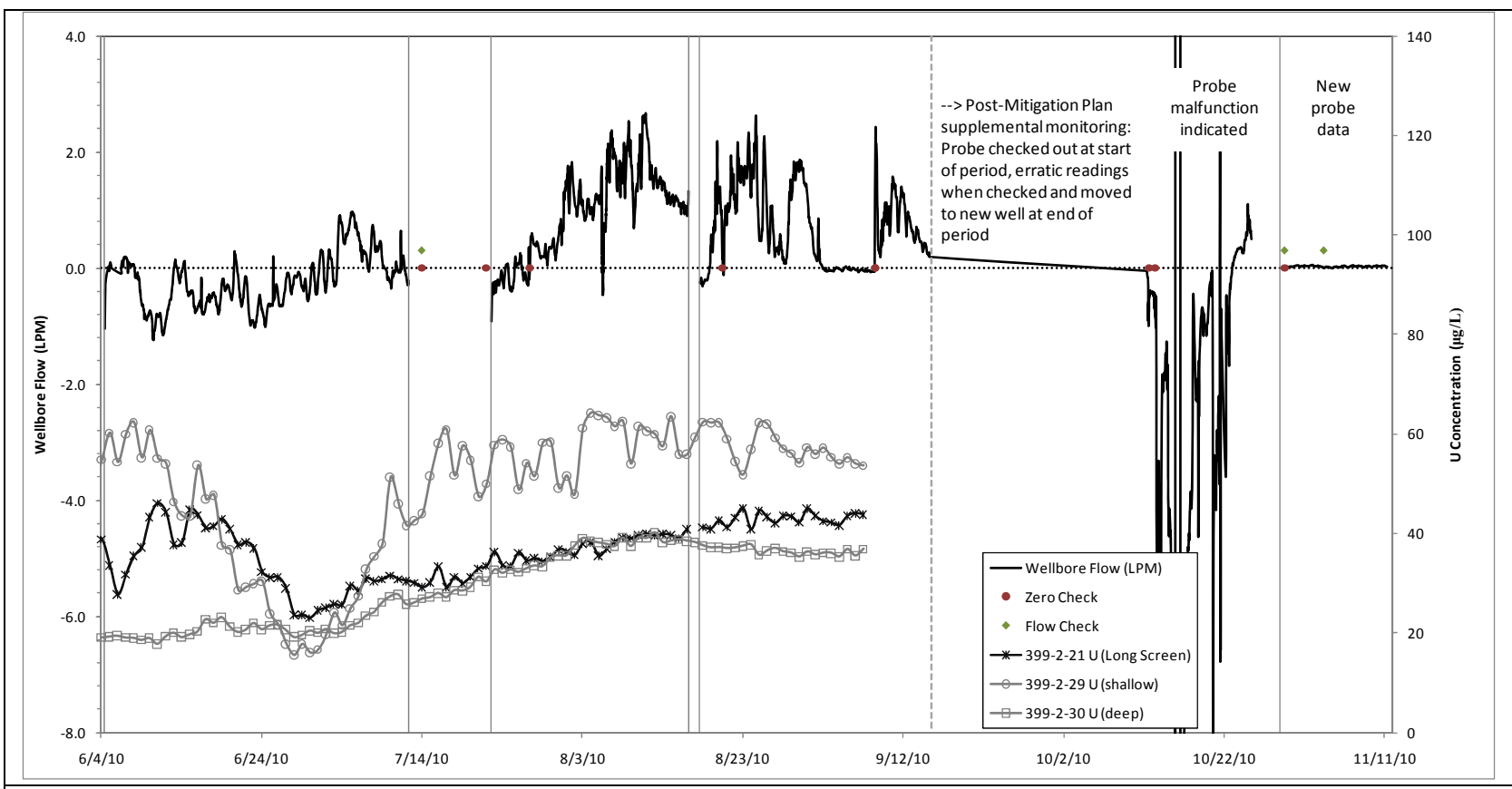

Figure II-3. Temporal trends in U concentration and ambient vertical flows in test well 2-21 during the wellbore flow mitigation trials. 


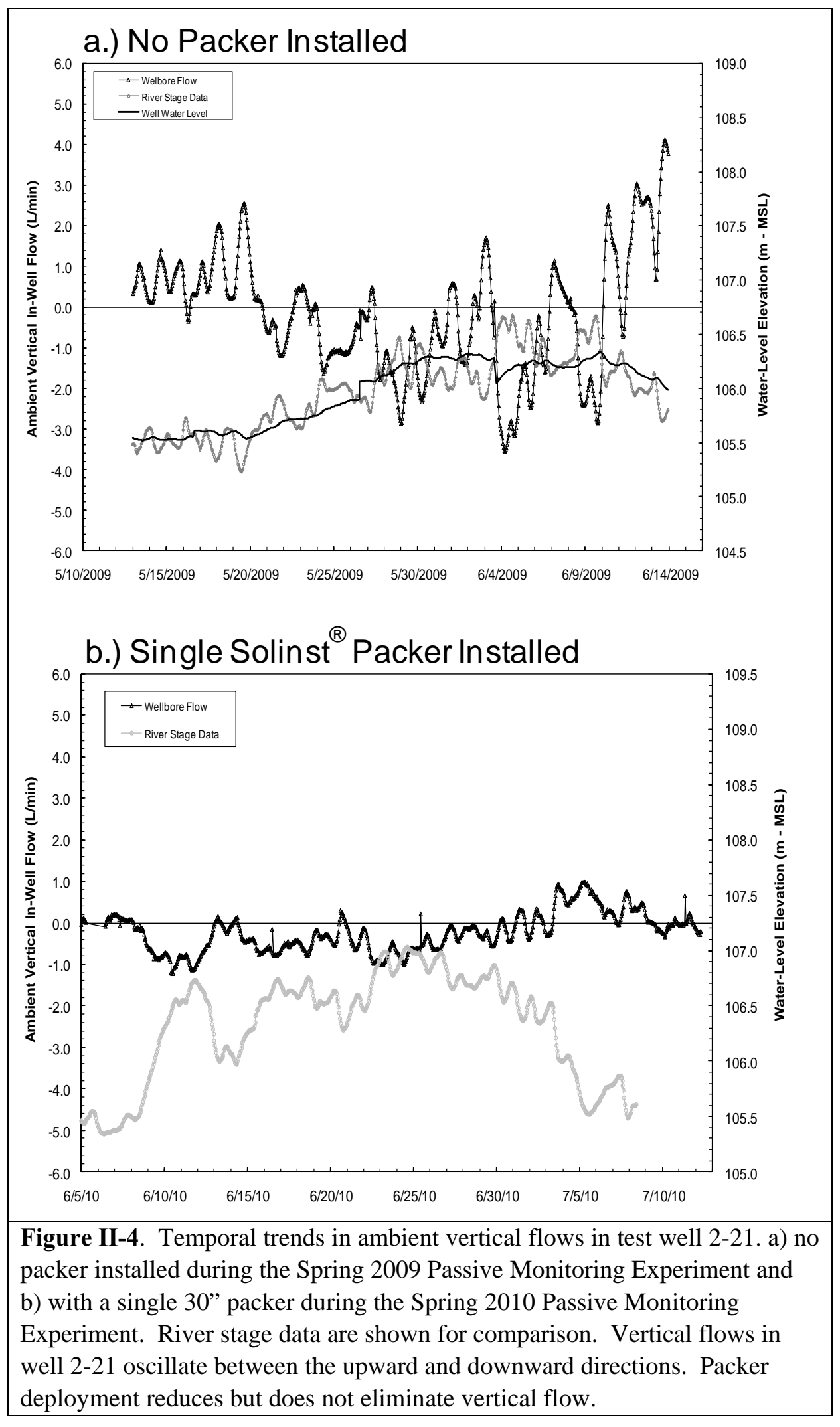




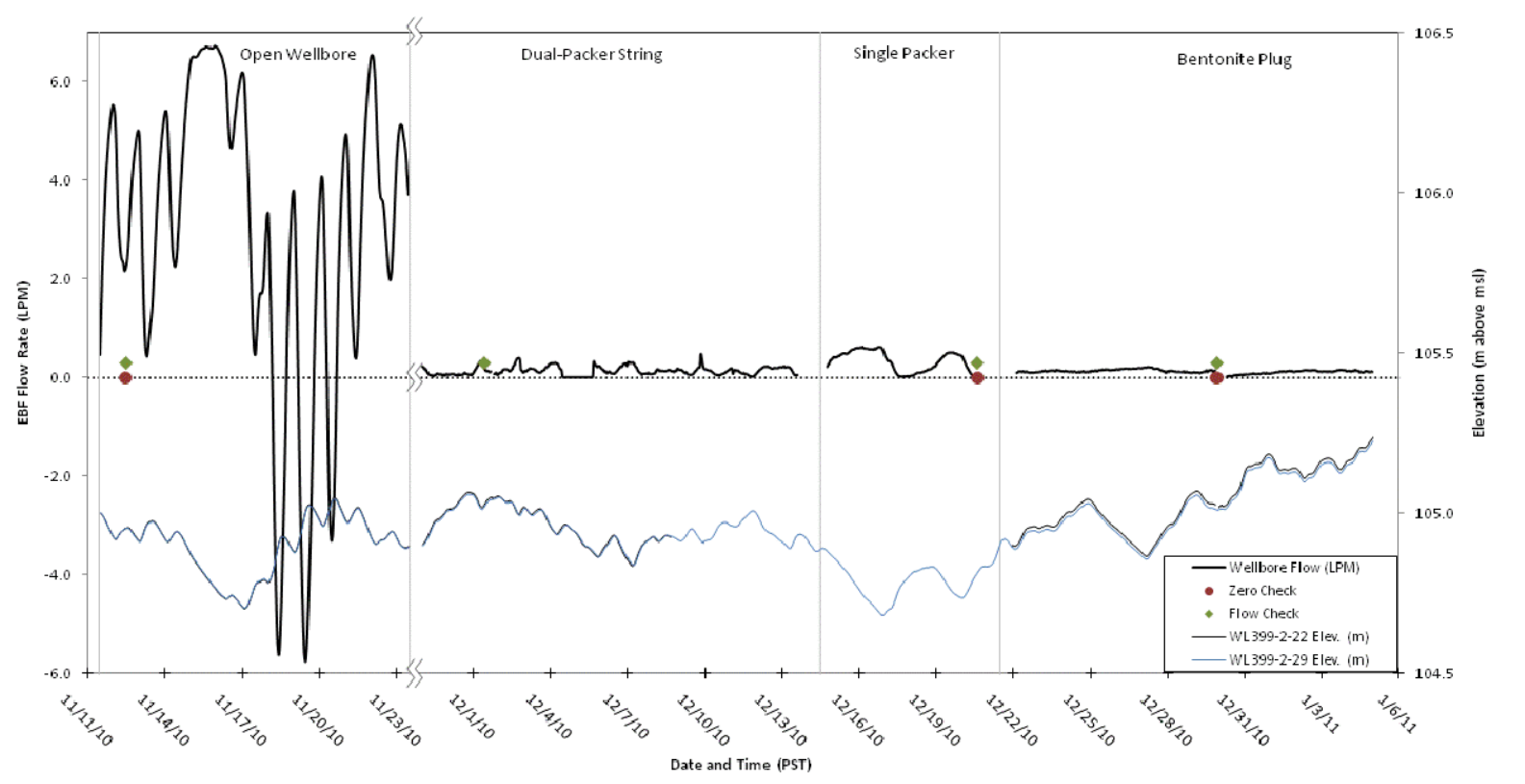

Figure II-5. Temporal trends in ambient vertical flows in test well 2-22 during the wellbore flow mitigation trials. Water-level elevation data are shown for comparison.

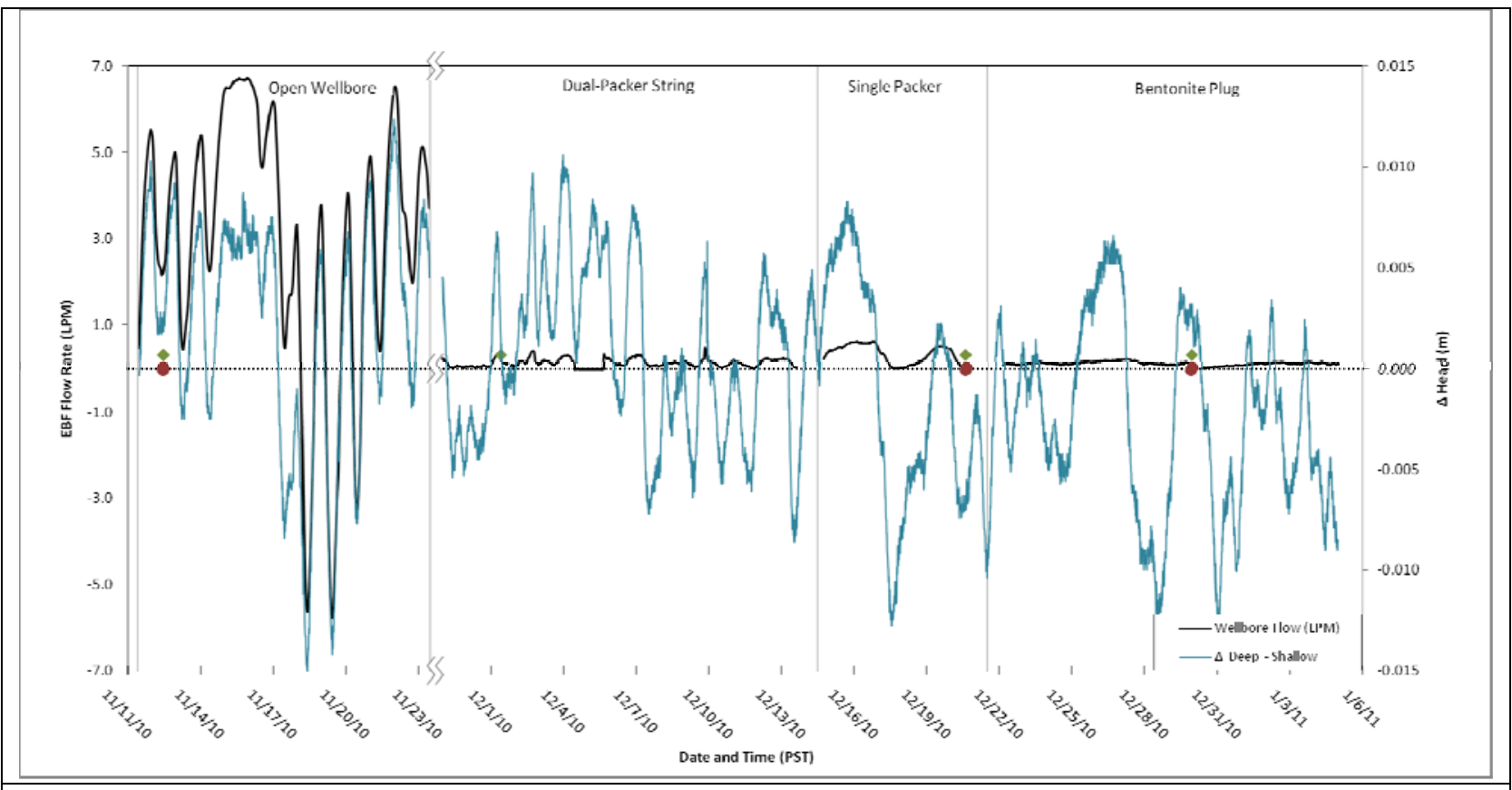

Figure II-6. Temporal trends in ambient vertical flows in test well 2-22 during the wellbore flow mitigation trials. Water-level elevation data are shown for comparison. 


\section{CHARACTERIZATION AND ASSIMILATION}

\section{Hydrophysical Data Assimilation}

A rigorous theoretical framework and associated numeric model has been developed for Hanford IFRC data assimilation and inverse modeling (Rubin et al., 2010) in order to construct a site-wide hydrophysical model with known and quantified uncertainties and statistics. We refer to that framework as the Method of Anchored Distributions, or MAD, in short. MAD has been applied to assimilate results of the constant-rate injection tests performed throughout the IFRC well-field with the EBF vertical profiles (Murakami et al., 2010), and with lithologic data (Murikami et al., 2011). Building upon these initial publications, MAD has been applied to the non-reactive tracer breakthrough data from the March 2009 experiment to assimilate static and dynamic data sets for further refinement of our site hydrogeologic model (e.g., the hydraulic conductivity field; Chen et al., 2011), and improved predictions of tracer transport. Figure III-1 demonstrates the results of MAD application to the March 2009 experiment (Chen et al., 2011). It shows predicted tracer breakthrough curves at wells not used for inversion. "Prior" refers to predictions without assimilation of the tracer experiments with the other types of data, whereas "posterior" refers to predictions after data assimilation. This figure shows the constant improvement in the quality of the prediction as more data from the field becomes available.

In other theoretical research in support of ongoing and future IFRC site characterization, we evaluated questions such as what types of data to collect for robust site characterization, where to collect samples for maximum knowledge impact, and how many samples to collect for statistically meaningful conclusions and uncertainty reduction. Such questions often arise in the context of site investigation, but are rarely addressed quantitatively. We created and tested a rational and computational framework that could address these questions. The key element of our approach, as outlined in Nowak et al., 2010, is to link the site characterization plan with the characterization goals; such as environmental risk, uncertainty reduction for key parameters, or tracer transport prediction. To exemplify this approach, we looked at questions related to the numerical modeling of solute transport (Barros and Rubin, 2011), a primary activity on the IFRC project. The analysis focused on the development of effective block-scale macrodispersion coefficients for numerical models such as PFLOTRAN that are being used on the IFRC project. Such coefficients hold the potential to reduce the computational burden of high-resolution, stoichastic modeling of the type shown in Figure III-1 and later sections of this report, where multiple realizations are used.

The development of the IFRC site-wide hydrophysical model is work in progress. The site model will be revised as more data becomes available, new experiments are performed, or as previous analysis and interpretations of field data are revisited. This is particularly relevant to upper aquifer that will be the primary zone of research focus after well-field remediation. 

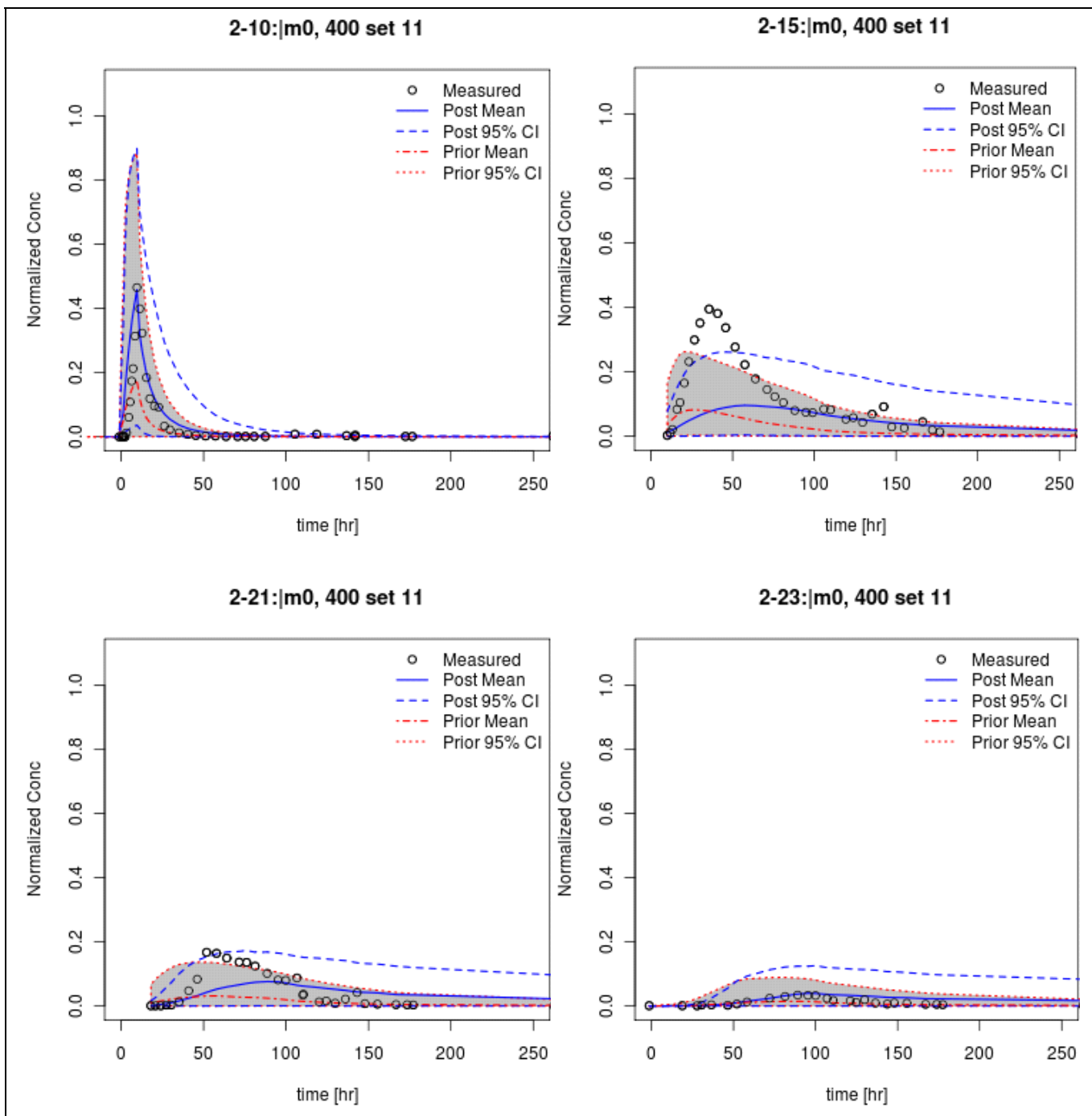

Figure III-1. Validation of breakthrough curves in selected wells for Mar09 Tracer Test (from Chen et al., 2011). 


\section{Geophysical Data Assimilation and Interpretation}

The hydrogeologic properties of the IFRC well-field must be robustly characterized or estimated to understand and model U migration. In 2009 the IFRC geophysical array was used to collect an electrical resistivity and time-domain induced polarization data set, which was inverted to estimate the 3D bulk electrical conductivity structure of the IFRC well-field (Johnson et. al 2010; Figure III-2a). Combined with the parallel inversion software developed for the IFRC effort, the geophysical array provides a capability to image electrical properties (and processes that influence those properties) at unprecedented spatial and temporal resolution. The high resolution 3D distribution of measured electrical properties can be used to infer the hydrogeologic properties of the IFRC at the same resolution, if the link between electrical properties and hydrogeologic properties can be determined. Such links have been published, but these are typically site specific. For instance, in non-conductive, unconsolidated granular media, bulk conductivity is typically positively correlated with porosity (Archie, 1942) and with permeability. Electromagnetic borehole flowmeter logging at the IFRC has revealed a layered permeability structure in the saturated zone, with upper and lower high permeability units separated by a central lower permeability unit. This same structure is evident in the ERT inversion results (Figure III-2a,b), suggesting a possible correlation between bulk conductivity and permeability throughout the saturated zone.

In 2010, efforts were initiated to use the 3D ERT characterization results to inform hydrogeologic models of the saturated zone within the IFRC well-field. Existing petrophysical data (such as grain size distribution) and parameters generated for other Hanford sediments were used with the electrical conductivity results to estimate porosity fields for the IFRC site using Archie's law. These porosity fields were then used in numerical simulations of the March 2009 experiment with PFLOTRAN (co-PI's Rockhold and Rubin with collaborators Hammond and Chen). This work was performed in preparation for the 300 Area IFRC all-hands meeting, held in January 2011 in Richland, Washington.

A 2D time-lapse ERT monitoring effort was initiated in early FY 2011 to monitor natural surface recharge at the IFRC site during wet fall and winter months. ERT is able to discern wetting fronts from single precipitation events (Figure III-3), based on changes to bulk electrical conductivity resulting from changes in water content. The images in Figure III-3.show time lapse results after a significant rain event beneath a 2D line installed at the surface of the IFRC wellfield. The wetting front reaches approximately three meters depth within six days of the rain event. The water table exists at approximately $7.5 \mathrm{~m}$, and this ongoing experiment will assess whether 2D ERT monitoring can follow the wetting front to groundwater. Episodic infiltration events such as this may be significant drivers for uranium mobilization from the vadose zone. Information from this monitoring effort will be used to inform unsaturated flow models to estimate transport parameters governing flux to the water table under episodic loading The results will also be used to plan a potential infiltration experiment for September 2011 where a significant rainfall event will be simulated by drip irrigation and the wetting and $\mathrm{U}$ mobilization front followed to and within the saturated zone. 


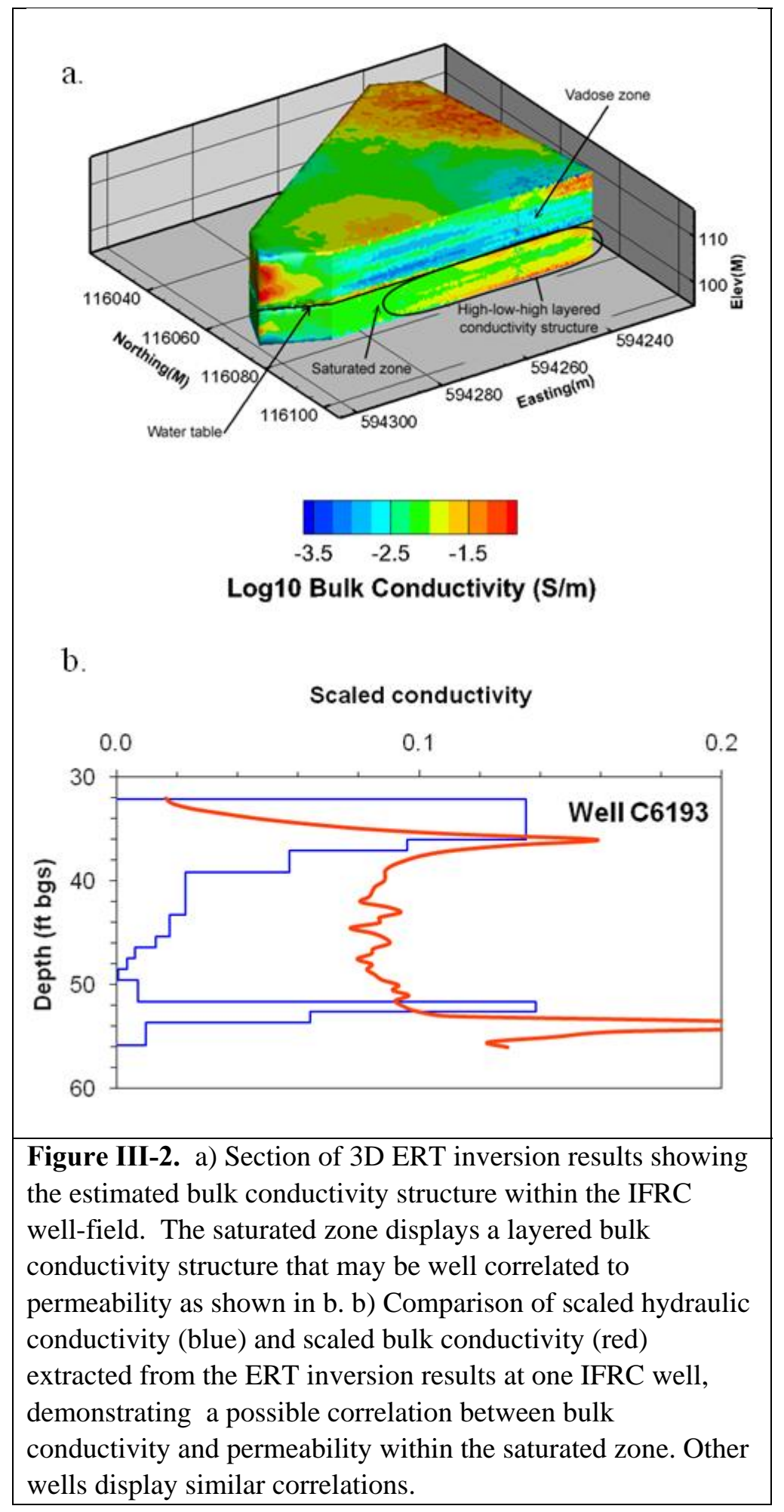




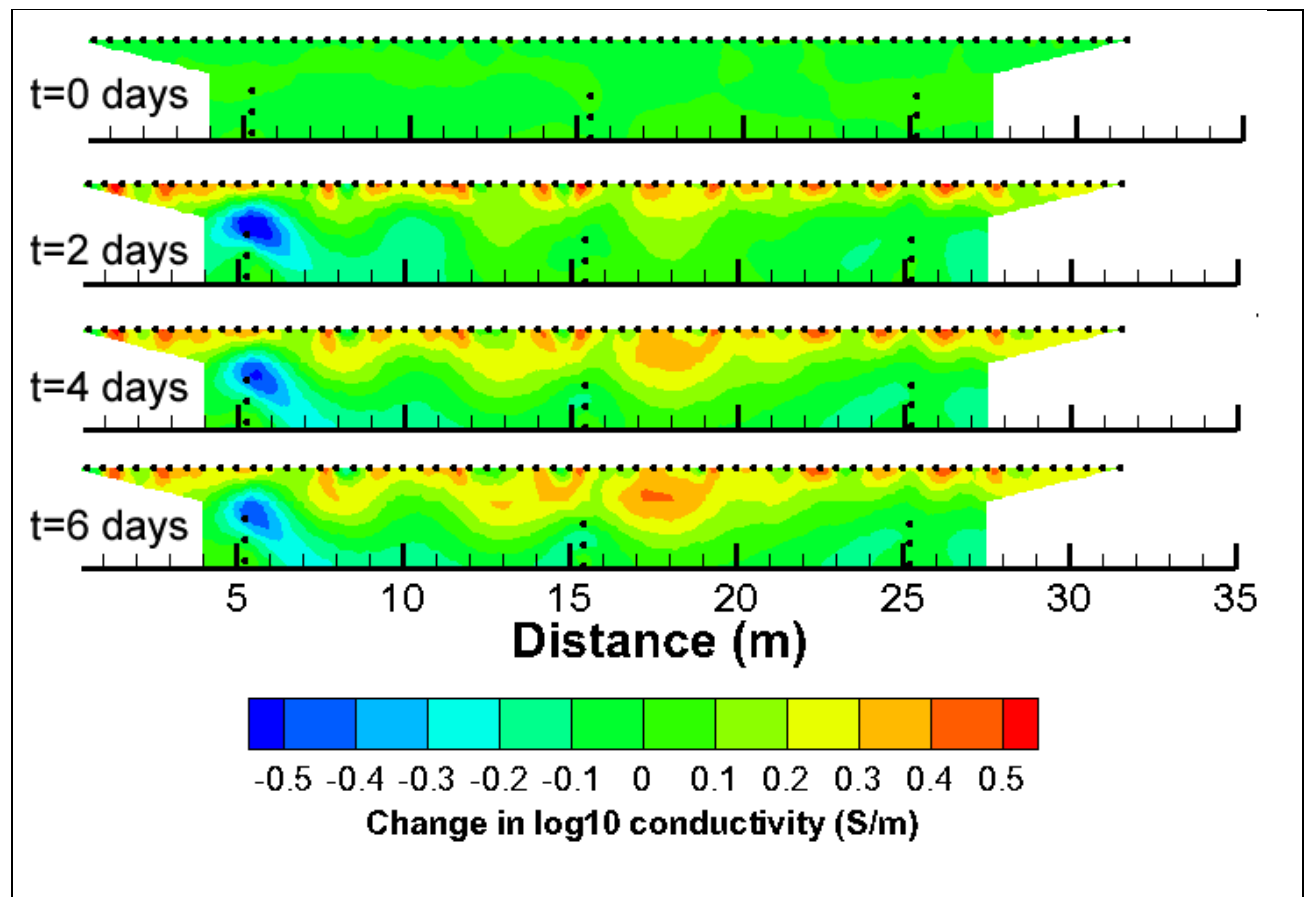

Figure III-3. Time lapse ERT imaging results after a significant rain event beneath a 2D line installed within the IFRC well-field. 


\section{Geochemical Data Heterogeneity Analysis}

During CY 2009, a preliminary geostatistical model of the spatial distribution of bicarbonate extractable uranium (BEU) was completed and work was initiated on a model of the adsorption distribution coefficient $\left(K_{d}\right)$ for U-233 that was completed early in CY 2010. Extractions and $K_{d}$ measurements were performed on the $<2 \mathrm{~mm}$ fraction; maps of gravel-corrected parameters were created using a geostatistical model of the fraction of sediment that was $<2 \mathrm{~mm}$. Additional measurements of the BEU and $K_{d}$ for U-233 that were made in CY 2010 provided the opportunity to update the geostatistical models of those variables. The updated models provide 3D input grids needed for reactive transport modeling of uranium transport in the IFRC experimental plot. We also generated an update of the Monte Carlo estimate of the mass of BEU in the smear zone of the IFRC. In addition to updating the models, we were able to use the new data to test the geostatistical models that were developed in CY 2009, and found general agreement between predicted and measured values, which provides some confidence in the derived spatial models. Work to be conducted in CY 2011 includes an analysis of the correlation of BEU and $K_{d}$ for U-233 with geophysical log data and particle size data. This will be used to determine if the $\log$ data could be used as soft or proxy data to constrain the geostatistical realizations of those variables. We will also examine the association between lithofacies and the geochemical properties.

After completion of the preliminary geostatistical model in CY 2009, an additional set of samples was identified to fill in holes in the data distribution (Figure III-4) that included 31 samples from 6 boreholes, 5 of which had not been sampled previously. As with the preliminary data, the histogram of extractable U concentrations for the revised data set was highly skewed (Figure III-5), with many low concentration values and a long tail of high concentrations. The values shown in Figure III-5 reflect correction for the fraction of sediment $<2 \mathrm{~mm}$, assuming no contribution from the gravel fraction. Because of the skewed nature of the BEU distribution, we performed the geostatistical analysis on a normal score transform of the data. The normal score transform is an alternative to the logarithmic transform often used in the earth sciences for positively skewed data. It has the advantage that the transformed data are an exact fit to the normal distribution, while logarithmically transformed data often deviate significantly from a normal distribution.

The distribution of gravel-corrected BEU with depth showed a significant upward trend (Figure III-6), with the lowest values in the saturated zone, and a shift to higher mean values and much greater variability in the smear zone and lower vadose zone. The $K_{d}$ for U-233 doesn't reflect an upward increasing trend, and the mean and variability of the $K_{d}$ are relatively constant with depth (Figure III-6).

The horizontal variogram for the new combined data set (Figure III-7) suggested a longer overall range (130 $\mathrm{m}$ rather than $70 \mathrm{~m}$ ) for BEU than was fit in the previous model (Table III-1), and the revised model was used in generating updated realizations of BEU using sequential Gaussian simulation. Note that the fit of the variogram model of the normal scores is constrained by the requirement that the total sill must equal 1.0 for use in sequential Gaussian simulation. Even with the new data, the horizontal variogram model is somewhat uncertain due to the number, spacing, and arrangement of the data; so alternative variogram model ranges could be tested in any reactive transport modeling that uses the distribution of BEU as an input parameter. Directional variograms were examined but the data were from too few locations to determine if directional anisotropy is present in the extractable $\mathrm{U}$ data. The 3D distribution of the mean simulated value of BEU (Figure III-8) generated using the revised variogram model shows a concentration of high BEU values in the smear zone and lower vadose zone, as was observed in the 
preliminary model. The mean simulated values of BEU that occur outside of the triangular footprint of the IFRC wells (Figure III-8) are highly uncertain due to lack of data.

We used the updated realizations of BEU to generate a revised Monte Carlo estimate of the mass of BEU in the smear zone and lower vadose zone within the $80 \mathrm{~m}$ by $82 \mathrm{~m}$ by $6 \mathrm{~m}\left(39,360 \mathrm{~m}^{3}\right)$ map area (Figure III-9). The revised estimate of the mass within the study area was $57.8 \mathrm{Kg}$, which is slightly lower than the previous estimate of the mass, $62.2 \mathrm{~kg}$. The revised $95 \%$ confidence interval for the estimated mass had a range of $37.6 \mathrm{~kg}$ to $73.3 \mathrm{~kg}$.

As with the BEU data, the data for the gravel-corrected $K_{d}$ for U-233 were highly skewed. Most values were less than $1 \mathrm{~L} / \mathrm{Kg}$, but a few values were much higher (Figure III-10). Those high values appear to be associated with silt that may represent rip-up clasts of Ringold Formation within the Hanford sediment. The variogram model for the revised $K_{d}$ data set (Figure III-11) was only slightly changed from the model fit to the preliminary data set (Table III-2). The horizontal spatial continuity of the $K_{d}$ for U-233 is much shorter than that of the BEU data, with the horizontal variogram reaching the total sill within a distance of $13 \mathrm{~m}$. The combination of a short horizontal variogram range for the $K_{d}$ and the highly skewed distribution of the data with the vast majority of values of corrected $K_{d}$ being less than $1 \mathrm{~L} / \mathrm{Kg}$, both contribute to a 3D distribution where most of the sediment has a low $K_{d}$ for U-233 with a few hotspots (Figure III-12).

New chemical characterization analyses performed in CY 2010 provided wider spatial coverage across the IFRC, but also allowed us to check the predicted values from the preliminary geostatistical model against the new measurements. We calculated the mean of the 100 realizations of BEU and $K_{d}$ for U-233 generated with the preliminary model and data; we also identified the $95 \%$ probability interval from the sorted set of realizations at the closest grid node to each new sampling location (Figure III-13). The comparison between predicted and measured results shows that all but one of the new measured values for BEU fell within the $95 \%$ probability intervals. In addition, the observed values are reasonably close to the mean value from the set of realizations, which was treated as the predicted value from the preliminary geostatistical model. The results for the new data for the $K_{d}$ for U-233 (not shown) were also quite good, with all new data values falling within the $95 \%$ probability intervals, and the observed values being close to the predicted values. Overall, the good agreement of predicted and observed values provides some confidence that the geostatistical models of BEU and $K_{d}$ for U-233 are reasonable depictions of the spatial distribution of those variables within the IFRC footprint.

Table III-1. Variogram parameters for combined and preliminary BEU data sets.

\begin{tabular}{ccccc}
\hline \multirow{2}{*}{$\begin{array}{c}\text { Normal Scores of } \\
\text { Extractable U }\end{array}$} & Nugget & Sill & \multicolumn{2}{c}{ Range (m) } \\
\cline { 4 - 5 } New Model & \multirow{2}{*}{0} & 0.4 & Horizontal & Vertical \\
\multirow{2}{*}{ Previous Model } & \multirow{2}{*}{0} & 0.6 & 130 & 1.3 \\
& & 0.4 & 12 & 2.4 \\
& & 0.6 & 70 & 1.6 \\
\hline
\end{tabular}


Table III-2. Variogram parameters for combined and preliminary data sets for $\mathrm{K}_{\mathrm{d}}$ for U-233.

\begin{tabular}{lcccc}
\hline $\begin{array}{c}\text { Normal Scores of } K_{d} \\
\text { for U-233 }\end{array}$ & Nugget & Sill & \multicolumn{2}{c}{ Range (m) } \\
\cline { 4 - 5 } New Model & 0.05 & 0.95 & Horizontal & Vertical \\
Previous Model & 0.05 & 0.95 & 13.0 & 1.1 \\
\hline
\end{tabular}





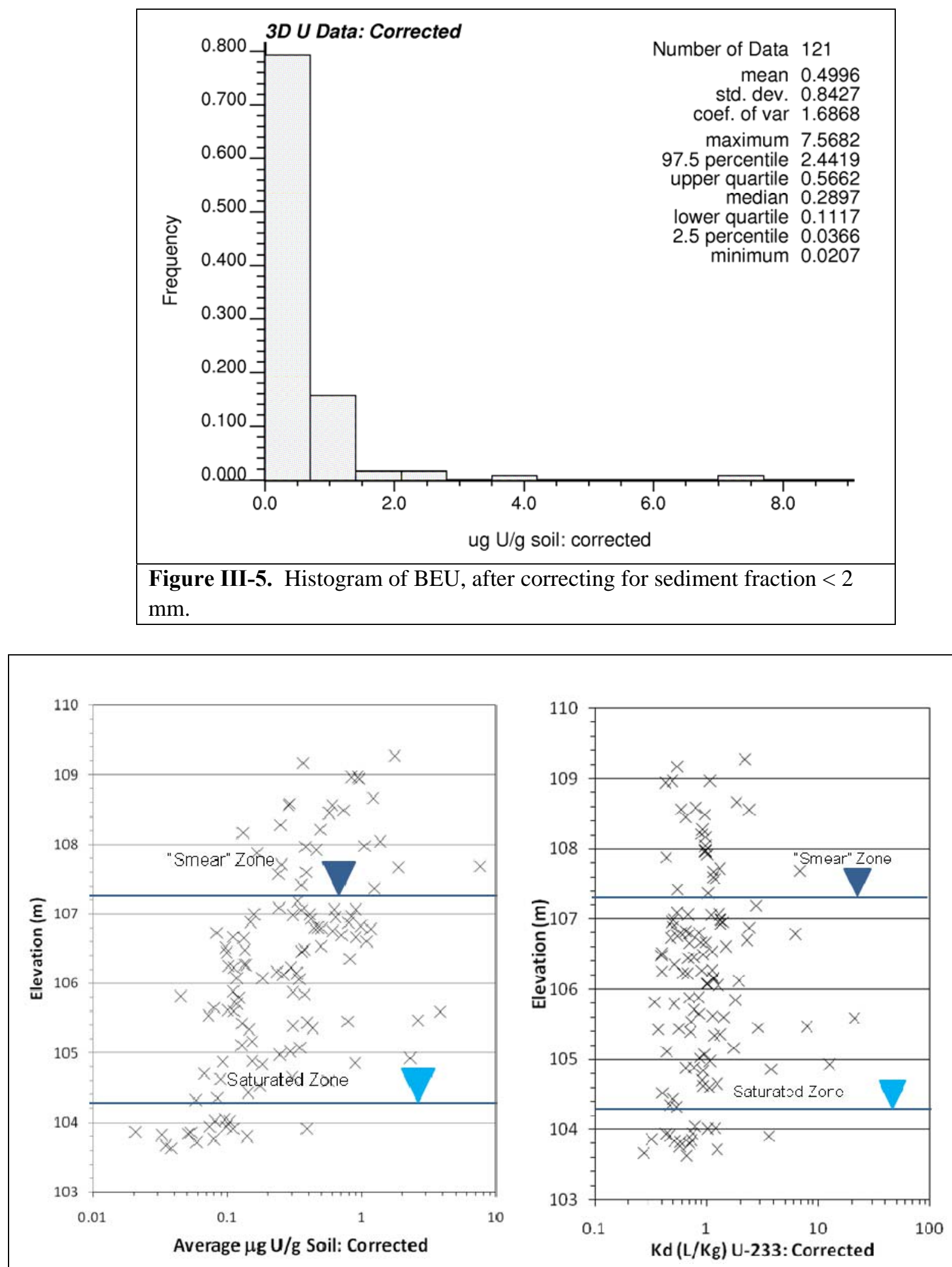

Figure III-6. Gravel-corrected BEU and Kd for U-233 plotted as a function of depth for values that fall within the $3 \mathrm{D}$ geostatistical grid. 

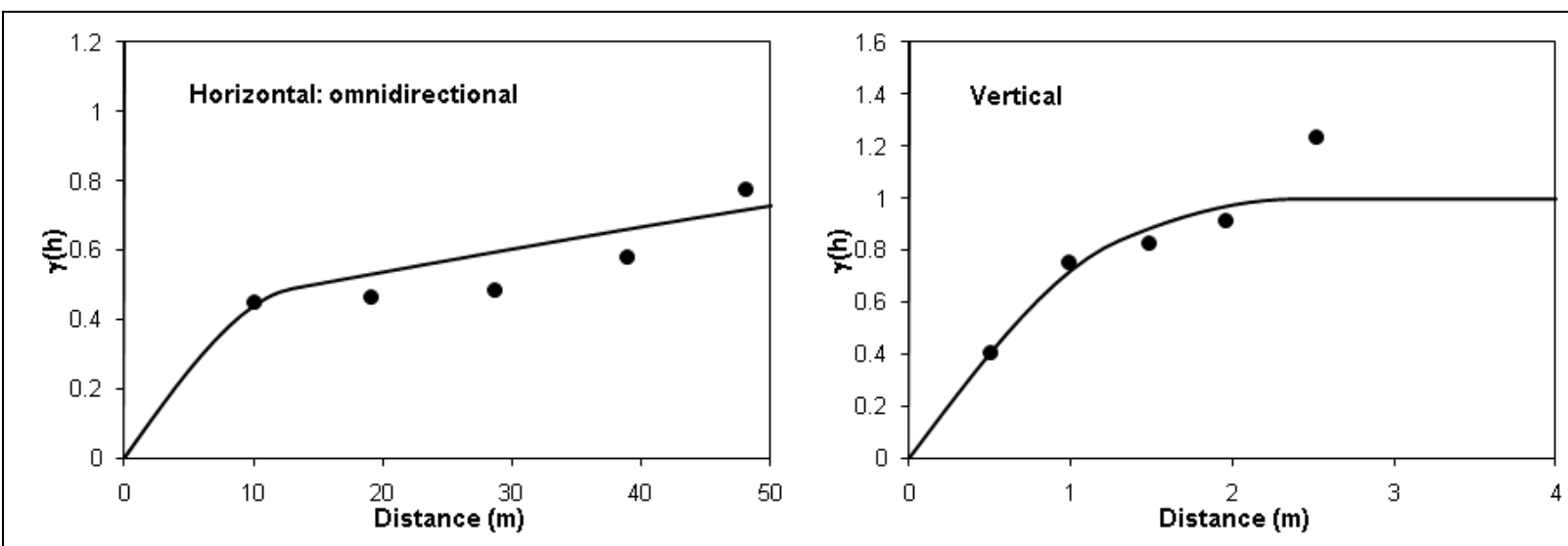

Figure III-7. Horizontal and vertical variograms of the BEU normal scores. The normal scores were calculated on the raw data, not gravel corrected. Black dots represent variogram values calculated from the data, and solid black line represents the model fit.

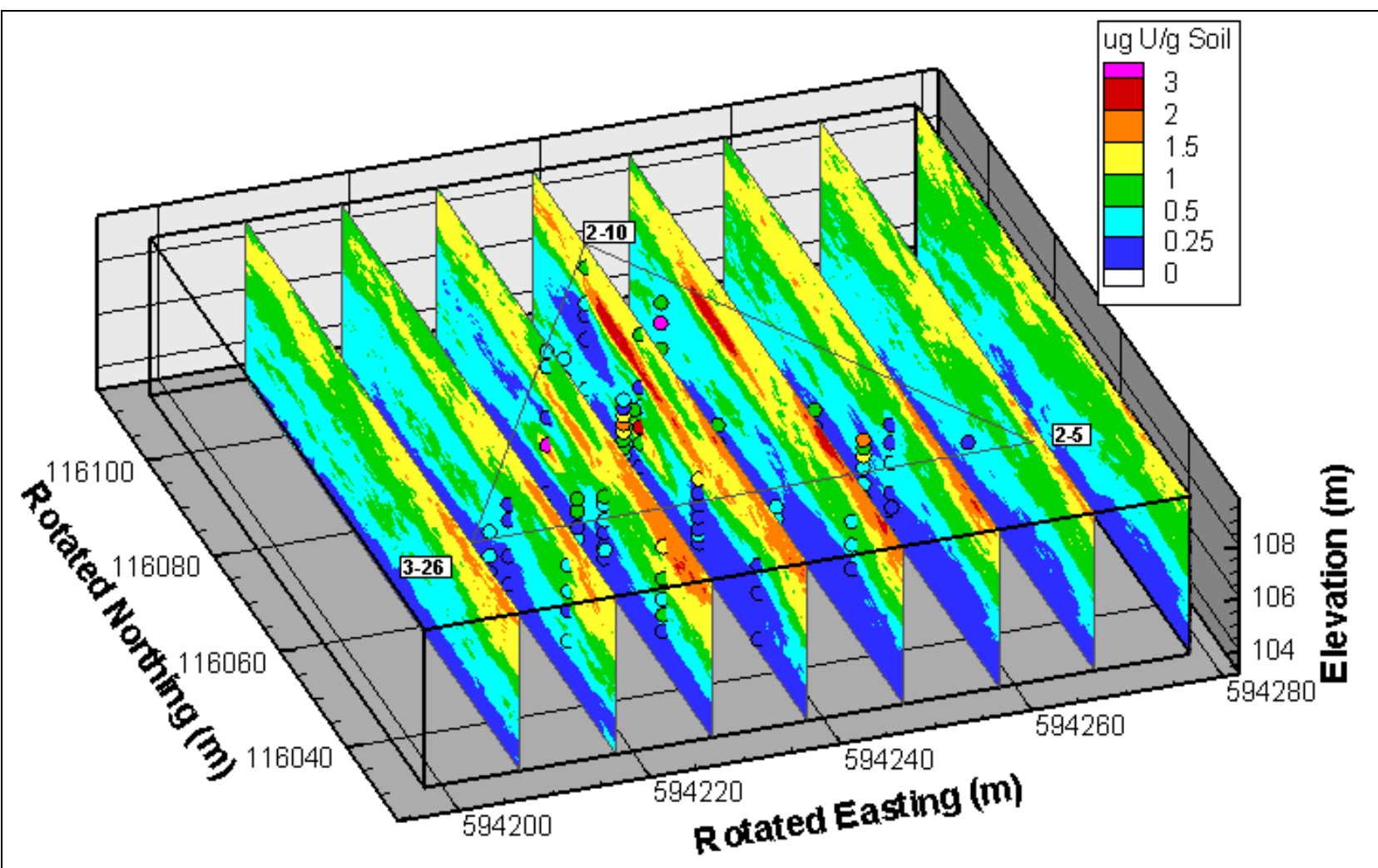

Figure III-8. Vertical cross-sections through the 3D grid of the mean simulated values of gravelcorrected BEU. The values at each grid note represent the average of 100 realizations of BEU generated using sequential Gaussian simulation. 

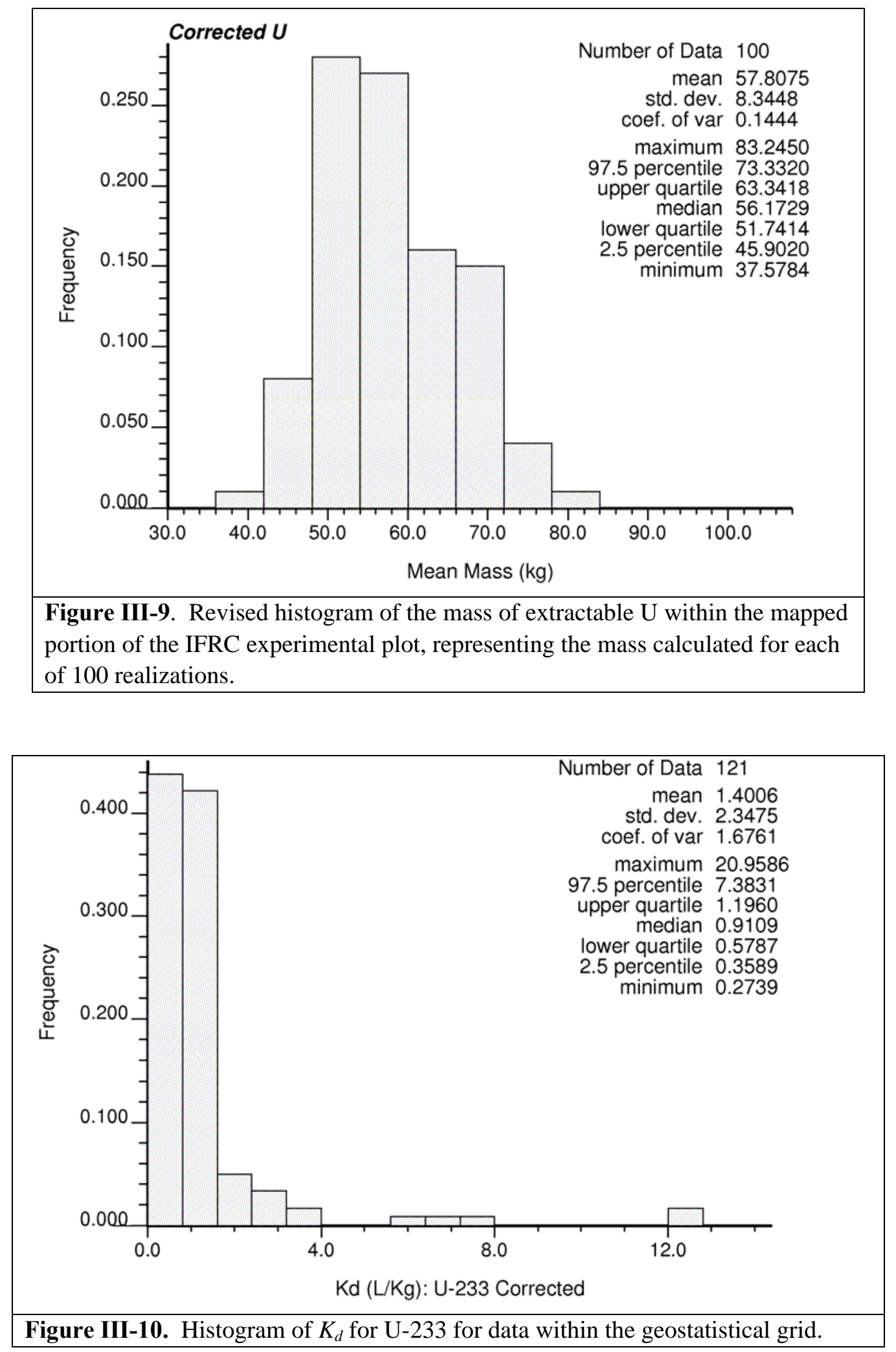

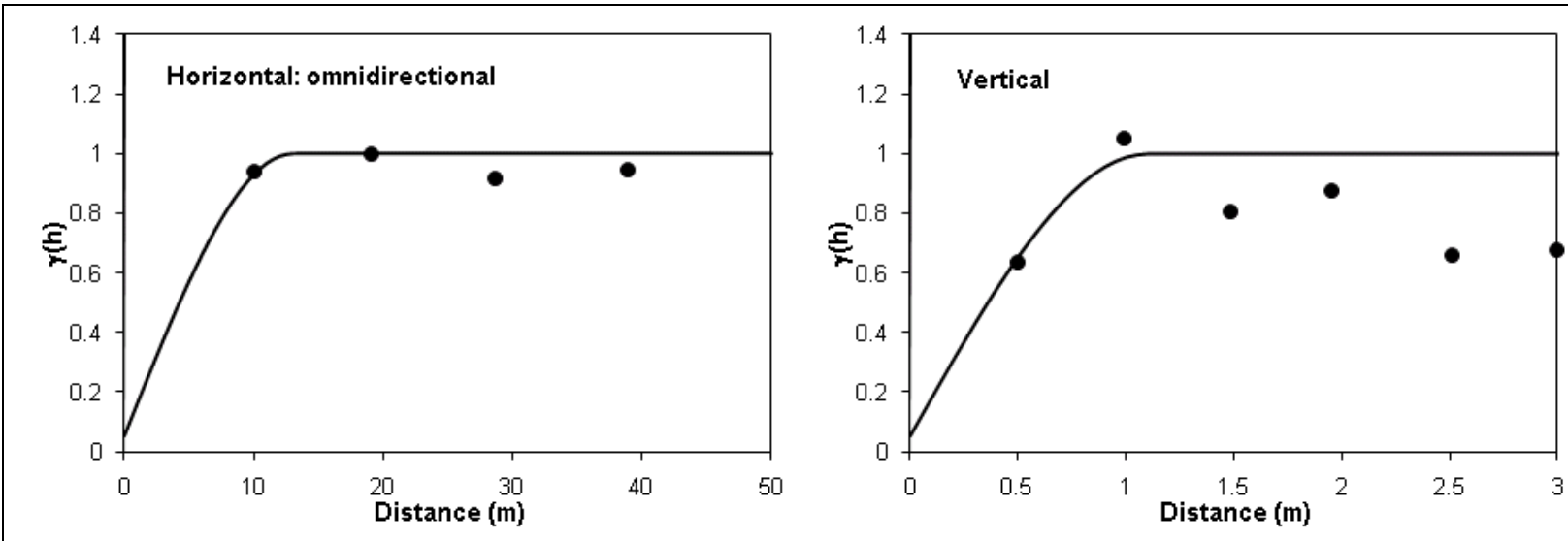

Figure III-11. Experimental variograms and models for $K_{d}$ for U-233. The normal scores were calculated on the raw data, not gravel corrected. Black dots represent variogram values calculated from the data, and solid black line represents the model fit.

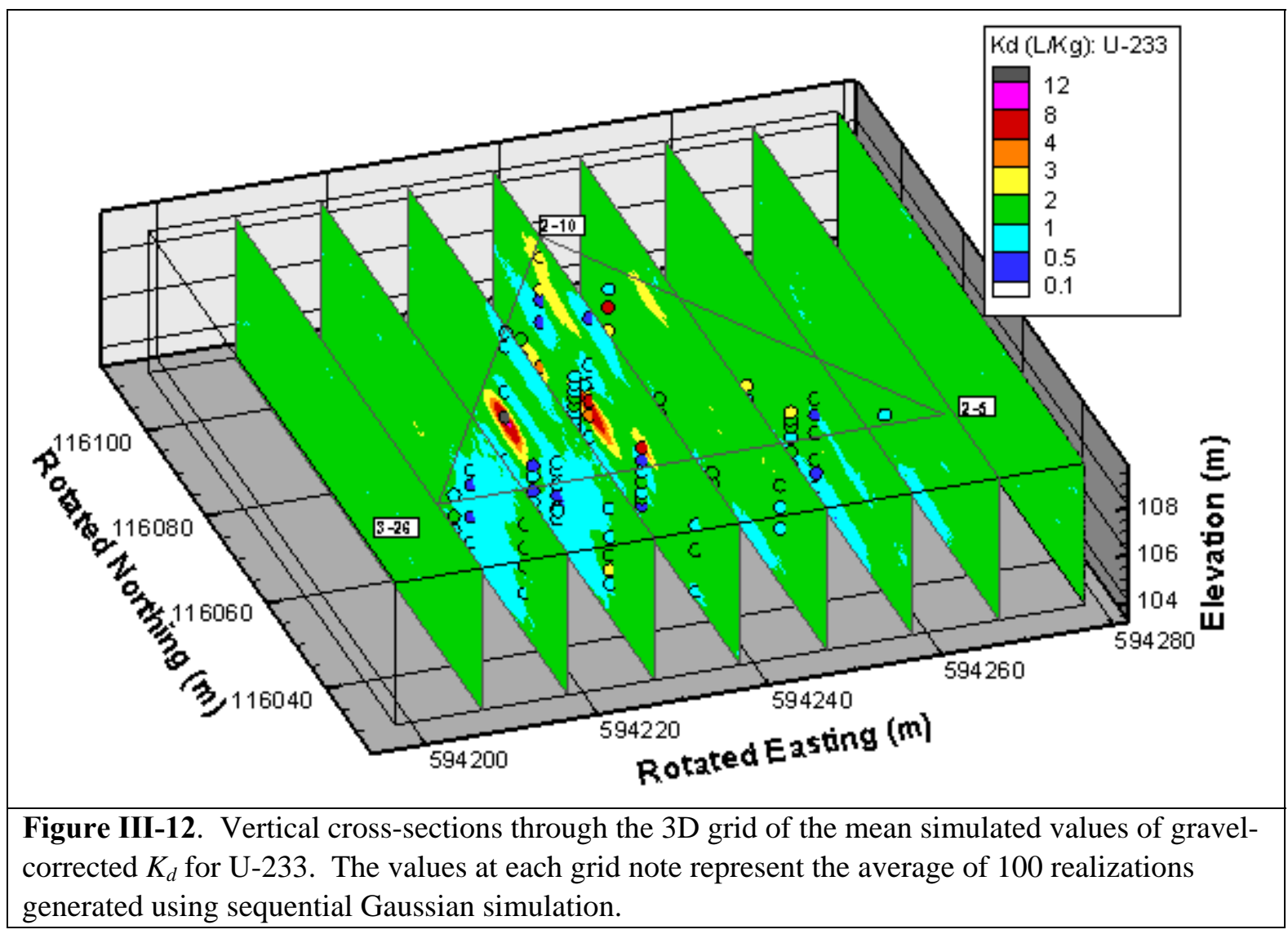




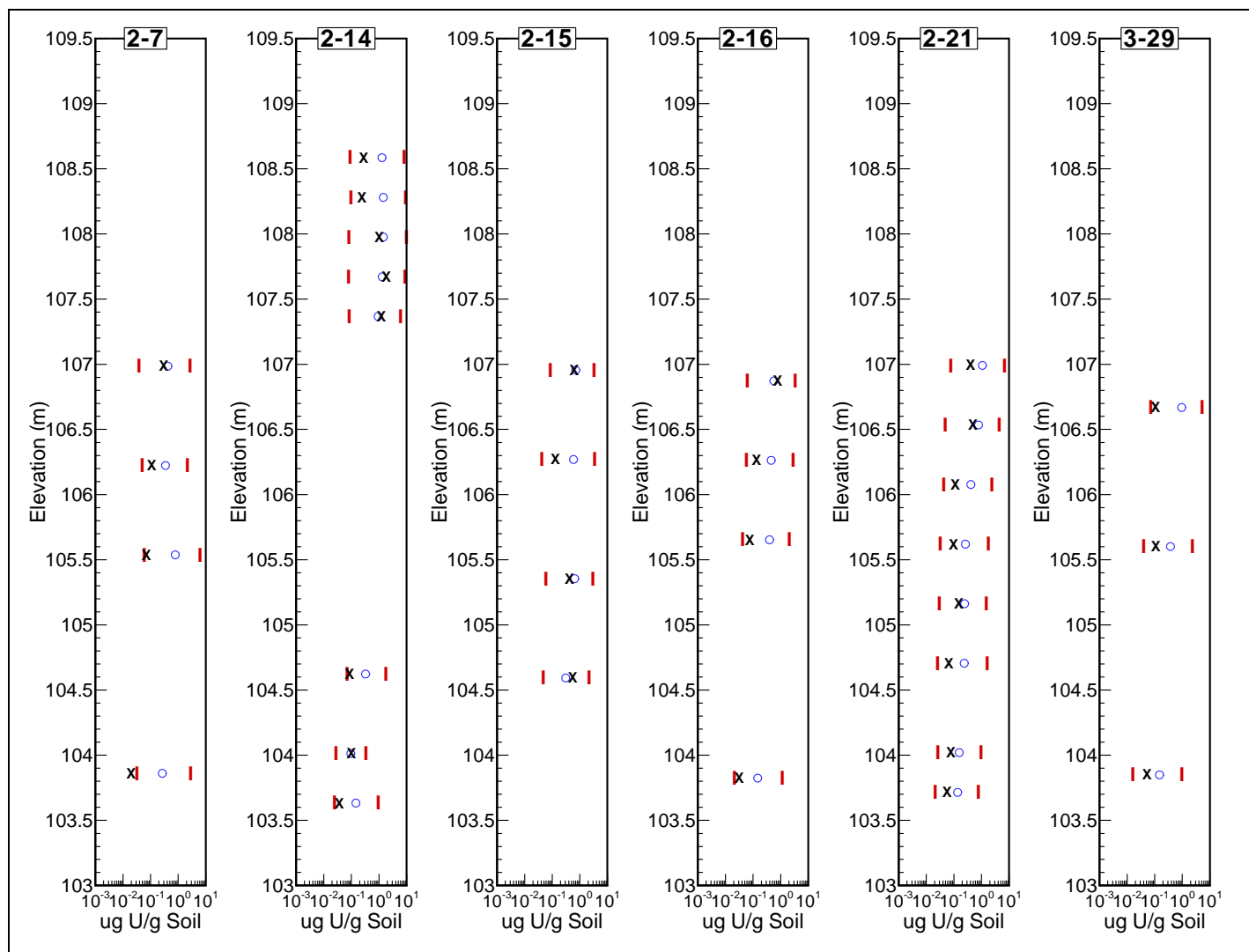

Figure III-13. Plots of predicted BEU versus measured values for samples from several wells where additional samples were measured in CY 2010. The blue circles are the predicted means, x's represent the measured values, and the red bars represent a $95 \%$ confidence interval for each prediction. 


\section{SATURATED ZONE EXPERIMENTAL PROGRAM}

\section{Spring Passive Experiment}

Beginning May 12, 2010, groundwater was bailed from the upper $15 \mathrm{~cm}$ of the aquifer, and pumped from the upper $2 \mathrm{~m}$ of the aquifer, daily, until July 26, 2010. This period included the annual rise and fall in river stage due to spring snowmelt in the Columbia River drainage. To assess the change in composition and the contribution of contaminant $U$ to the aquifer during the resulting changes in hydraulic head across the IFRC, the water table elevation was recorded, and samples were analyzed for U, major cations (ICPAES), major anions (ion chromatography), dissolved inorganic carbon (carbon analyzer), conductivity (electrode), and $\mathrm{pH}$ (electrode). Charge balance was used as a quality control tool (all combined results were within 5\% of neutral), and an experiment-specific plotting tool (Silverlight) was written to aid in data analysis.

Selected results for a passive experiment that investigated the effects of the annual water table excursion, which accompanies the spring snowmelt event at the Hanford IFRC, are presented in Figure IV-1. Bailed samples were collected to avoid the effects of pumping samples from long screens and potentially obscuring the effects of vadose zone contributions to the aquifer during the water table rise. Prior to the experiment, difficulties in intra-well flow (Vermeul et al., 2010) were minimized by installing mid-screen packers and raising sampling pumps to the upper $2 \mathrm{~m}$ of the low-water aquifer. This procedure eliminated most discrepancies between bailed and pumped samples that were observed previously (McKinley et al., 2011), and only pumped-sample results are shown here. Groundwater compositions, U concentrations, and water table elevation were relatively constant from the start of the experiment until June 7, 2010. The water table rose from an elevation of $105.4 \mathrm{~m}$ to a maximum of $106.8 \mathrm{~m}$ on June 26 , and then sank to $105.5 \mathrm{~m}$ at the end of the experiment on July 26 (Figure IV-1A). The rise was driven and closely correlated with the rise and fall of the Columbia River (not shown). The water table rise was accompanied by an abrupt rise in U concentrations (Figure IV-1B), from 30-40 $\mu \mathrm{g} / \mathrm{L}$ to $330 \mu \mathrm{g} / \mathrm{L}$. The analytical results shown in Figure IV-1B were from a three-well cluster (wells 3-30, -31, and -32) completed at short intervals $(0.6 \mathrm{~m})$ at shallow, intermediate, and deep locations within the Hanford formation aquifer, in the southern part of the IFRC. The $\mathrm{U}$ contributed to the aquifer varied across the IFRC, from little or no contributed $U$ at the eastern edge of the site, to maximum contributions as shown, at or near the location of the shallow-completion well 3-30. Wells completed at intermediate (3-32) and deep (3-31) locations showed small or no increase in $U$ concentrations during the water table rise. Uranium was thus contributed from the smear zone to the upper portion of the aquifer by saturation of the smear zone.

Previous studies showed that $\mathrm{U}$ desorption from IFRC sediments is generally slow and incomplete (Liu et al., 2009; Qafoku et al., 2005), consistent with the repeated annual release of $U$ to the aquifer during water table excursions (i.e., $\mathrm{U}$ was partially removed during each excursion event, but significant $\mathrm{U}$ remained for capture during subsequent excursions). Uranium capture could be affected and aided also by the differential saturation within the capillary fringe, where sediments are saturated but under hydraulic tension above the water table (Freeze and Cherry, 1979). Since desorption was kinetically controlled in part by diffusion (Liu et al., 2009), immobile, saturated sediments within the capillary fringe could equilibrate with sorbed $\mathrm{U}$, then incorporate that $\mathrm{U}$ into the aquifer through dilution during water table rise. The small impact of the added $U$ on the lower portions of the aquifer suggests that the aquifer was stratified during the course of the experiment. 
River water intruded across the IFRC during the rise in river stage, represented by $\mathrm{Cl}$ - concentrations (Figure IV-1C). The plot comprises a transect from the eastern site boundary (well 2-24), progressing northwest along the direction of river water intrusion to the northern site boundary (well 2-9). The site groundwater concentration for Cl- was approximately $21 \mathrm{mg} / \mathrm{L}$ prior to the experiment, equal to the mean concentration for the previous two-year period. The Columbia River at the time of the experiment contained $1.1 \mathrm{mg} / \mathrm{L} \mathrm{Cl-}$, and its intrusion into well 2-24 was represented by the dip in concentration to 4.1 $\mathrm{mg} / \mathrm{L} \mathrm{Cl}$ - on June 26. The Cl- low concentration thus represented a river water component of about $85 \%$. The plots for wells 2-19, at an intermediate location, and 2-9 indicated a lesser component of river water within the IFRC to the northwest of well 2-24, with the western site boundary experiencing fractional mixing of less than $15 \%$ river water. The influx of river water was also estimated using $\mathrm{NO}_{3}{ }^{-}$ concentrations (Figure IV-2), where the pre-experiment concentration was estimated at $21 \mathrm{mg} / \mathrm{L} \mathrm{NO}_{3}{ }^{-}$, and river water was measured to $0.4 \mathrm{mg} / \mathrm{L} \mathrm{NO}_{3}{ }^{-}$. River water invaded and retreated from the IFRC from the proximity of well 2-24 at the east to well 2-9 near the north site boundary.

The extensive incorporation of river water indicated that the IFRC was within the extended hyporheic zone. Previous studies focused on the hyporheic zone as a narrower band of Columbia River watergroundwater interaction (Peterson and Connelly, 2004), although the zone of river water intrusion has been estimated to extend up to $150 \mathrm{~m}$ inland from the river shoreline (Waichler and Yabusaki, 2005). The porous, conductive sediments of the Hanford formation and the dramatic fluctuations in river stage at the Hanford site may facilitate an extreme example of hyporheic groundwater interaction with river water. Previous studies (Woessner, 2000) generally defined the hyporheic zone as extending 1-3 m into a streambed adjacent to surface water, even in terrain similar to the Hanford site (Sinclair and Kardouni, 2009), albeit in the presence of surface streams of much lesser flow variation. The large fluctations in ionic strength, in the concentrations of key components such as dissolved cations, inorganic carbon and $\mathrm{NO}_{3}^{-}$, the potential influx of carbon sources for the local microbial community, and the rapid advection of these dissolved species into and across the site may drive significant geochemical and biogeochemical transformations within the IFRC site and throughout the broader 300 A plume. 

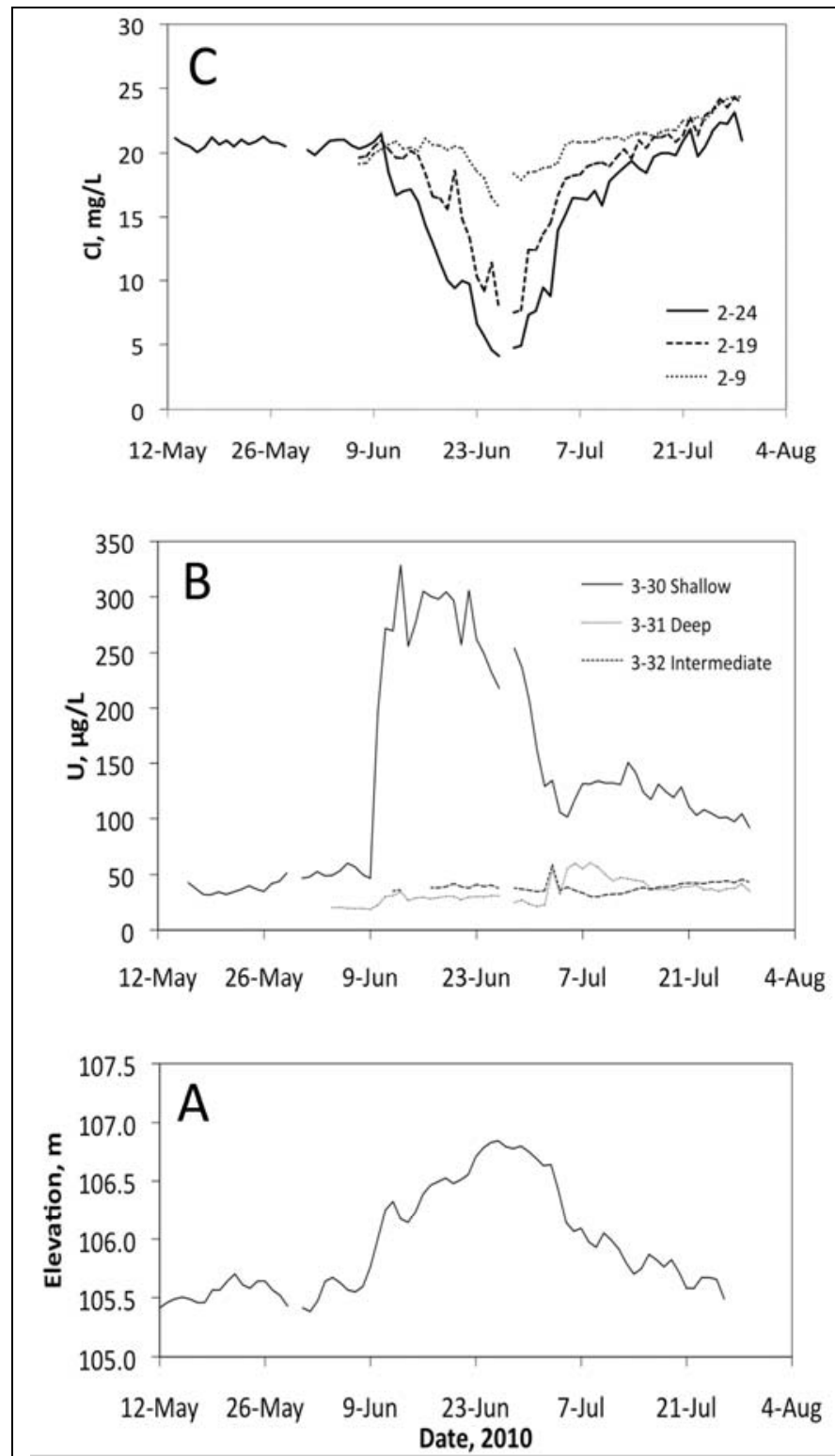

Figure IV-1. Selected time series groundwater data, collected during major spring-melt water table excursions. A) Water table elevation; B) U concentrations at the south corner of the IFRC, for the shallow, intermediate and deep portions of the unconfined aquifer; and C) $\mathrm{Cl}^{-}$ concentrations for three wells that transect the IFRC from east to north. 


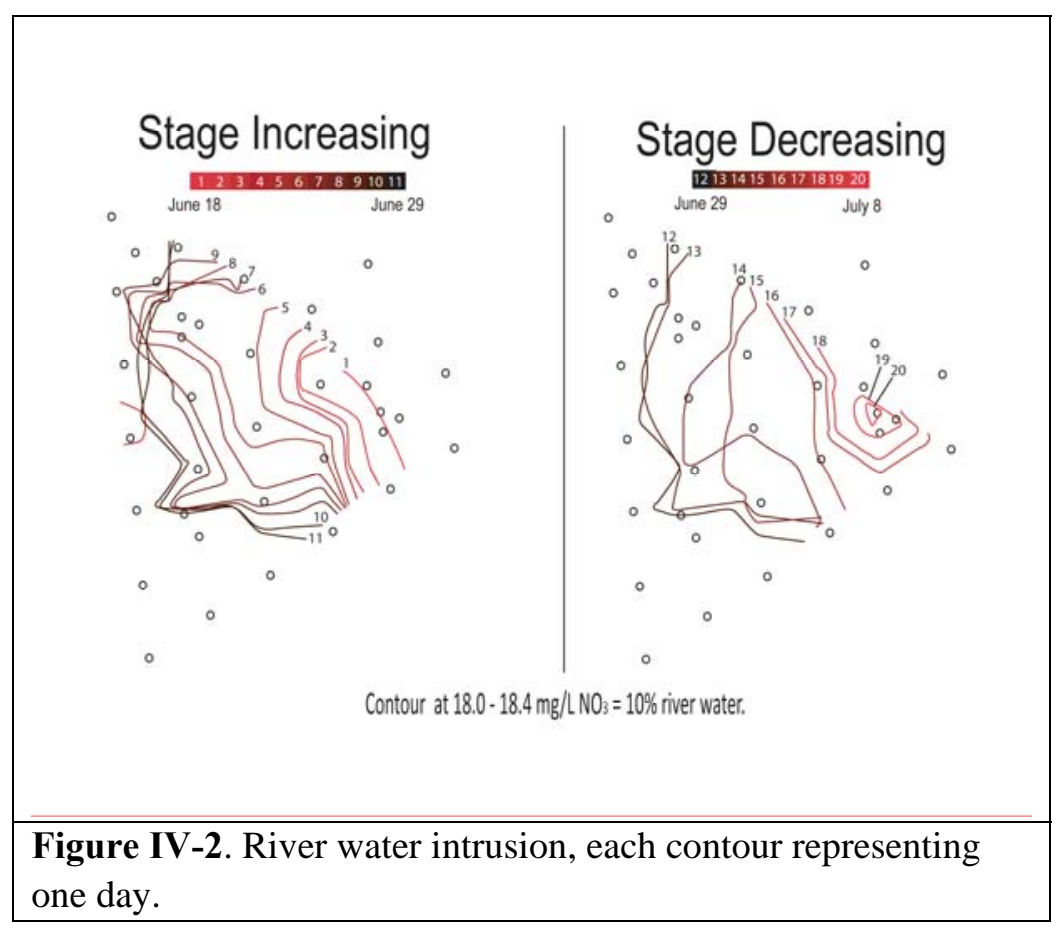




\section{Isotopic Analysis of U Sources}

We have extended our data set of $U$ isotopic analyses of sediment bicarbonate extracts, focusing in particular on the "smear zone" within the IFRC plot. We have also analyzed for U isotopes time series of samples from wells 3-30, 2-6 and 2-29 taken during the Spring 2009 Passive U Mobilization Experiment. We have shown that ${ }^{87} \mathrm{Sr} /{ }^{86} \mathrm{Sr}$, in addition to $\mathrm{U}$ isotopes, provides a tracer of contributions from the lower vadose zone.

As described previously in the FY 2009 annual report, there is large U isotopic variability both vertically and horizontally within various sub-pond sediments of the 300 Area, both within the aquifer and the vadose zone. Significant U isotopic variability in sediments is also observed at the scale of the IFRC plot. Shown in Figure IV-3 is an updated plot of ${ }^{235} \mathrm{U} /{ }^{238} \mathrm{U}$ vs. depth with the latest smear zone data included. The observed range in ${ }^{235} \mathrm{U} /{ }^{238} \mathrm{U}$ has been significantly extended with the most depleted value so far $\left({ }^{235} \mathrm{U} /{ }^{238} \mathrm{U}=0.0044\right)$ coming from a smear zone sample from 3-28. Mapping the smear zone ${ }^{235} \mathrm{U} /{ }^{238} \mathrm{U}$ and ${ }^{236} \mathrm{U} /{ }^{238} \mathrm{U}$ onto the IFRC well plot (not shown), shows that the eastern corner of the plot (2-30, 2-20, $2-22,2-23,2-5)$ is characterized by high ${ }^{235} U /{ }^{238} U(>0.0079)$ and high ${ }^{236} U /{ }^{238} U\left(>100 \times 10^{-6}\right)$, while the very northwest corner $(2-102-8,2-26)$ has low ${ }^{235} \mathrm{U} /{ }^{238} \mathrm{U}(<0.0072)$ and low ${ }^{236} \mathrm{U} /{ }^{238} \mathrm{U}\left(<50 \times 10^{-6}\right)$. The southwest corner (3-24, 3-27, 3-32, 2-28) straddles a sharp boundary between high ${ }^{235} \mathrm{U} /{ }^{238} \mathrm{U}$ and ${ }^{236} U /{ }^{238} U(3-24,3-27)$; and quite low ${ }^{235} U /{ }^{238} U$ and ${ }^{236} U /{ }^{238} U(3-31,3-28)$. Along the west edge of the plot, 2-11, which is situated between two former sub-ponds, has high ${ }^{235} \mathrm{U} /{ }^{238} \mathrm{U}$ and ${ }^{236} \mathrm{U} /{ }^{238} \mathrm{U}$, similar to the east corner. At this point, except for the SW corner of the plot, the pattern of $U$ isotopic variation appears to correspond to the footprint of the sub-ponds of the former South Process Pond complex.

We have greatly expanded our U isotopic dataset for samples from the spring 2009 Passive U Mobilization Experiment, supplementing analyses presented in the FY 2009 report with additional analyses for 3-30 as well as new analyses for well 2-29 and 2-26. As reported previously, during the series of rises of the water table into the "smear" zone, the U isotopic compositions of bailed samples from well 3-30 repeatedly swung from the background $U$ isotopic composition to the composition of the U found in the local (3-31) "smear" in concert with rises of the water table into the "smear" zone. Likewise, we now find that the isotopic compositions of bailed samples from wells 2-26 and 2-29 displayed excursions toward high ${ }^{236} \mathrm{U} /{ }^{238} \mathrm{U}$ compositions, defining mixing trajectories nearly orthogonal to the trajectories observed in 3-30. Figure IV-4 shows time series of the calculated percentage of "smear" zone $U$ in the bailed samples for each of the wells 3-30, 2-29 and 2-26 during the Spring 2009 Passive Experiment. In each case the "smear" zone end-member was chosen based on the U isotopic mixing trajectories on a ${ }^{235} \mathrm{U} /{ }^{238} \mathrm{U}$ vs. ${ }^{236} \mathrm{U} /{ }^{238} \mathrm{U}$ plot. The greatest response to water table rises was seen in well 3-30, where as much as $99.9 \%$ of the $U$ was derived from the "smear" zone. At 2-29, the greatest response was seen on 4/25/09, two days earlier than the peak at 3-30. For 2-26, the response was relatively muted but still coordinated with water table rises.

We have also undertaken a Sr isotopic study $\left({ }^{87} \mathrm{Sr} /{ }^{86} \mathrm{Sr}\right)$ of the 2009 passive rise experiment. We have found that there is a strong correlation between changes in ${ }^{87} \mathrm{Sr} /{ }^{86} \mathrm{Sr}$ and in ${ }^{235} \mathrm{U} /{ }^{238} \mathrm{U}$ (so far we have ${ }^{87} \mathrm{Sr} /{ }^{86} \mathrm{Sr}$ for just 3-30, we should have ${ }^{87} \mathrm{Sr} /{ }^{86} \mathrm{Sr}$ for 2-26 \& 2-29 as well by the end of Feb. 2011). For 330 , with the rise of the water table into the "smear" zone not only is U picked up with a distinct isotopic composition, but $\mathrm{Sr}$ also is added to the groundwater that shifts ${ }^{87} \mathrm{Sr} /{ }^{86} \mathrm{Sr}$ of the groundwater to higher ratios. Thus $\mathrm{Sr}$ isotopes provide an additional tracer of interaction between groundwater and the "smear"/vadose zone due to changes in water table elevation. 


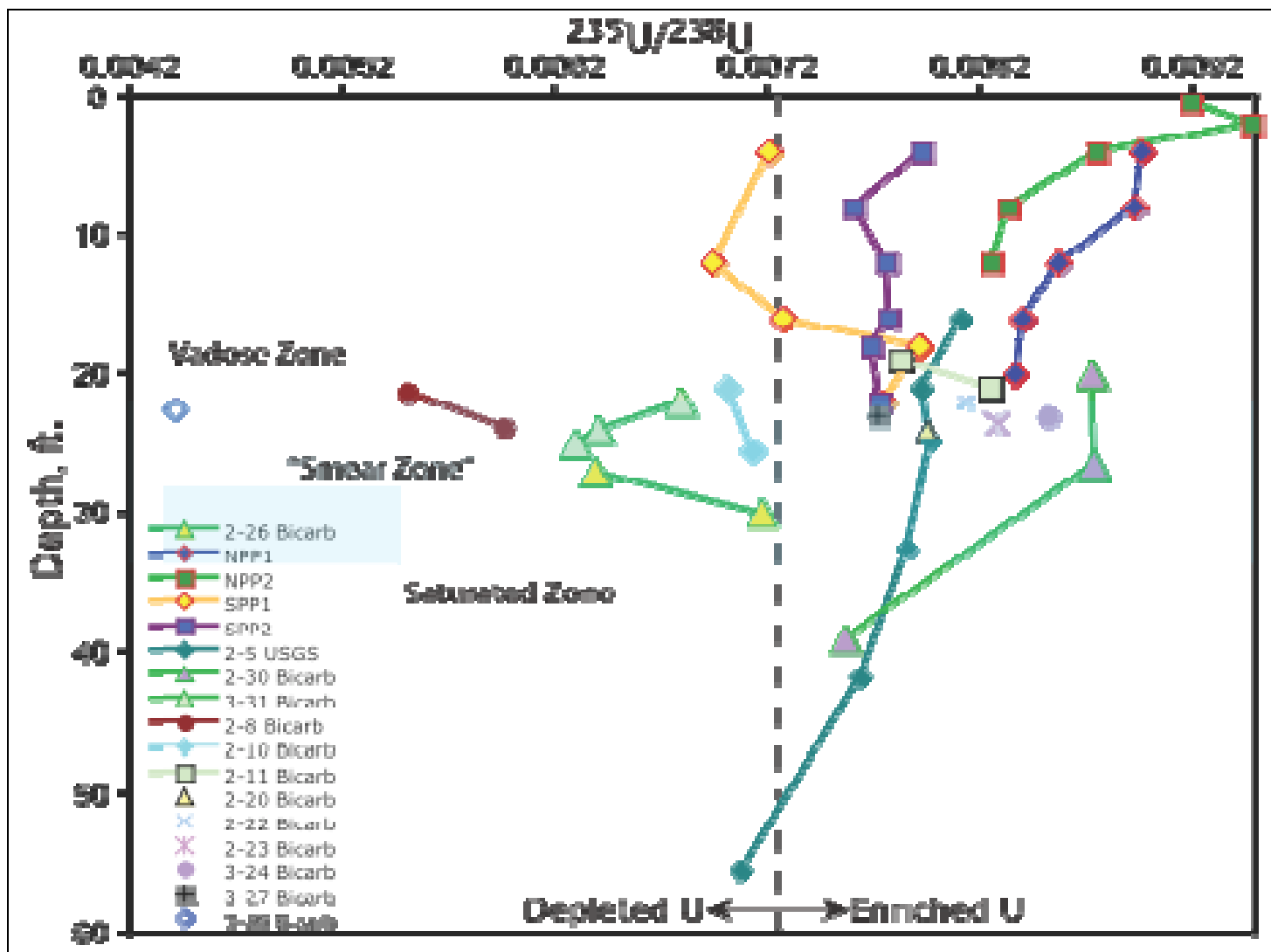

Figure IV-3. Plot of ${ }^{235} \mathrm{U} /{ }^{238} \mathrm{U}$ of sediment sample leachates vs. sampling depth. Significant $\mathrm{U}$ isotopic local spatial heterogeneity (vertical \& horizontal) is represented by the sampled IFRC sediments, including within the "smear" zone. 

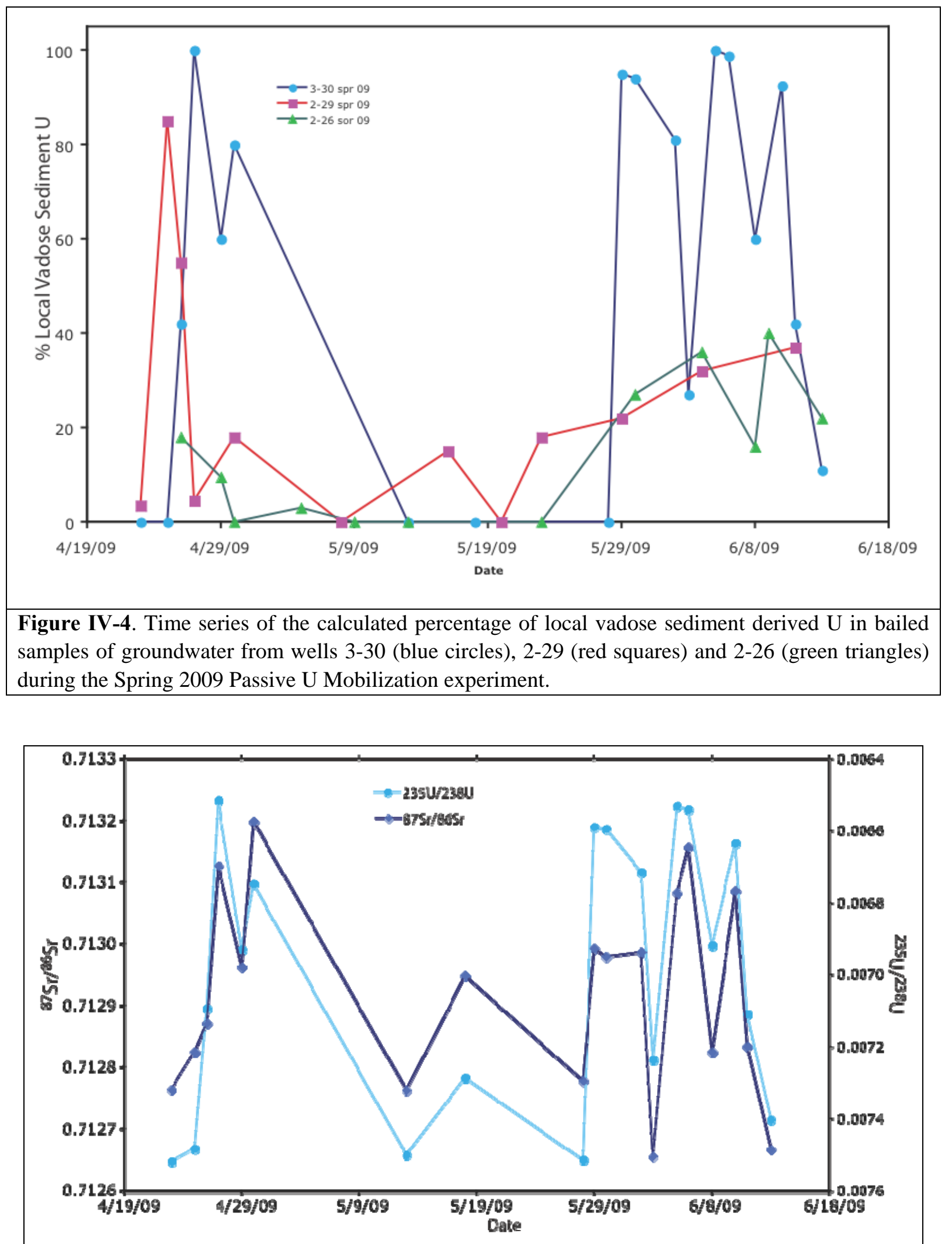

Figure IV-5. Time series comparing ${ }^{87} \mathrm{Sr} /{ }^{86} \mathrm{Sr}$ and ${ }^{235} \mathrm{U} /{ }^{238} \mathrm{U}$ (shown in reverse scale) for well 330. 


\section{MLS Biogeochemistry Experiment: Joint IFRC \& SFA Activities}

The PNNL Scientific Focus Area (SFA) project has been investigating subsurface transition zones using three IFRC wells (3-24, 3-27, and 2-25) for in-well biogeochemical investigations. Passive multi-level samplers have been used to define geochemical gradients across textural (Hanford-Ringold contact) and redox (Ringold fine-grained subunit) transition zones. Multiple MLS experiments have been conducted to-date or are in progress (Table IV-2). These include several experiments where sediments, sterile sand, Fe mineral coupons, bio-sep beads for microbial capture, i-chips for microbial enrichments, and aqueous and gas phase diffusion cell samplers (Figure IV-6) were incubated in wells 3-24 and 3-27. In addition to the shallow IFRC wells, a 25' MLS string was deployed in well 2-25 (the deep microbiology characterization borehole). The diffusion cells sampled the complex the redox transition zone and redox variable facies existing from 60-100' (BGS) to characterize aqueous geochemistry deeper in the Ringold Formation, and to aid in interpretation of microbiological analyses on associated core samples. Example results from MLS investigations are provided below.

Gas analyses from the MLS deployed in IFRC well 3-24 (Figure IV-7) revealed a well-defined redox transition trending from oxidizing in the lower Hanford formation (samples 10A, B) to reducing towards the bottom (samples 1A, B) of the Ringold fine-grained unit. Dissolved $\mathrm{O}_{2}$ decreased concurrently with increases in $\mathrm{H}_{2}, \mathrm{CO}$ and $\mathrm{CH}_{4}$ over the transition zone (sulfide was at or near detection). Similar trends were observed in well 3-27 although $\mathrm{CH}_{4}$ was below detection and sulfide concentrations were 0.9-1.9 $\mu \mathrm{M}(0.03-0.06 \mathrm{mg} / \mathrm{L})$ at and below the Ringold redox interface. Subsequent MLS experiments and analyses at greater spatial resolution have confirmed this redox transition. Moreover, they suggest that this transition zone may represent an oxidation front moving into the Ringold fine-grained unit based upon increases in sediment Fe(II), pyrite, and organic carbon combined with decreases in dissolved DO and nitrate as determined by MLS analyses. Based on aqueous ion and dissolved gas concentration gradients, we hypothesize that this oxidation front is being catalyzed by microbial $\mathrm{Fe}(\mathrm{II})$ and $\mathrm{S}$ oxidation coupled to $\mathrm{O}_{2}$ and nitrate respiration. Consistent with this hypothesis, $\mathrm{Fe}(\mathrm{II})$-oxidizing bacteria have been cultivated from Ringold fine-grained sediments and MLS i-chip smaples by E. Roden's laboratory (U. of Wisconsin SFA collaborator, see below). While the areal extent of the reduced fine-grained Ringold Unit is not well defined, other similar redox boundaries exist within the Ringold elsewhere on the Hanford Site and could have important implications for the subsurface migration of redox sensitive contaminants.

Fe(II)-oxidizing enrichment cultures from Hanford 300 groundwater were obtained through an in situ incubation technique employing i-chips (diffusion chambers) developed by S.S. Epstein (Northeastern U.). The diffusion-chamber-based approach is an alternative method of microbial isolation that allows microorganisms to grow in their natural environment. An inoculum is sandwiched between semipermeable $(0.03-\mu \mathrm{m}$-pore-size) membranes of the chamber, which is then returned to the source environment. The chamber allows for a free exchange of solutes from the external medium via diffusion, while restricting the movement of cells. A modification of the original i-chip approach was used in this study: model clay minerals or fine fraction of Ringold sediments were added to diffusion chambers as solid phase sources of electron donor or acceptor. Groundwater for this study was collected on 10/15/09 from IFRC well 399-3-27. The i-chips were used to enrich and secure growth of difficult-to-cultivate subsurface Fe(II)-oxidizing and Fe(III)-reducing microorganisms. Fresh groundwater was diluted in agarized medium, mixed with corresponding clay minerals and loaded into isolation chips (i-chips). Groundwater was collected on 10/15/09, i-chips were loaded on 10/16/09, and deployed with the MLS on 
10/21/09. The MLS and i-chips were recovered on 03/01/2010 after ca. 5 months of in situ incubation (Table IV-2).

The results of microbial cultivations for Fe(II)-oxidizing organisms from i-chips are shown in Table IV-3. Between 3 and $10 \%$ of the total number of colonies transferred from the i-chips were subsequently recovered in $\mathrm{Fe}$ (II)-oxidzing growth medium. In addition to the i-chip cultivation, $\mathrm{Fe}(\mathrm{II})$-oxidizing bacteria phylogenetically related to Bradyrhizobium japonicum have been isolated from Ringold sediment that can grown on soluble and solid phase Fe(II) (biotite, basaltic glass). Although results are not quantitative, they do indicate the Fe(II)-oxidizing bacteria that can utilize Fe(II) associated with solid phases are present in the Hanford unconfined aquifer and, more specifically, within the Hanford-Ringold redox transition zone. Additional work is underway at the U. of Wisconsin to characterize these isolates as part of SFA research.

Near-term research plans include deploying an MLS in well C7656 that is outside of the IFRC and lies to the NE, adjacent to the Columbia River. This well was drilled as part of the site's 300-FF-5 RI/FS plan for installing additional groundwater monitoring wells in the 300A. The Ringold fine-grained unit is not present at this location and the well is screened from approximately 65-75 ft. bgs and hence is completed entirely within the Ringold Formation. It offers the opportunity to define redox conditions in the Ringold at a location that is lacking the fine-grained "aquitard" present at the IFRC site. In addition, samples of the Ringold fine-grained subunit will be collected from four new IFRC corner wells that are planned (March 2011) for hydrologic control. These cores will be subject to $\mathrm{cm}$-scale sampling for microbiological and geochemical analyses by SFA microbiologists to better define biogeochemical redox processes across this transition zone.

Table IV-2. Summary of Hanford 300A IFRC MLS deployments.

\begin{tabular}{|c|c|c|c|c|c|}
\hline Well ID \#1 & Well ID \#2 & $\begin{array}{c}\text { Date } \\
\text { installed }\end{array}$ & $\begin{array}{c}\text { Date } \\
\text { removed }\end{array}$ & $\begin{array}{l}\text { Depth } \\
\text { top } \\
\text { feet btc }\end{array}$ & $\begin{array}{l}\text { Depth } \\
\text { bottom } \\
\text { feet btc }\end{array}$ \\
\hline $399-2-20$ & C6198 & $2 / 19 / 10$ & $3 / 8 / 10$ & 31.8 & 56.5 \\
\hline $399-2-25$ & C6209 & 10/6/09 & $12 / 1 / 09$ & 57.7 & 82.6 \\
\hline $399-2-25$ & C6209 & 12/1/09 & $3 / 1 / 10$ & 99.9 & 124.8 \\
\hline $399-2-25$ & C6209 & 10/8/10 & $11 / 3 / 10$ & 60.7 & 67.3 \\
\hline $399-2-25$ & C6209 & $8 / 20 / 10$ & $12 / 13 / 10$ & 60.7 & 67.3 \\
\hline $399-3-24$ & C6199 & $10 / 22 / 09$ & $12 / 7 / 09$ & 46.8 & 56.1 \\
\hline $399-3-24$ & C6199 & 12/7/09 & $5 / 21 / 10$ & 46.8 & 56.1 \\
\hline $399-3-24$ & C6199 & $11 / 4 / 10$ & in progress & 46.8 & 56.1 \\
\hline $399-3-27$ & C6204 & $10 / 22 / 09$ & $3 / 1 / 10$ & 47.2 & 56.5 \\
\hline $399-3-27$ & C6204 & $10 / 12 / 10$ & $11 / 1 / 10$ & 32.3 & 56.5 \\
\hline $399-3-27$ & C6204 & $11 / 4 / 10$ & in progress & 47.2 & 56.5 \\
\hline
\end{tabular}


Table IV-3. Recovery of Fe(II)-oxidizing organisms from i-chips incubated in well 3-27 MLS (E. Roden and E. Shelobolina, U. of Wisconsin).

\begin{tabular}{llcccc}
\hline \multicolumn{1}{c}{$\begin{array}{c}\text { Medium } \\
\text { Electron donor (s) }\end{array}$} & $\begin{array}{l}\text { Electron } \\
\text { acceptors(s) }\end{array}$ & i-chip & $\begin{array}{c}\text { Colonies } \\
\text { transferred }\end{array}$ & $\begin{array}{c}\text { Cultures } \\
\text { recovered }\end{array}$ & $\begin{array}{c}\% \\
\text { recovery }\end{array}$ \\
\hline Chemically reduced & Nitrate & B1 & 100 & 7 & 7 \\
NAu2 smectite & $\mathrm{O}_{2}$ & $\mathrm{~B} 3$ & 100 & 10 & 10 \\
Biotite & & $\mathrm{B} 1$ & 100 & 3 & 3 \\
& & $\mathrm{~B} 3$ & 100 & 9 & 9 \\
\hline
\end{tabular}

${ }^{\mathrm{a}}$ Recovery was calculated as $\%$ of positive cultures on specific medium.

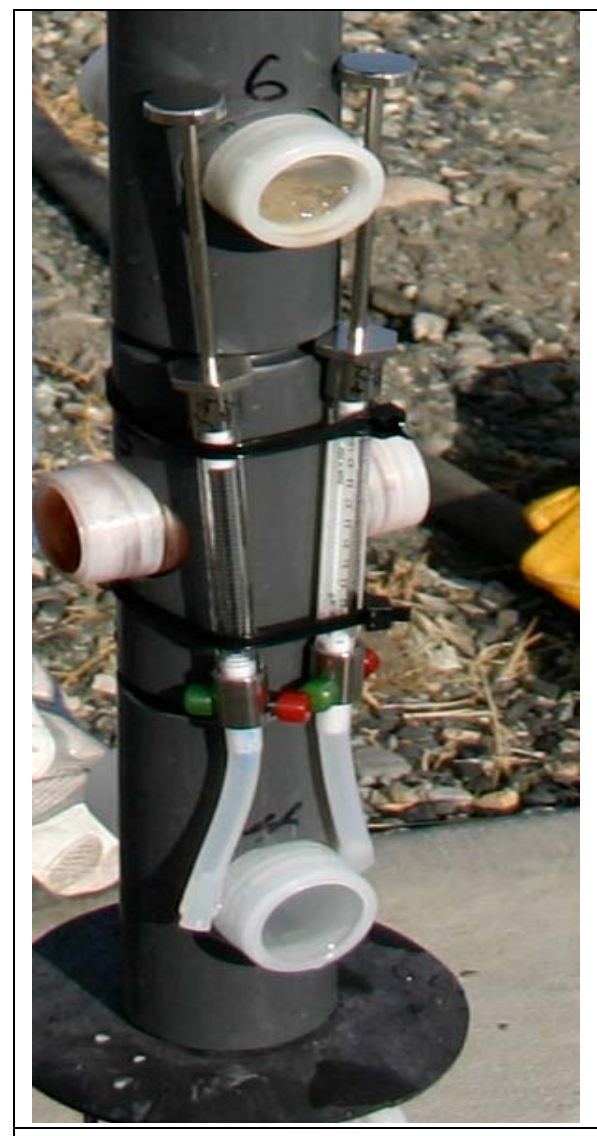

Figure IV-6. Passive multi-level sampler showing cells containing solids for microbiological experiments and water for aqueous geochemical analyses. Dissolved gas samplers (air-filled gas syringes) shown in photo on left were shipped to ORNL (B. Spalding and S. Brooks) for analyses immediately upon removal of the MLS. 


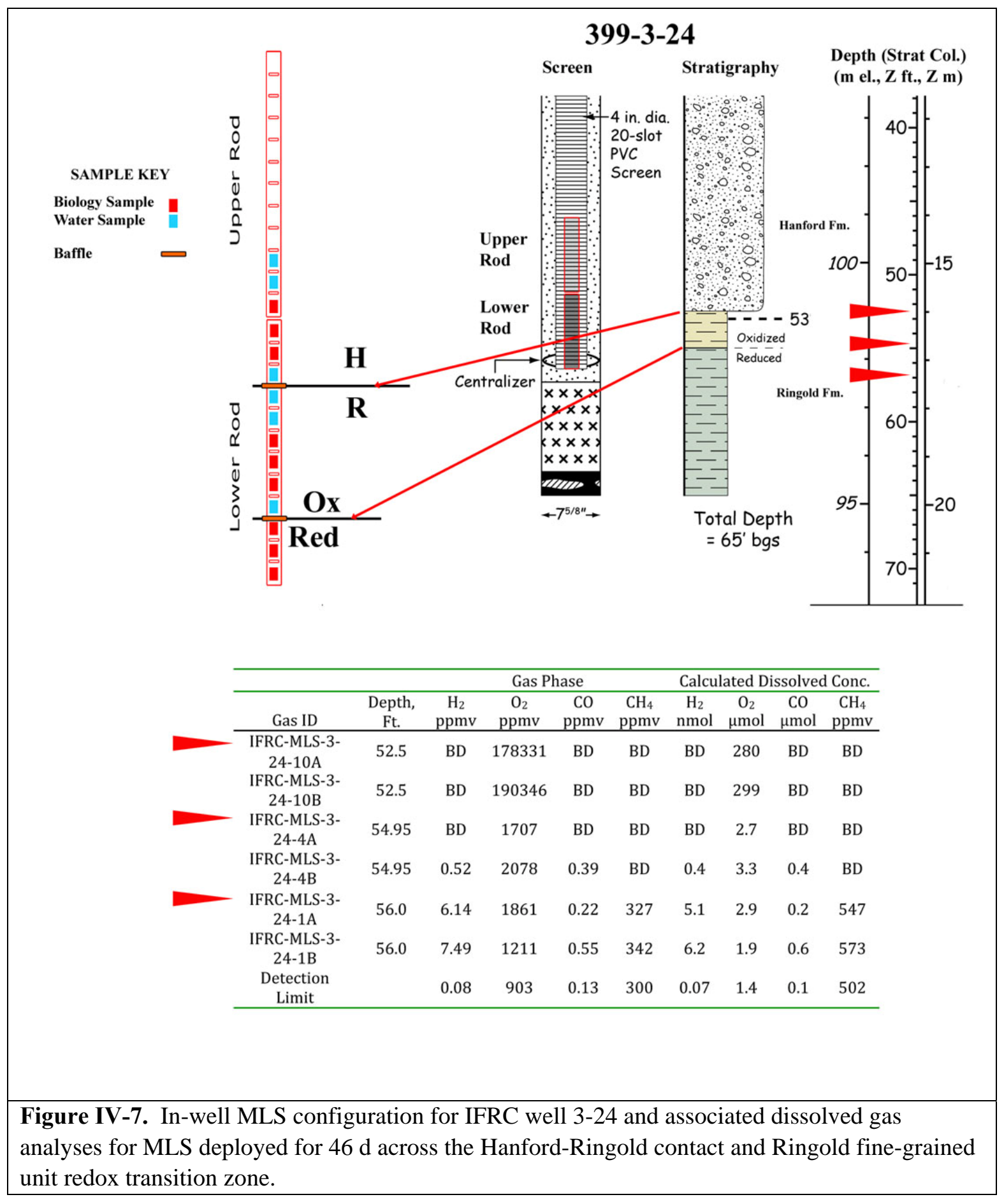




\section{MODELING AND INTERPRETATION}

\section{Geochemical Model Development}

\section{U(VI) Equilibrium Adsorption and Modeling}

Equilibrium U(VI) adsorption experiments were conducted with the less-than 2 millimeter size fraction of seven different composite samples prepared from sediments collected from the smear zone during installation of the IFRC well-field (IFRC composites). Previous studies demonstrated reactivity of bulk sediments from the Hanford formation is dominated by the $<2$ millimeter size fraction (Liu et al., 2008). Six of the composites came from specific locations (boreholes for IFRC wells 2-26, 2-27, 2-30, 2-31, 331, and 3-32). A seventh composite was prepared from sediments collected across the site and is called the site-wide composite (SWC) (Yin et al., in press). Uranium(VI)-contaminated sediments were allowed to equilibrate with various artificial groundwater preparations similar in composition to Hanford-300-area groundwater but differing in initial alkalinity (Yin et al., in press; Stolker et al., submitted). Suspensions were agitated and sampled over time for periods up to one year. Throughout the one-year period, significant changes in U(VI) concentration and other chemical compositional parameters were observed. Adsorbed U(VI) concentration on each composite was assayed using high-pH, high dissolved carbonate solutions (Kohler et al., 2004; Bond et al., 2008).

Experimentally determined U(VI) adsorption for selected samples, expressed as the ratio of adsorbed (moles $/ \mathrm{kg}$ ) to dissolved (moles/L) U(VI) concentration $\left(\mathrm{K}_{\mathrm{d}}\right)$, on suspensions equilibrated for 12 to 14 weeks is shown in Figure V-1. As shown previously (Bond et al., 2008), the extent of U(VI) adsorption decreases with increasing carbonate concentration (here expressed as alkalinity).

Equilibrium constants for U(VI) surface complexation reactions were obtained by non-linear, least squares optimization (Herbelin and Westall, 1999). All model calibrations were made using experimental data from suspensions that had equilibrated for 12 to 16 weeks. The adsorbed U(VI) concentration, dissolved $\mathrm{U}(\mathrm{VI})$ concentration, $\mathrm{pH}$, alkalinity, and total dissolved concentrations of sodium, potassium, magnesium, calcium, and sulfate were used in the optimizations along with the thermodynamic data for U(VI) aqueous species from Dong and Brooks (2006). Uncertainties in the fitted equilibrium constant(s) were obtained by propagation of experimental uncertainties and represent 95 percent confidence limits. Several surface complexation reactions differing in stoichiometric relationships between adsorption sites, $\mathrm{U}(\mathrm{VI})$, carbonate, and hydrogen ion (Bond et al., 2008) were tested for their ability to fit the experimentally determined U(VI) adsorption. The goodness of fit was evaluated using the weighted sumof-squares of residuals divided by the degrees of freedom (WSOS/DF, Herbelin and Westall, 1999). Total adsorption site concentrations were calculated from the specific surface area using an assumed adsorption site density of 3.84 micromoles per square meter $\left(\mu \mathrm{mole} / \mathrm{m}^{2}\right)$ (Davis and Kent, 1990).

The same, single-reaction SCM provided the best fit to the data for each, individual composite as well as the data for all composites fitted together:

Reaction $1 \quad>\mathrm{SOH}+\mathrm{UO}_{2}{ }^{2+}+2 \mathrm{H}_{2} \mathrm{CO}_{3} *=>\mathrm{SOUO}_{2}\left(\mathrm{CO}_{3} \mathrm{HCO}_{3}\right)^{2-}+4 \mathrm{H}^{+}$

where $\mathrm{H}_{2} \mathrm{CO}_{3} *$ refers to the sum of neutral dissolved $\mathrm{CO}_{2}$ species following standard conventions. The WSOS/DF values for individual composites ranged from 1.6-2.8. A value of 4.2 was obtained for data 
from all samples fitted together (Table 1). For comparison, the WSOS/DF obtained using the tworeaction model from Bond et al. (2008) for all samples fitted together was 13.8.

The equilibrium constants for the SWC and for all samples fitted together were in excellent agreement: 11.73 and -11.72 , respectively (Table 1 ). The equilibrium constant obtained for the composite sample from 2-26 was a factor of 1.9 greater than that for the composite sample from 3-32. Differences in equilibrium constants for most of the other composite samples were not statistically different. Calculations with this set of equilibrium constants (Table 1) showed that equilibrium in all experiments was achieved within 1000 hours (6 weeks). Further changes in U(VI) concentration were driven by changes in chemical conditions in the suspensions that favored increased desorption (Stoliker et al., submitted).

\section{Grain-Scale U(VI) Desorption Rate Experiments}

Batch experiments with smear zone IFRC sediments showed that water chemistry evolves steadily over thousands of hours owing to mineral dissolution/precipitation and other reactions occurring on the same time scale as U(VI) desorption. In order to avoid complications introduced by changing water chemistry driving U(VI) desorption, flow-through batch reactor experiments have been implemented so that U(VI) mass transfer can be observed at a constant, controlled chemical composition (Figure V-2). Current studies focus on the SWC because of the availability of sufficient material.

Experiments were carried out in a $50 \mathrm{~mL}$ cell fitted with a $0.4 \mu \mathrm{m}$ polycarbonate filter and filled with $\sim 5 \mathrm{~g}$ of sediment and $\sim 40 \mathrm{~mL}$ of artificial groundwater (AGW). Solution was introduced to the cell at a flow rate of $20 \mathrm{~mL}$ per hour using stainless steel syringe pumps. The solution was stirred by a floating stir-bar cage situated above the floor of the cell to prevent grinding of the sediment along the filter. The sediment was not suspended in solution however the thin layer of sediment on the floor of the cell was in contact with well-mixed bulk solution as it moved towards the outlet. Fractions collected every 45 minutes were analyzed for $\mathrm{pH}$, alkalinity, aqueous uranium concentration, and major solution cation concentrations. Stop flow events were conducted once aqueous uranium concentration reached the analytical detection limit.

Flow-through batch extractions carried out on the $<2 \mathrm{~mm}$ SWC demonstrated a significant increase in $\mathrm{U}(\mathrm{VI})$ desorption rate with increasing carbonate concentration (Figure V-3). A four-fold increase in alkalinity resulted in a 2.5 -fold increase in the initial rate of release of $\mathrm{U}(\mathrm{VI})$ after each of the stop flow events. This is in good agreement with the 2.2-fold increase predicted by the multi-rate SCM model (Liu et al., 2008; Yin et al., 2008). Approximately $80 \%$ of the labile U(VI) was extracted with AGW containing $1 \mathrm{meq} / \mathrm{L}$ alkalinity and $~ 95 \%$ using an AGW with 4 meq/L (Figure V-3). Flow-through batch extractions conducted with different size fractions (1-2 mm, 0.5-1 mm, 0.25-0.5 mm and 0.125-0.25 mm) of the SWC show a 5-fold increase in the initial rate of U(VI) release between the largest $(1-2 \mathrm{~mm})$ and smallest $(0.125-0.25 \mathrm{~mm})$ size fractions, as expected based on shorter diffusion path-lengths in smaller particles. Experiments are planned to examine further the influence of particle size and chemical conditions on U(VI) adsorption and desorption. A grain-scale U(VI) mass-transfer rate model will be developed in collaboration with Chonxuan Liu and used to design targeted experiments with locationspecific composite sediments, for which more limited quantities of sample are available. 


\section{Upscaling and Estimation/Prediction of Adsorption/Desorption Rate (with the PNNL SFA)}

Laboratory experiments were performed to investigate the contribution of different grain sizes to uranium adsorption/desorption kinetics in IFRC sediment. The experimentation supports the development of upscaling relationships for mass-transfer modeling at the field scale. Contaminant uranium in the sediment was removed by desorption in a column system using synthetic IFRC groundwater. The cleaned sediment was wet-sieved into four size fractions: coarse sand (1-2 mm), medium sand (0.2-1 mm), fine sand (0.05$0.2 \mathrm{~mm}$ ), and clay/silt $(<0.05 \mathrm{~mm})$. For each size fraction and their composite (the whole sediment), batch experiments were performed to determine uranium adsorption isotherms, and stirred flow-cell experiments were performed to derive kinetic data for uranium adsorption and subsequent desorption. A surface complexation model that involved one uranyl surface complex [ $\left.>\mathrm{SOUO}_{2}\left(\mathrm{HCO}_{3} \mathrm{CO}_{3}\right)\right]$ and all necessary aqueous speciation reactions was used to describe uranium adsorption isotherms by adjusting the equilibrium reaction constant and surface site concentration. The parameterized surface complexation model was then linked with a multiple first-order rate expression to formulate a multi-rate surface complexation model to describe uranium adsorption and desorption kinetics in each size fraction. The additivity of size-specific uranium adsorption isotherms and adsorption/desorption kinetic parameters was evaluated by comparing measured and additively calculated uranium adsorption isotherm and adsorption/desorption kinetics for the composite/whole sediment.

The study yielded important findings. Uranium adsorption isotherms and adsorption/desorption kinetics were found to be size-specific (Figures V-4 and V-5), reflecting the effects of size-specific adsorption site concentrations and kinetic rate constants. While the larger-size fraction occupied a higher mass percent of the sediment, it had a lower adsorption site concentration and a slower uranium adsorption/desorption rate. The same equilibrium surface complexation reaction and reaction constant could describe the uranium adsorption isotherms for all size fractions and the composite, after accounting for the effect of adsorption site concentration (Figure V-4A). Unexpectedly, the uranium adsorption site concentration estimated from the adsorption isotherms was 2-3 orders of magnitude lower than that estimated from a generic site density and sediment surface area. An important conclusion was that, for U(VI) at groundwater concentrations $(<2 \mu \mathrm{mol} / \mathrm{L})$, mass-weighted, linear additivity was observed for both uranium adsorption (e.g., the isotherms, Figure V-4B) and adsorption/desorption kinetics (Figure V-5). The critical implication of this work is that grain size distribution may be used to calculate uranium adsorption site concentration and rate constant distribution in IFRC sediments without direct measurement.

\section{Effects of Variable Groundwater Composition and Water Table Fluctuations on U(VI) Transport}

The fluctuation in Columbia River stage has a twofold impacts on the U(VI) plume in the site groundwater: dilution of the plume near the river and remobilization of U(VI) in the deep vadose zone (Peterson et al., 2008). To better understand U(VI) transport and mass transfer associated with these conditions, we conducted two sets of column experiments using the IFRC project-wide, smear-zone composite sediment. First, we demonstrated that the low U(VI) concentrations near the river are caused not only by dilution but also by enhanced adsorption. Second, preliminary results indicate that the lower water content in deep vadoze zone may have little effect on the kinetics of U(VI) desorption - i.e., that rates of desorption in the smear zone appear to be very similar to those in the saturated zone. This will allow us to improve our estimate of smear zone flushing with water table movement. 
First, a batch experiment was conducted to develop a surface complexation reaction describing U(VI) adsorption/desorption as a function of alkalinity (Yin et al., 2011). Second, two desorption column experiments were conducted. In column \#1, synthetic Hanford groundwater (SGW) was injected to desorb U(VI). In column \#2, SGW and synthetic Columbia River water (SCRW) were alternately injected to desorb U(VI). pH, alkalinity, major cations and major ions, and U(VI) were measured in column effluent waters. Stop-flow events were applied in each experiment, pumps to evaluate the kinetic behavior of U(VI) mass transfer. Finally, the multirate surface complexation model (built in Pht3D) was used to simulate the results.

In both experiments, significant decreases in dissolved salt concentrations and changes in other chemical conditions were observed in the first a few pore volumes (Figure V-6a,b). The rapid decrease is likely a result of the dissolution of salts that had precipitated prior to the experiment during sediment drying, and/or re-equilibration of ions on the exchange sites. Over the following pore volumes, changes in major ion concentrations steadily approached those expected based on changes in the influent concentrations. Trends in U(VI) desorption in column \#1 were similar to those reported previously for vadose-zone U(VI)-contaminated sediments from the site (e.g., Qafoku et al., 2005; Liu et al., 2008), with an initial rapid decline in U(VI) followed by a long tail (Figure V-7a). Trends in U(VI) desorption in column \#2 were generally consistent with imposed water composition changes (Figure V-7b). More specifically, during the time periods when SCRW was injected, chemical conditions favored significant decreases in $\mathrm{U}(\mathrm{VI})$ desorption (or significant increases in U(VI) adsorption) throughout the column. Rate-limited $\mathrm{U}(\mathrm{VI})$ desorption was observed in all five stop-flow events (Figure V-7a,b), indicating that the mass transfer of $\mathrm{U}(\mathrm{VI})$ is not in equilibrium with the aqueous water chemistry. During stop-flow, the sites at the faster end of the rate-coefficient distribution become populated with the U(VI) released from sites at the slower end of the distribution (Liu et al., 2008). The increased U(VI) concentration after each stop-flow is attributed to this redistribution.

In the applications of the surface complexation model, we manually adjusted the $\mathrm{pH}$, alkalinity and other major cations of the influent SGW and SCRW to the corresponding values observed in the effluent in both experiments. This was necessary due to insufficient information on buffering capacity/reactivity of the composite sediment. Model calibration was carried out by adjusting only the mean of the rate constant distribution with the condition that the log-standard deviation had to be the same as measured by Liu et al. (2008). An additional simulation using a single fast rate constant $\left(0.0241 \mathrm{~h}^{-1}\right)$ was also used to evaluate whether the number of discrete adsorption domains could be reduced. With constant water composition, desorption of $\mathrm{U}(\mathrm{VI})$ is fully controlled by rate-limited mass transfer, and the underestimation of $\mathrm{U}(\mathrm{VI})$ increase in the stop-flow event at the later stage of the experiment could be compensated by assigning several slower adsorption domains to retard the desorption (Figure V-8a). In the experiment with transient chemistry, however, U(VI) adsorption/desorption was mainly controlled by the rate of changes in water chemistry rather than the mass transfer rates (Figure V-7b). In both columns, using a one-site model seemed to be sufficient to obtain very similar simulation results (Figure V-7a,b). From the study, it can be concluded that the application of the multirate surface complexion model to the field is feasible when the groundwater composition is constrained, or if the evolution of the groundwater chemistry can be accurately predicted. However, the rate constant distributions and the number of the adsorption domains should be carefully calibrated to characterize the physical and chemical properties and the contamination history of the investigated sediments. 
Two additional comparison column experiments were conducted to mimic water table fluctuations and evaluate their resulting impact on U(VI) transport. The $<8 \mathrm{~mm}$ size fraction from the site-wide smear zone composite sediment was used for the experiment. Coarser sediment was used than in the transient chemistry experiments described above in order to obtain sufficient column drainage under unsaturated conditions. Both columns were leached in a water-saturated state with IFRC SGW. Two stop-flow events were conducted to calibrate the multirate distribution. The experiment in the second column followed the injection and stop-flow sequences in the first column. However, before each stop-flow event, the upper end of the second column was opened, and the column was drained by gravity. Therefore during the stopflow events, one column was saturated and the other column was unsaturated. The unsaturated column was saturated again after each stop-flow event and injection continued.

Very similar results were observed from both columns. The results of the conservative tracer (Br) showed that physical transport in two columns was identical (results not shown). The measured U(VI) showed similar concentration trends in both experiments (Figure V-8). In the drained samples from the unsaturated column, $\mathrm{U}(\mathrm{VI})$ had almost constant concentrations of $0.084 \mu \mathrm{mol} / \mathrm{L}$ regardless of the U(VI) concentrations in the previous pumped samples. Considering that the drained pore water samples were mainly from the macro-pores in the column, we hypothesize that $\mathrm{U}(\mathrm{VI})$ desorption occurs from the fine materials where pore water is under higher tension and not drained by gravity. Based on this hypothesis, the mass transfer of U(VI) during the stop-flow was not hindered by lower water content because most of the fine material was still saturated. After the stop-flow events, the higher U(VI) concentrations in the saturated column were caused by the limited additional U(VI) mass transfer in coarse materials associated with macro-pores, while the greater U(VI) mass transfer in fine materials associated with smaller-pores was similar.

Our preliminary results indicate that it should be feasible to use the same multirate surface complexation model in saturated and unsaturated zones, and that it should be possible to estimate the flushing rate of $\mathrm{U}(\mathrm{VI})$ from the smear zone with this model. In order to make the U(VI) flushing rate calculation, we need drainage curves for the smear zone and measurements of mixing between macro- and micropores during resaturation and drainage.

\section{Comparison of Physical Versus Chemical Non-Equilibrium Models for Simulating Adsorption of U(VI) Under Transient Flow and Hydrochemistry}

Coupled intra-grain diffusional mass-transfer and non-linear surface complexation processes play an important role for the transport behavior of U(VI) within the 300 A plume. Two alternative model approaches for simulating these coupled processes were analyzed and compared: i) the physical nonequilibrium approach that explicitly accounts for aqueous speciation and instantaneous surface complexation reactions in the intra-grain regions and approximates the diffusive mass exchange between the immobile intra-grain pore water and the advective pore water as multi-rate 1st-order mass transfer and ii) the chemical non-equilibrium approach that approximates the diffusion-limited intra-grain surface complexation reactions by a set of multiple 1st-order surface complexation reaction kinetics, thereby eliminating the explicit treatment of aqueous speciation in the intra grain pore water. Model comparison has been carried out for column and field scale scenarios, representing the highly transient hydrological and geochemical conditions in the Hanford 300 A uranium plume. 
It was found that the response of U(VI) adsorption/desorption kinetic behavior to hydrogeochemically induced changes in U(VI) adsorption strength was more pronounced in the physical than in the chemical non-equilibrium model. The magnitude of the differences in model behavior depended particularly on the degree of disequilibrium between the advective and immobile phase U(VI) concentrations. While a clear difference in U(VI) transport behavior between the two models was noticeable for the column-scale scenarios, only minor differences were found for IFRC field scale scenarios, where the model-generated disequilibrium conditions were less pronounced as a result of frequent groundwater flow reversals.

Table V-1. Specific surface areas, fitted $\log \mathrm{K}$ values for reaction 1, and associated WSOS/DF values for the less-than 2 millimeter fractions of smear-zone and shallow aquifer IFRC composite sediment samples. ${ }^{1}$

\begin{tabular}{lccc}
\hline \multicolumn{1}{c}{ Composite sample } & $\begin{array}{c}\text { Specific surface area } \\
\left(\mathrm{m}^{2} / \mathrm{g}\right)\end{array}$ & $\begin{array}{c}\text { Log K } \\
\text { (reaction } 1)\end{array}$ & WSOS/DF \\
\hline All samples & $12.5^{2}$ & $-11.72 \pm 0.04$ & 4.2 \\
SWC composite & $14.1 \pm 0.9^{3}$ & $-11.73 \pm 0.11^{3}$ & 2.8 \\
2-26 composite & $11.7 \pm 0.6$ & $-11.78 \pm 0.11$ & 2.4 \\
2-27 composite & $13.4 \pm 0.7$ & $-11.61 \pm 0.12$ & 2.1 \\
2-30 composite & $13.3 \pm 0.7$ & $-11.69 \pm 0.12$ & 2.2 \\
2-31 composite & $12.1 \pm 0.6$ & $-11.60 \pm 0.11$ & 2.5 \\
3-31 composite & $11.7 \pm 0.6$ & $-11.80 \pm 0.13$ & 1.6 \\
3-32 composite & $11.5 \pm 0.6$ & $-11.88 \pm 0.11$ & 2.0 \\
\hline
\end{tabular}

1) All values from Stoliker et al., submitted, unless otherwise noted.

2) Weighted average based on experimental data used to obtain fit.

3) Yin et al., in press. 


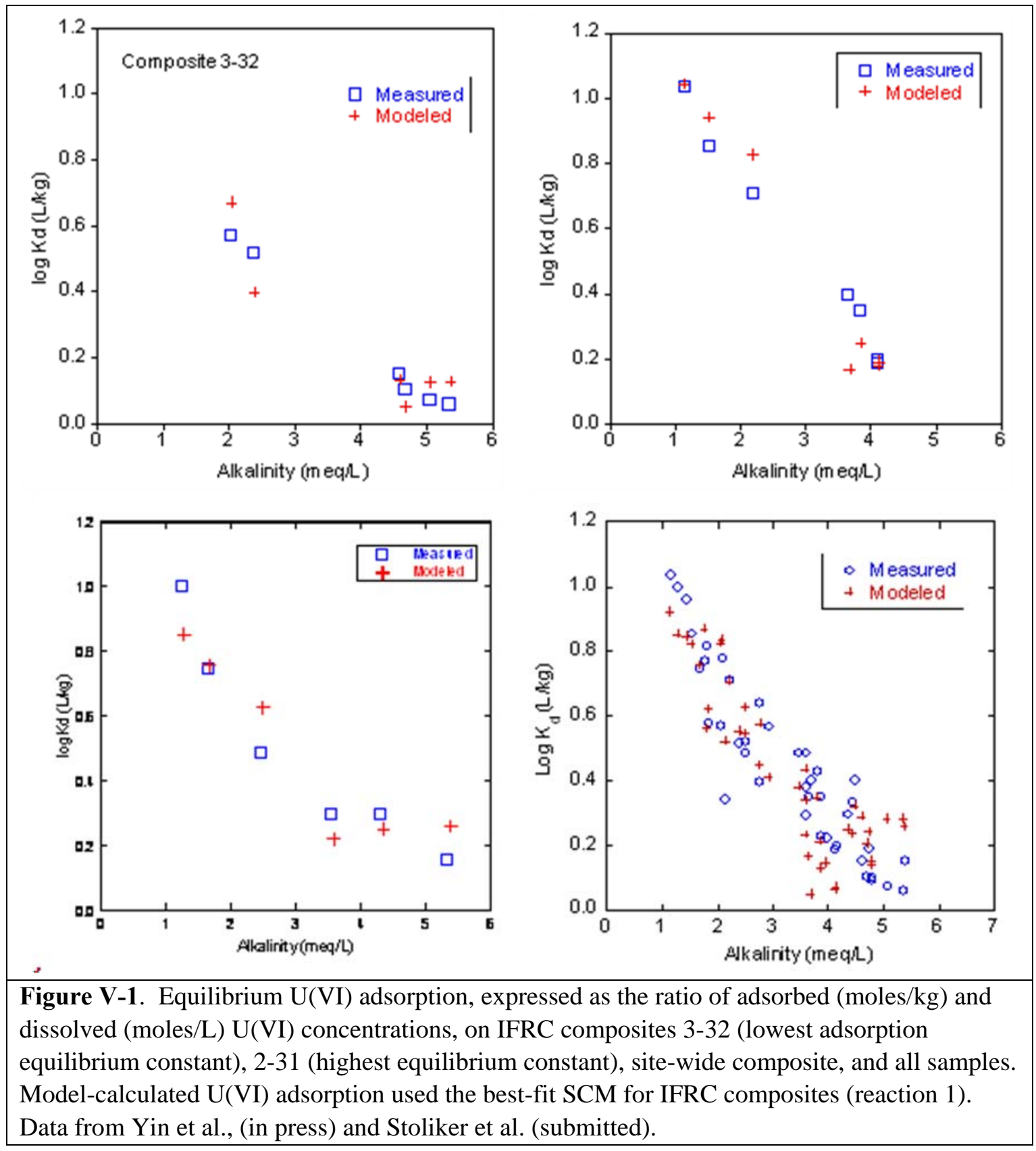




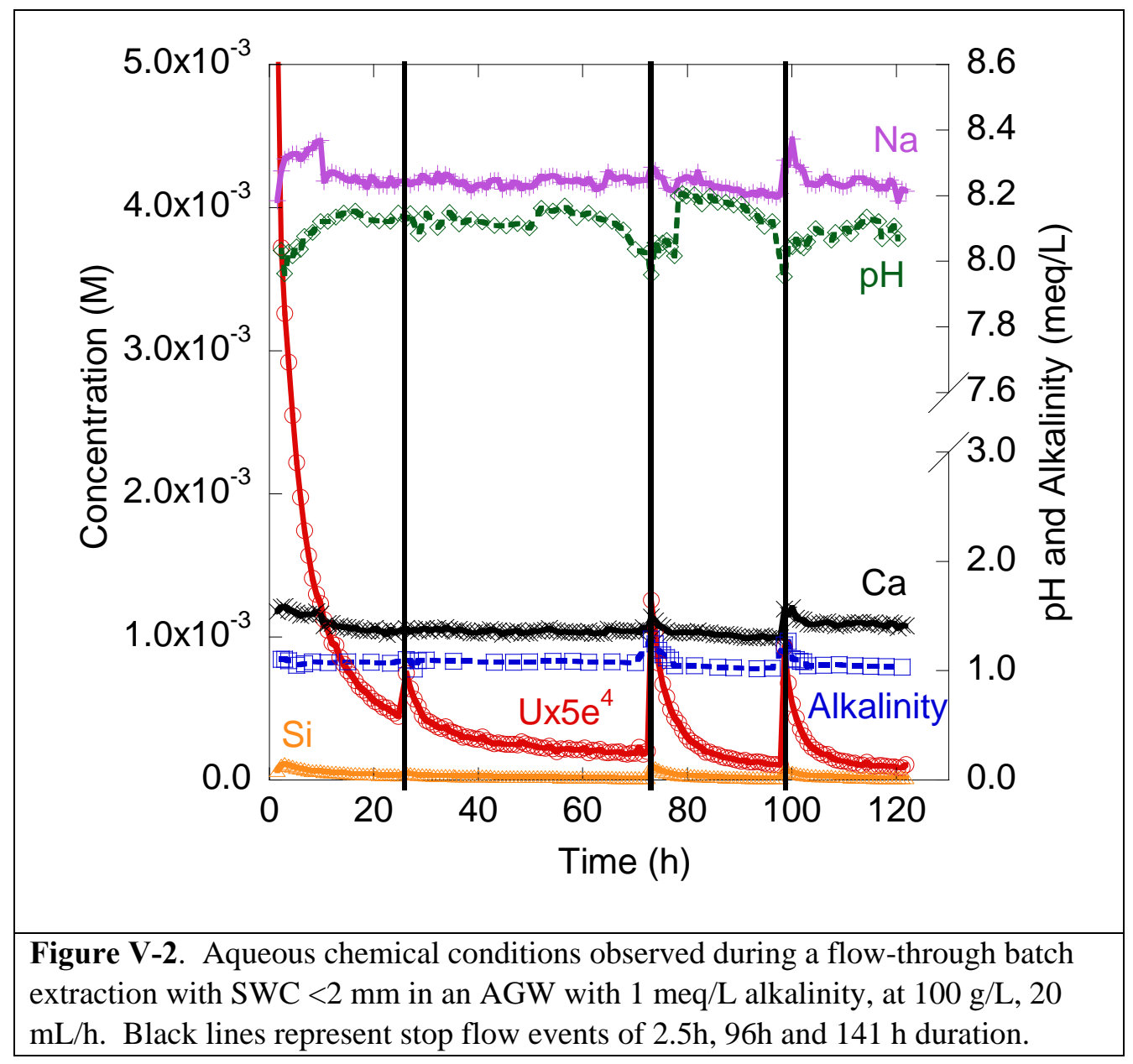




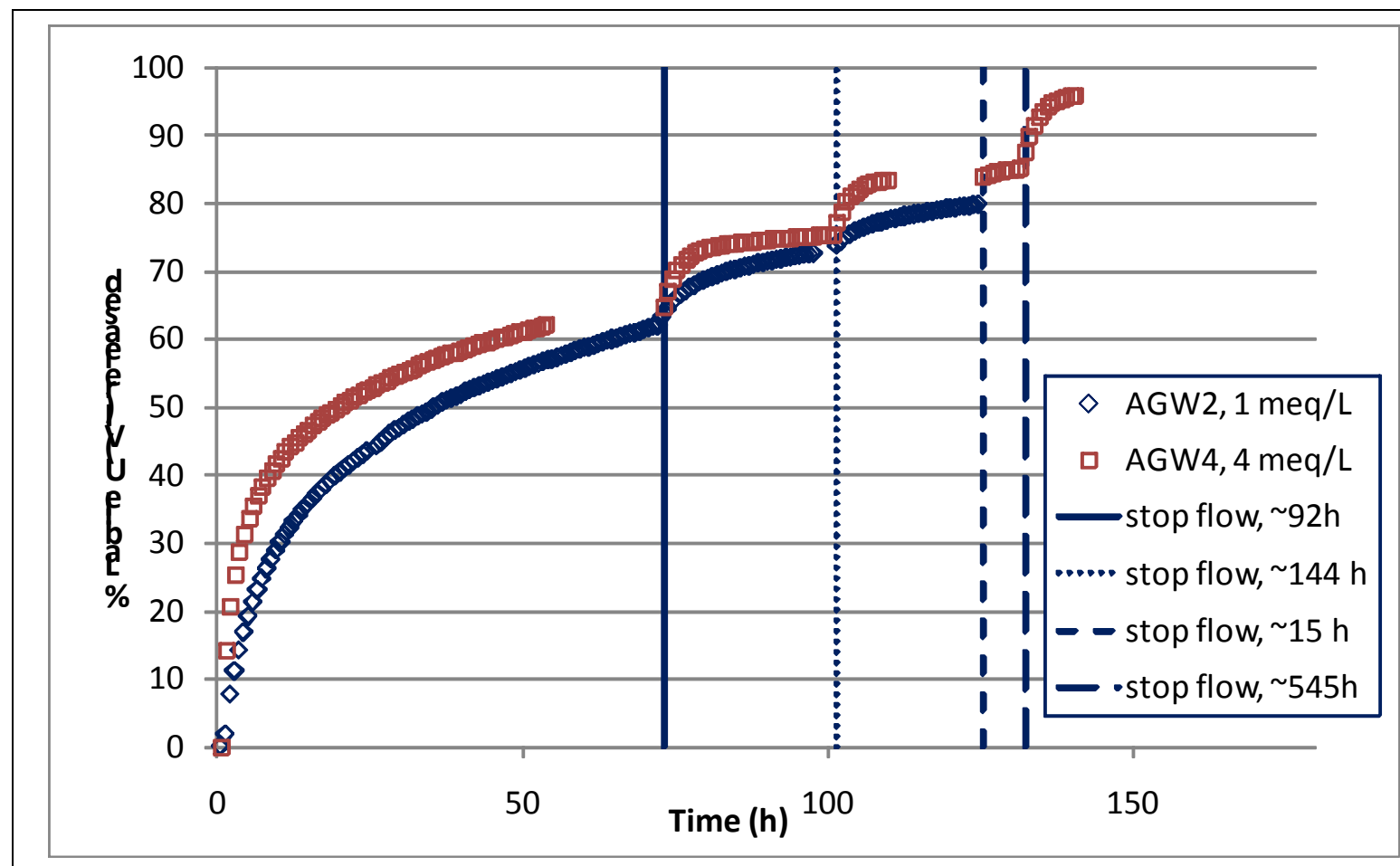

Figure V-3. Influence of alkalinity on U(VI) release observed in flow-through reactors. SWC $<2 \mathrm{~mm}, 100 \mathrm{~g} / \mathrm{L}, 20 \mathrm{~mL} / \mathrm{h}$. X-axes have been adjusted to overlay stop-flow events.
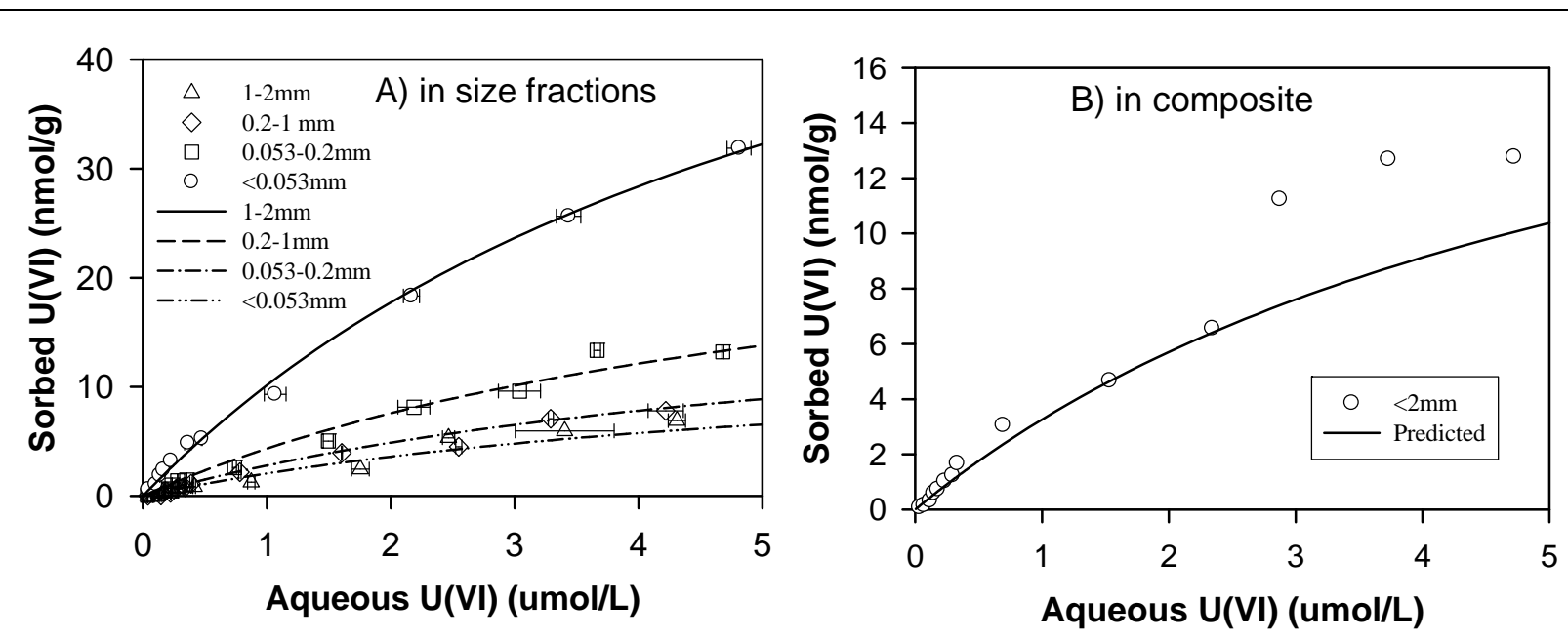

Figure V-4. U(VI) adsorption isotherms in each grain size fraction (A) and in the composite (sediment) (B). Symbols are measured and lines are calculated results. The line in plot B was calculated by linearly adding the isotherms in plot A weighted by their mass percentages in the sediment (composite). 


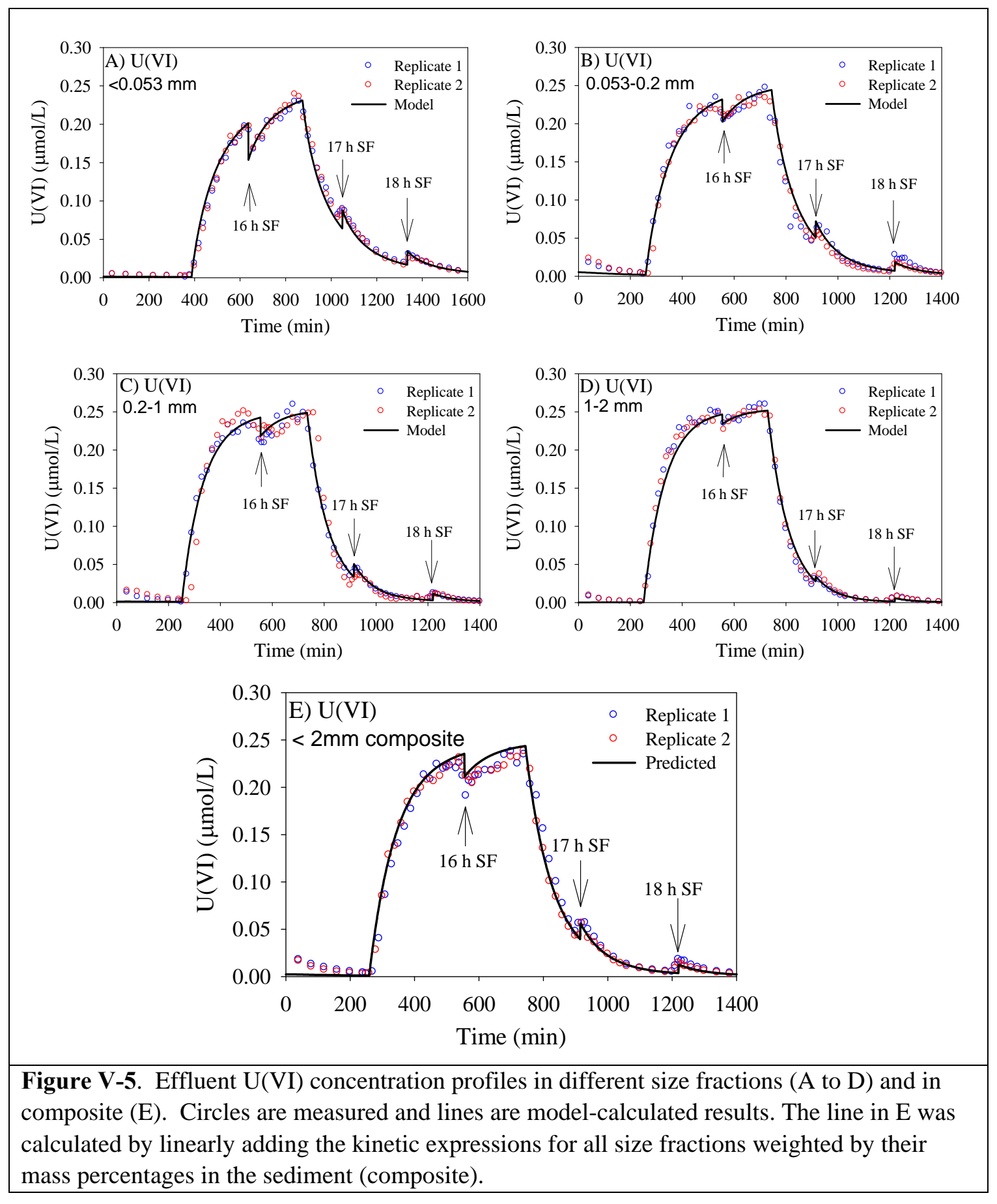



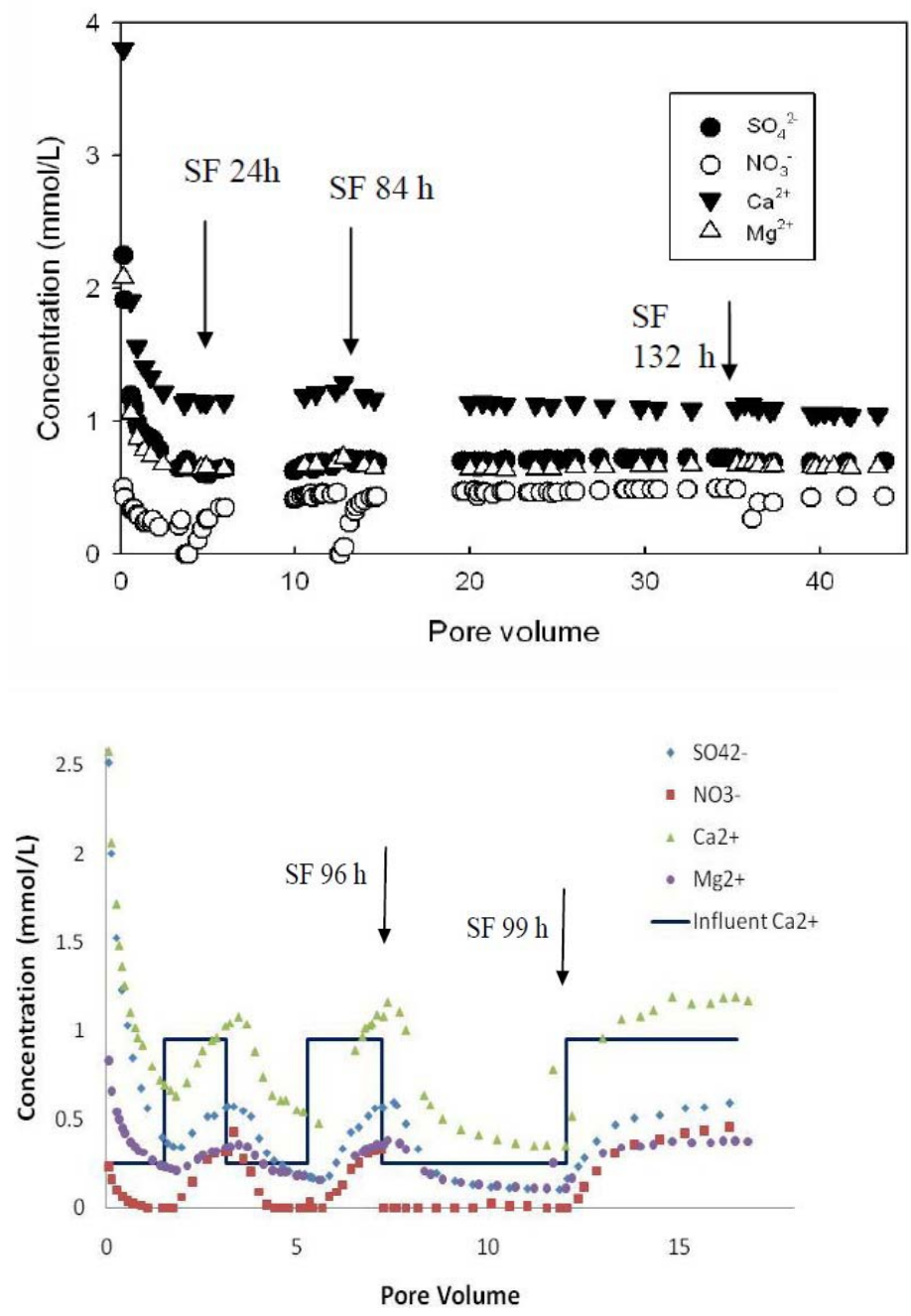

Figure V-6. Transient water chemistry. Selected chemical compositions in Experiment set 1: a) effluent in column \#1, 2) effluent and influent in column \#2. 

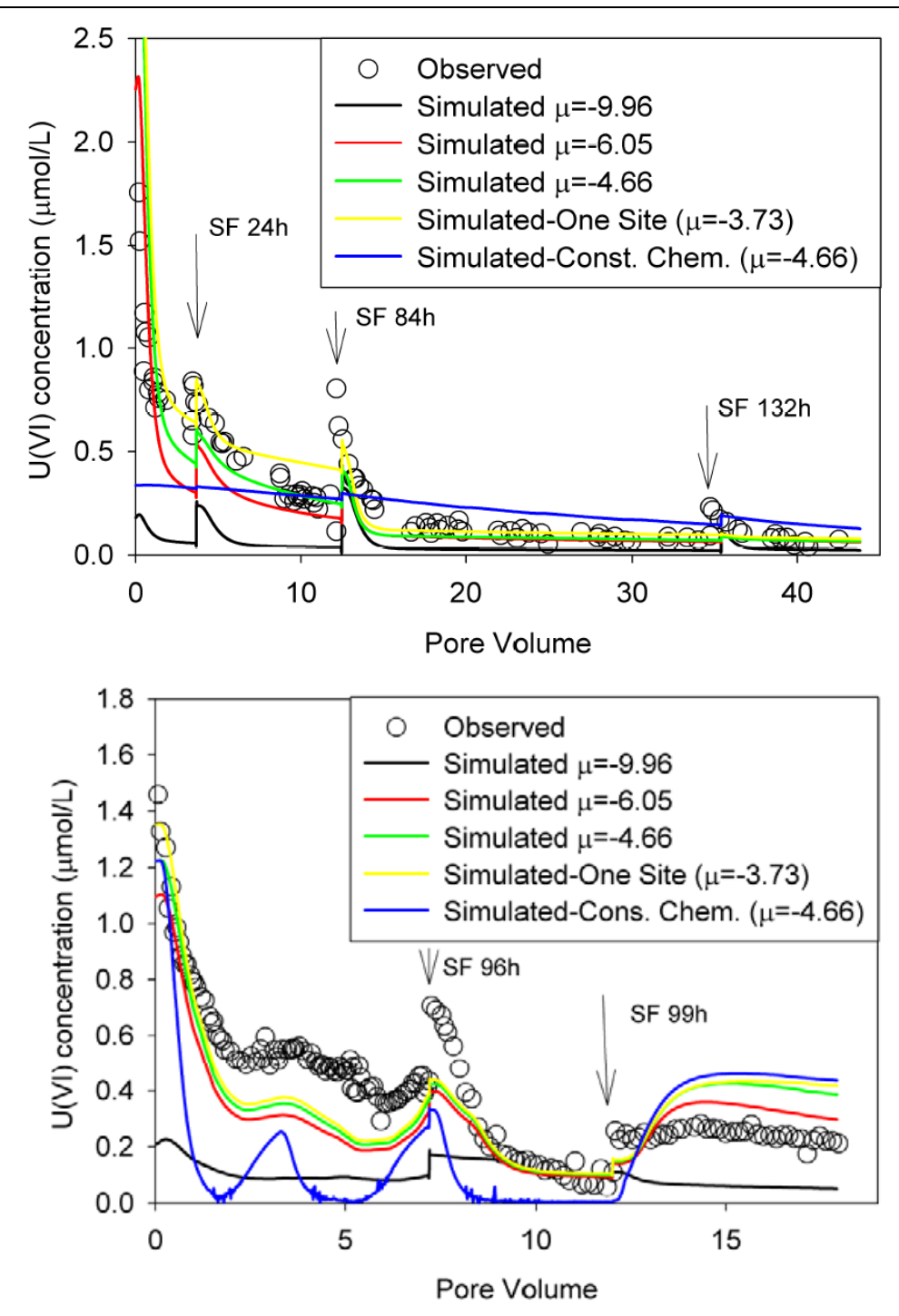

Figure V-7. Transient water chemistry. Observed and simulated U(VI) desorption in Experiment set 1: a) desorption (column \#1); b) transient chemistry desorption (column \#2). 


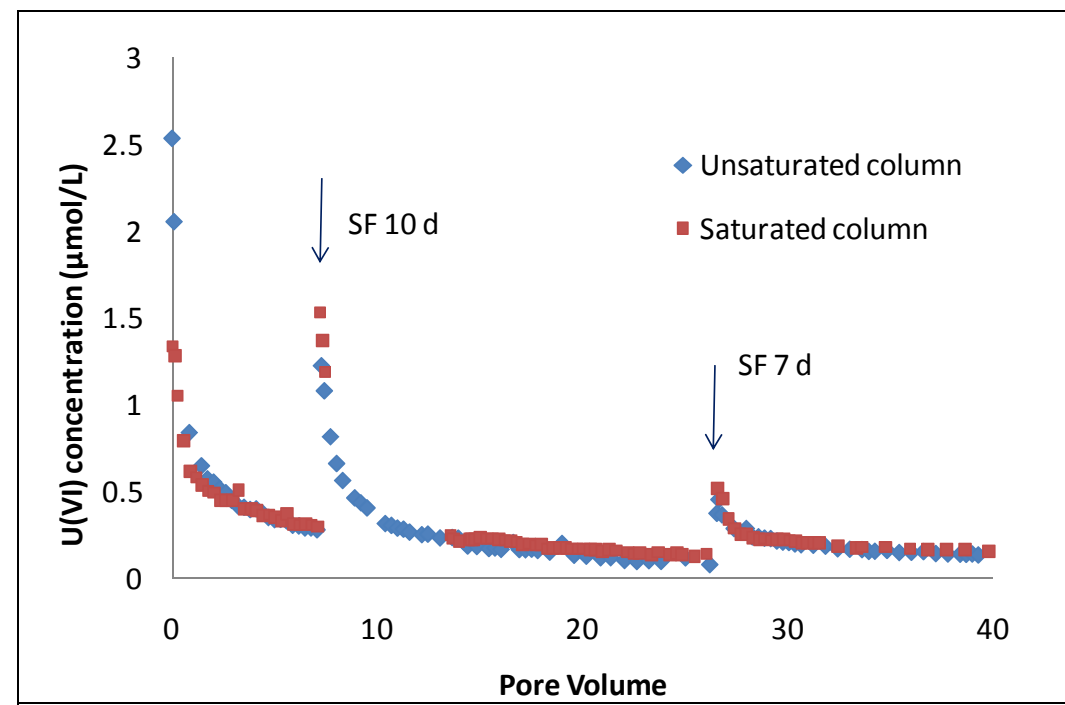

Figure V-8. Observed U(VI) concentrations in the transient water table experiment. During the stop flow events, one of the columns was allowed to drain (unsaturated) while the other was kept fully saturated. The pore volume needed to re-saturate the unsaturated column is not included in the calculation of pore volumes. 


\section{Hydrologic and Reactive Transport Modeling}

\section{Utility of Bromide and Heat Tracers for Aquifer Characterization in a Highly Dynamic Flow Environment}

A numerical simulation study was performed of the data set obtained from the March $2009 \mathrm{Br}$ and heat tracer test at the Hanford IFRC site. The numerical study revealed that the groundwater head data alone were insufficient to calibrate the hydraulic conductivity distribution. Inclusion of the $\mathrm{Br}$ tracer data from the experiment greatly improved the estimation of hydraulic conductivity and the determination of boundary conditions, but the data set in general was hampered by a lack of depth discrete tracer analyses.. The experiment also involved the injection of chilled water; with temporally robust, depth-specific temperature measurements of the movement and dissipation of the thermal plume. The modeling study evaluated how the increased measurement density of the temperature data might be used to further constrain the hydraulic conductivity distribution implied by the Br breakthrough data. The resulting temperature data were found to be difficult, but not impossible to interpret because of multiple processes involved in heat transport, and significant noises present in the temperature data.

Vertical intraborehole flows in the fully screened monitoring wells impacted the measurement and modeling analysis of solute concentrations from the experiment (Ma et al., 2011). The intraborehole flow effect was less significant on temperature data because depth-discreet temperature was measured by an array of thermisters installed at multiple depths on the outer wall of the wellbore. However, a temperature-induced fluid density effect on heat transport was pronounced, as observed during the field test and confirmed by the modeling results (see Figure V-10). The density effect occurred because the temperature difference between the injected fluid and background aquifer was $7^{\circ} \mathrm{C}$. The injected fluids of lower temperature had a tendency to sink to the lower aquifer zone. The results of the heat transport model calibration indicated that the thermal distribution coefficient $\left(K_{d}\right)$ was three orders of magnitude larger than literature reference data for similar sediment types. This implied that the IFRC sediments may contain more fine components, such as silt and clay, than previously thought because the direction and magnitude of change in $K_{d}$ was consistent with the specific heat/thermal conductivity of clays. In-situ heat transport within the aquifer was significantly retarded due to the high $K_{d}$ value. This, in turn, enhanced the density effect on heat transport in spite of the high flow velocity at the study site.

The trends of temperature changes and arrival times of the thermal plume in the simulated temperature breakthrough curves were in reasonable agreement with those in the measured data. A sensitivity analysis revealed how the most sensitive and controlling parameters to heat transport changed over time in response to different flow and transport conditions. In the early period of the field test, the temperature change was most sensitive to the hydraulic conductivity, indicating that the heat tracer was mainly transported by advection along with the groundwater flow. In the middle period, heat transport was more affected by retardation, and the thermal distribution coefficient $K_{d}$ became the most sensitive parameter, followed by porosity and hydraulic conductivity. For both periods, temperature was least sensitive to thermal conduction and dispersion, indicating the heat conduction in the aquifer sediments and heat dispersion in the aqueous phase were not important for controlling the heat transport. In the late period, most of the heat plume dissipated and the temperature difference between the heat plume and background aquifer became negligible. The sensitivities of all parameters converged close to each other, and consequently, thermal conduction in the sediments and heat dispersion in the aqueous phase played a greater role than in earlier periods. 
Modeling revealed that the simulated temperature breakthrough curves can match reasonably well with the observed ones, even though the hydraulic conductivity distribution calibrated for the Br tracer was directly used for modeling heat transport without any adjustment. This suggests that the temperature data can be used as a cost-effective proxy for conservative solute tracers to help constrain and improve the calibration of the hydraulic conductivity distribution, especially in the vertical direction. The advantage of such a proxy is obvious considering the ease and low cost in obtaining depth-specific temperature measurements.

However, the temperature-induced fluid density effect and heat peaks caused by sampling pumps represent modeling complications that make it more difficult to interpret and analyze a field heat tracer test. To mitigate these difficulties, a thermal tracer tests should be deliberately and carefully designed to eliminate unintended noises in the measurement data. Moreover, the temperature difference between the injected tracer fluid and background aquifer should be carefully determined by considering both the flow velocity and thermal distribution efficient $K_{d}$ to minimize the density effect, which could introduce additional parameters for calibration and complicate modeling analysis.

\section{IFRC Uranium Desorption Experiment}

The IFRC October 2009 U(IV) desorption experiment involved an injection rate at well 2-9 of $180 \mathrm{gpm}$, for a duration of $6.5 \mathrm{hrs}$. Injected concentrations of U(VI) were $5 \mathrm{mg} / \mathrm{L}$ and $\mathrm{Br}^{-}$were $180 \mathrm{mg} / \mathrm{L}$. Background U(VI) concentrations at the time of injection were $44 \mu \mathrm{g} / \mathrm{L}$ in the upper aquifer zone and 26 $\mu \mathrm{g} / \mathrm{L}$ in the lower zone. A major complication at the site is the extremely dynamic groundwater flow regime with oscillatory vertical flow (upward and downward) occurring in fully-screened wells between the upper and lower high conductivity zones. This results in fluctuating U(VI) concentrations pumped from the fully screened wells, as well waters can be dominated by either groundwater from the upper or lower aquifer zones depending on river stage and whether it is increasing or decreasing. In addition, the plume may leave the boundary of the site as river water intrudes and recedes.

Calculations were carried out using the multiple realization capability of PFLOTRAN (Hammond et al., $2010 \mathrm{~b}$ ). The code has the capability to run 100 s to 1000 s of realizations executed simultaneously on 100 s to 1000 s of processor cores within a single parallel job. Parallel simulations were executed on the Jaguar supercomputer at ORNL. A total of 64,000 processor cores were employed per ensemble of 500 realizations using 128 cores per realization. This results in 50,625 degrees of freedom per processor core for each realization. Note that each ensemble would require $\sim 7$ years to run on a desktop computer assuming parallel runs are 50\% efficient. Running in parallel it takes only 2 hours to complete an ensemble of runs - the time to complete one realization. Initial calculations have focused on only one of the 35 monitoring wells involved in the experiment, the injection well 2-9. The two primary objectives of the modeling were to evaluate: i.) the applicability of several different conceptual geochemical models to describe the U(VI) breakthrough trend and ii.) the most suitable boundary representation for the experiment. This initial series of calculations is intended to inform a more robust modeling activity of the desorption experiment results

A computational domain of $120 \times 120 \times 15 \mathrm{~m}^{3}$ was used in the simulations with a grid resolution of $1 \times 1$ x $0.5 \mathrm{~m}^{3}$ resulting in 430,000 grid cells. Geochemistry was represented by 15 primary and 88 secondary aqueous species, 2 minerals and 2 surface complexes. This resulted in a total of 6.48 million degrees of freedom per realization. 
In performing the sensitivity calculations based on multiple realization simulations several different scenarios were considered:

- Multirate kinetic vs. equilibrium surface complexation

- Three boundary conditions: A, B, C (see triangles on map in Figure V-11)

- $\mathrm{U}(\mathrm{VI})$ mineral dissolution vs. no dissolution

Each scenario consisting of 500 realizations required two hours to run on 64,000 processor cores. The simulations did not explicitly consider the different U(VI) concentrations present in the upper or lower aquifer zones, or the impacts of well bore flows as described by Ma et al., (2011)

Previous research by the IFRC team has revealed the high sensitivity of hydrologic modeling calculations to the boundary condition. This results from the very small hydrologic gradient at the site, the large perturbations to gradient that can occur with river stage oscillations, and the absence of ideally situation monitoring wells for groundwater elevation measurements. The modeling results are presented for each of the three boundary conditions in Figures V-12 to V-14. Well water concentrations between 0 and $150 \mathrm{~h}$ are reflective of upper aquifer conditions. The field data for $\mathrm{U}(\mathrm{VI})$ begins to display concentration oscillations between $22 \mu \mathrm{g} / \mathrm{L}$ and $35 \mu \mathrm{g} / \mathrm{L}$ after approximately $150 \mathrm{~h}$ as a result of vertical well bore flows. This particular model does not compute the effects of well bore flows on the monitoring data, but others used by the IFRC site do.

Observations from this preliminary study include:

- Boundary condition A, the multi-rate model, and no mineral dissolution; and boundary condition $\mathrm{C}$, the equilibrium model, and no mineral dissolution delivered best the best overall fits based on visual inspection.

- Mineral dissolution results in an overshoot of observed U(VI) concentrations, but could be reduced using a lower dissolution rate.

- The simulation quality is strongly influenced by the magnitude of the surface complexation and rate constants for adsorption. It is important that these are correctly defined and parameterized.

- Adsorption rate constants should be calibrated to better represent in-situ chemical conditions [lowered from $2 \times 10^{-17} \mathrm{~mol} / \mathrm{cm}^{3} / \mathrm{sec}$ used in Hammond and Lichtner (2010)].

- Equilibrium surface complexation almost always undershoots observed U(VI) concentrations.

- The three boundary conditions give significantly different results (compare A vs. B vs. C; see Figures V-12, V-13 and V-14).

Future directions in this ongoing work include: integrating updated field characterization results to generate random fields; imposing stratified U(VI) groundwater concentrations that are observed at the beginning and end of the experiment; calibrating multirate model parameters from field data, explicitly considering flow-paths with different sediment properties as implied by characterization measurements; considering more wells in the simulation domain; and implementing an adaptive mesh refinement 
algorithm to enable moving the boundary conditions imposed on the site to the river and farther inland. The boundary problem for the IFRC well-field will be solved during FY 2011 with the installation of 4 new corner-point wells (note black box in Figure V-11) for continuous and high-resolution monitoring of groundwater elevation. 


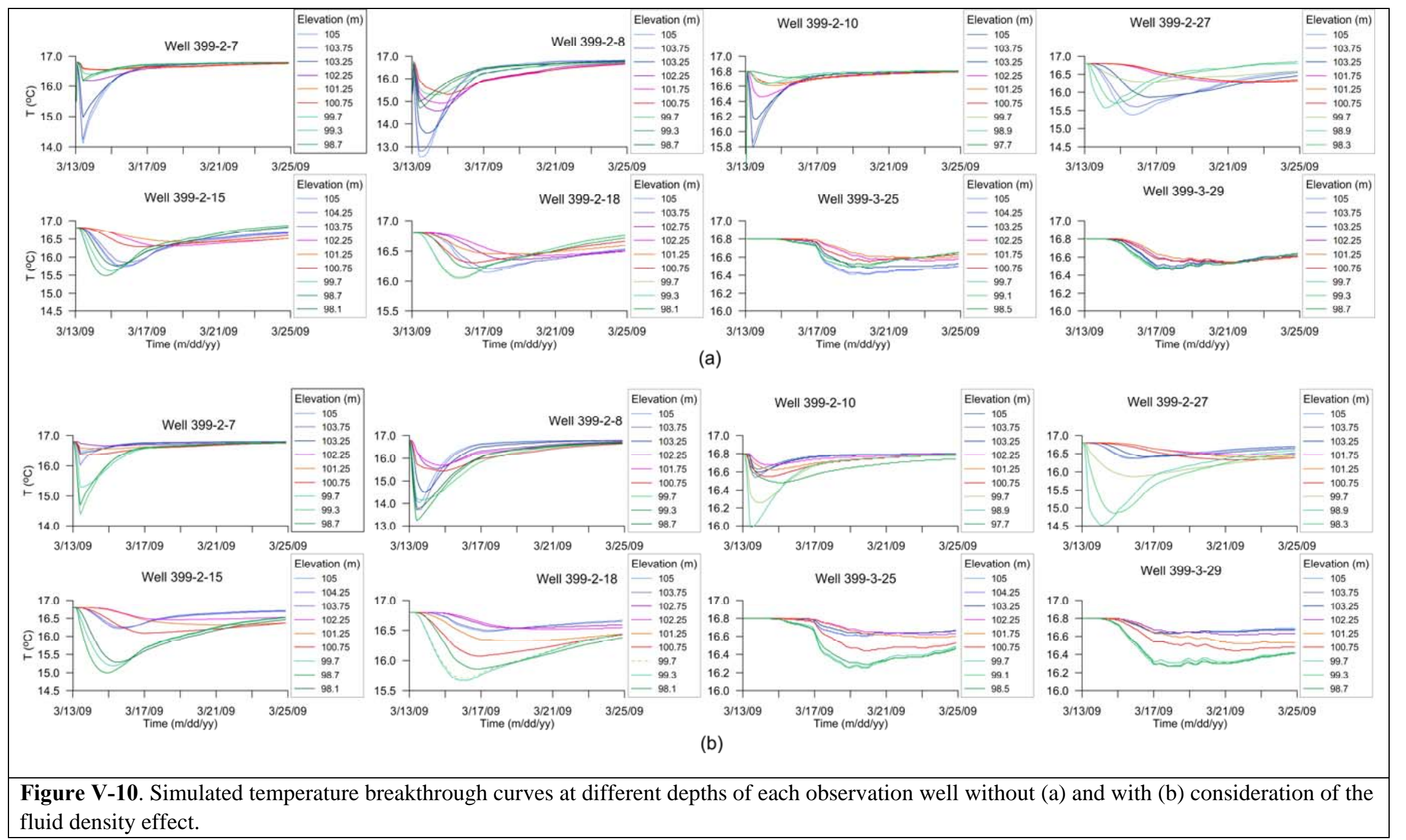




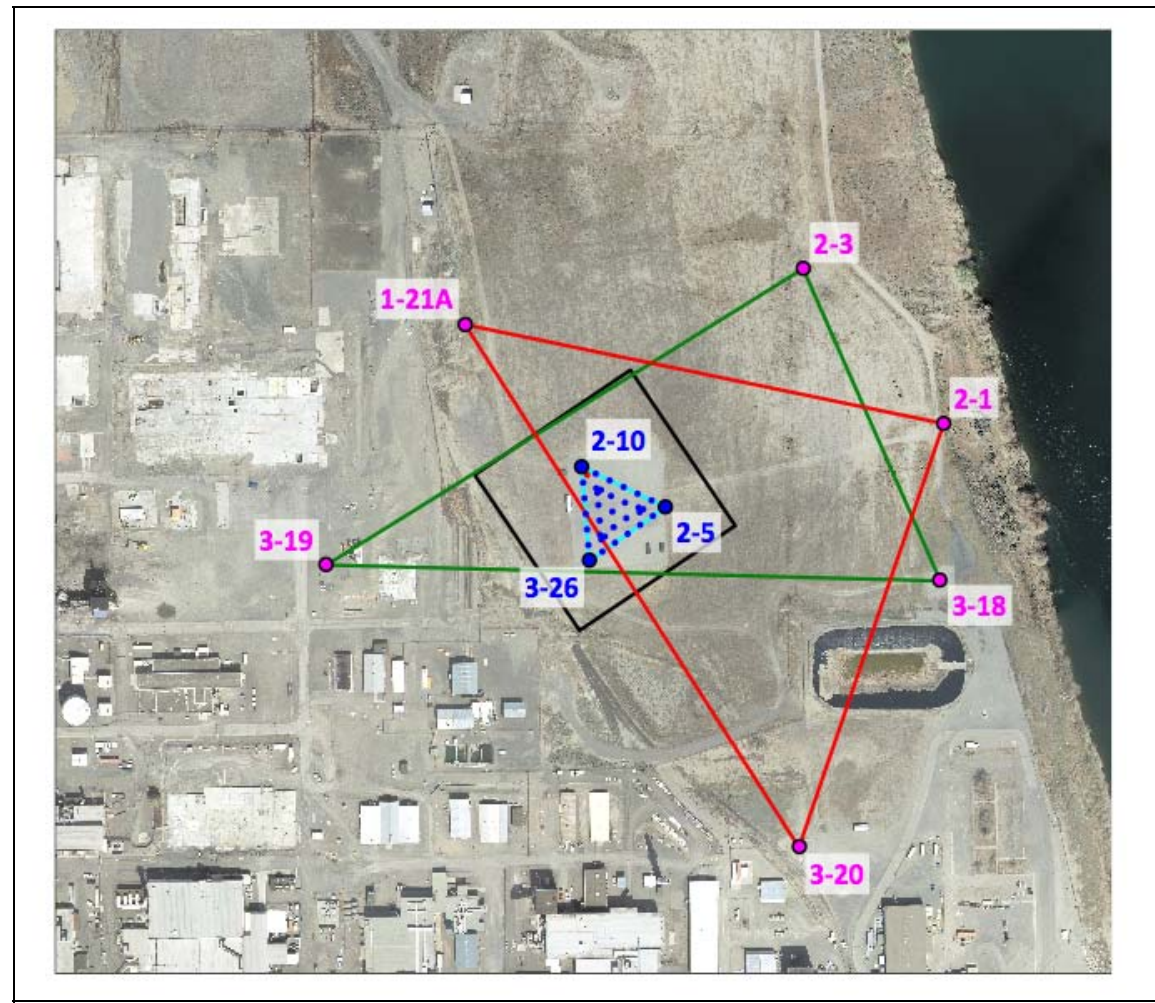

Figure V-11. Boundary conditions for scenarios A (green), B (red) and C (black). 

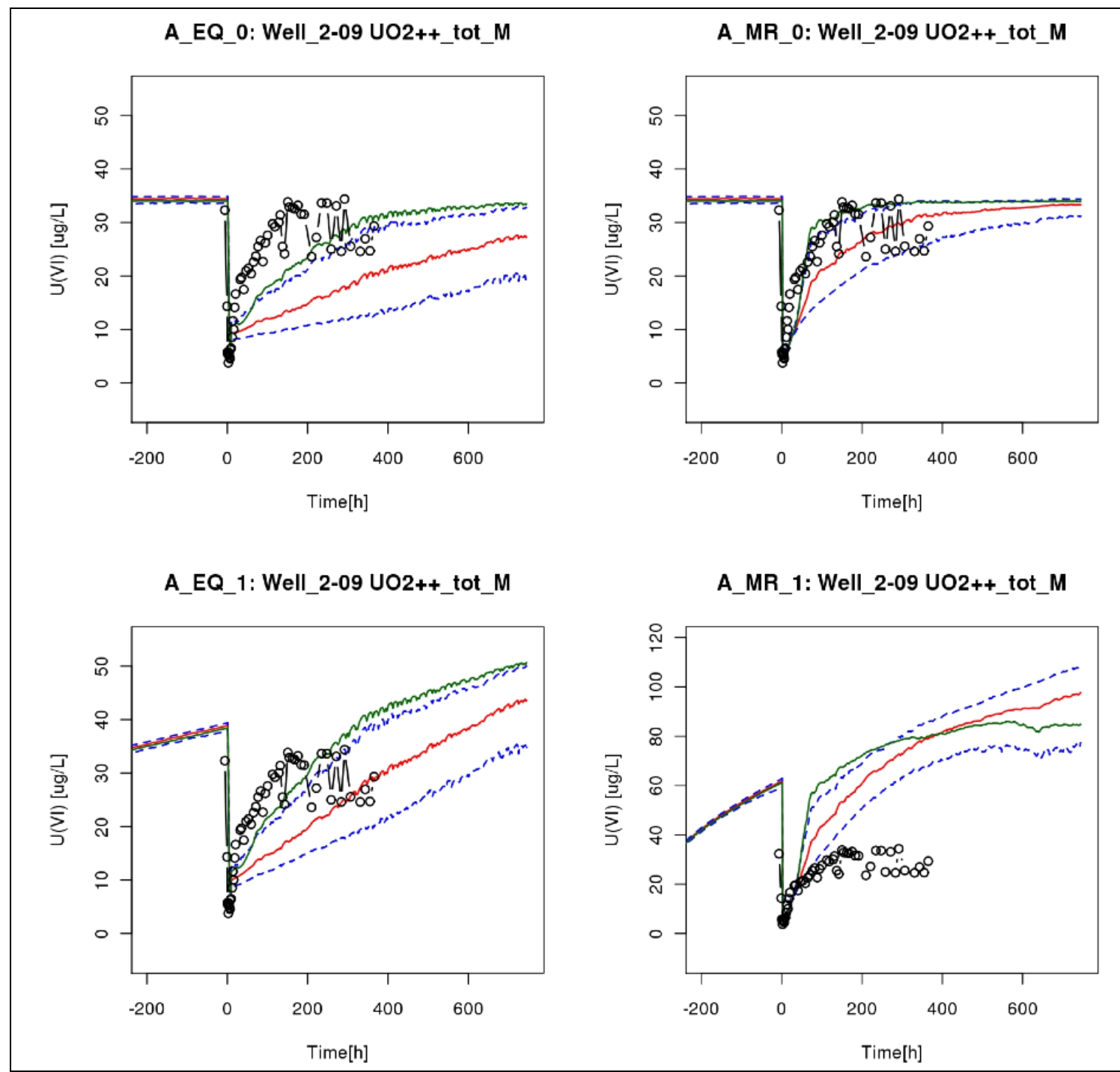

Figure V-12. Comparison of model simulations for U(VI) concentration with field data for boundary condition scenario A. 


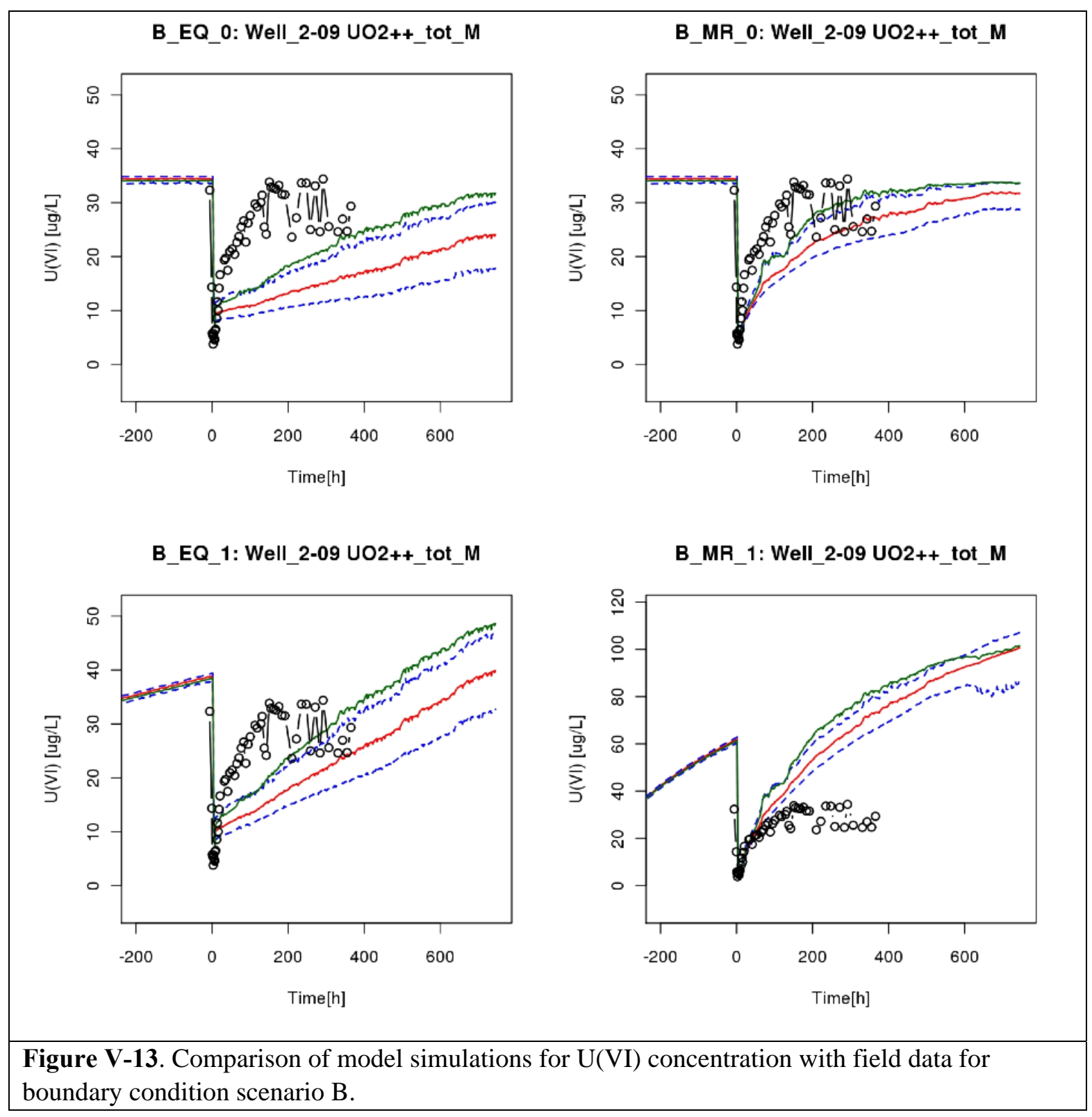




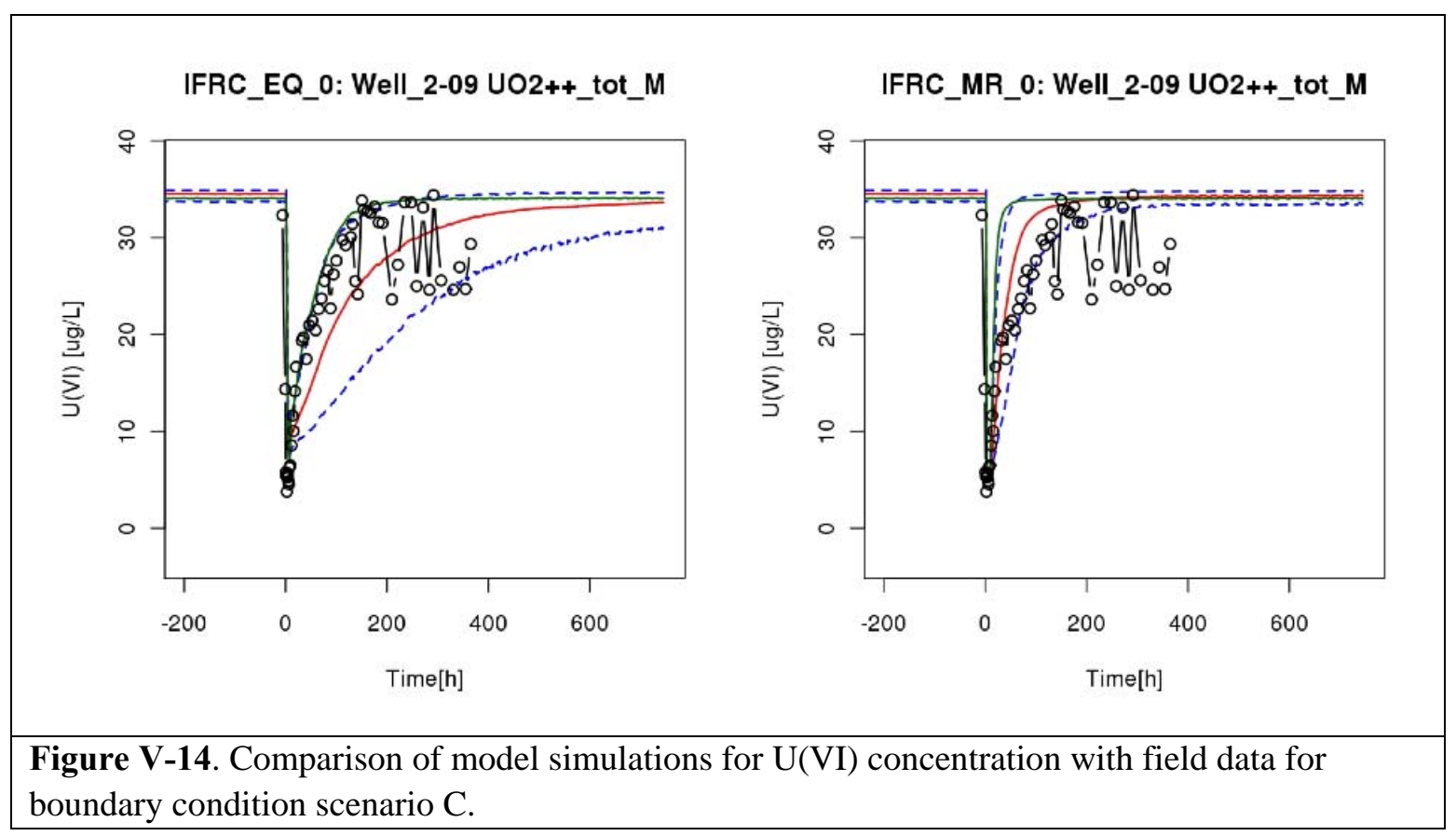




\section{FUTURE PLANS}

Significant plans for CY 2011 are described below.

\section{Hydrologic Control Wells}

Four new wells will be installed during CY 2011 at corner points of the IFRC modeling grid for hydrologic control. These wells will yield sediment samples for a variety of ongoing studies and characterizations, and they will be completed with high resolution pressure transducers for continuous water-level monitoring. The wells will be used for water composition monitoring, but will not be disturbed for any other purpose to assure continued accuracy in water level monitoring.

\section{Hydrologic Characterization of the Upper Aquifer}

The mitigated well-field will monitor the upper high-K zone of the U-plume and the smear zone when the water table is high. Hydrologic measurements will be performed at low and high water to better quantify the hydraulic conductivity of this domain. The wells will monitor the upper $1 \mathrm{~m}$ of the plume when the river stage is low, and $3 \mathrm{~m}$ of water when the water table is high. The measurements will include electromagnetic borehole flow-meter (EBF) surveys to obtain vertical profiles of relative hydraulic conductivity in each well. The EBF measurements will be complemented with constant rate injection tests in each well to measure bulk hydraulic conductivity. The results will be assimilated into the site-wide hydrophysical model using MAD.

\section{Spring 2011 Injection Experiment}

A non-reactive tracer and $\mathrm{U}(\mathrm{VI})$ desorption injection experiment will be performed in the upper high-K zone in early spring 2011. Significant pre-modeling has already been completed for this experiment using the eSTOMP code and reaction parameters fitted to laboratory experiments. The planned experiment will utilize a much longer injection period, 1 to 2 weeks, than other experiments performed to date. The injected waters will have a $\mathrm{U}$ concentration of approximately $3 \mu \mathrm{g} / \mathrm{L}$, as compared to the site background of $30 \mu \mathrm{g} / \mathrm{L}$. The experimental objective is to keep the plume of low concentration $U$ waters within the IFRC site for as long as possible to maximize the extent of $U$ desorption. This, in turn, will allow greater attenuation of returning higher concentration ground-waters. A major challenge will be the sampling and analysis of the plume over the expected month-long duration of the experiment. A sampling plan has been developed based on experiment pre-modeling, but sampling frequency is controlled to large extent by river stage fluctuations that influence plume trajectory. These day-to-day fluctuations are difficult to predict.

\section{Smear Zone Model}

Multi-scale laboratory experimental studies with the project-wide smear zone composite will continue, culminating in a smear zone reactive transport model in eSTOMP. The model will explicitly describe the time variable evolution of U(VI) concentration in groundwater that occurs during water table advance and retreat; as well as the influence of advective removals, river water intrusion and groundwater composition, and smear zone desaturation and drainage. The model, that explicitly includes the heterogeneous distribution of sorbed U(VI) as determined by site-wide characterization and geostatistical 
analysis, will be first applied to generic site hydrologic scenarios and then to simulate the results of past passive monitoring experiments as controlled by their recorded hydrologic history.

\section{IFRC Microbiology and Biogeochemistry}

Down-hole microbiology research in IFRC wells will continue in collaboration with the PNNL SFA. These studies will emphasize biogeochemical processes within the Ringold aquitard (redox transition zone) utilizing two fully-screened wells that allow unique access to this zone. These wells are located along the perimeter of the IFRC well-field; they were not remediated to allow for these continuing studies. IFRC-supported research will focus on preparations for a future resazurin (oxygen surrogate) injection experiment to assess in-situ heterotrophic activity in the upper high $\mathrm{K}$ zone, and the influence of seasonal oxygenated river water intrusion on this. Planned research for CY 2011 includes a series of reactive transport experiments with freshly sampled intact cores (collected from the new hydrologic control wells) where the rates of resazurin transformation by the in-situ community will be evaluated in a laboratory setting. The experiments will utilize different carbon sources and concentration, including DOC that has been isolated from up-gradient groundwater and the Columbia River.

\section{Infiltration Study}

Given success in our testing of geophysical imaging for monitoring of rainwater infiltration during wet winter months, we are planning a controlled infiltration experiment for September 2011. We will slowly apply a known volume of water consistent with a relatively large natural precipitation event to a small area of the IFRC site surface that has been selected based on underlying vadose-zone U(VI) inventory. The area will be one with good, down-gradient well coverage; and one shown by the passive monitoring experiments to be a U(VI) source zone to groundwater during periods of high water table. The infiltration of the "event" and its transport to the water table will be monitored by geophysical techniques, and the resulting impact of its discharge to groundwater monitored by compositional analysis of nearby, downgradient well-waters. Piezometers will be placed in the deep vadose zone and at the groundwater surface by direct drive technology if feasible. 


\section{CHALLENGES AND CONCERNS}

One of the greatest challenges to the project, that of vertical well bore flows, has hopefully been rectified by our well-field mitigation activity. This activity is underway with a planned completion date at February end. EBF measurements and tracer testing of all wells will determine the success of this activity. However, three remediated wells have already been tested and these have shown superior response with no detectable vertical flow. We are consequently optimistic. We do have concern as to how well the hydraulic characteristics of the upper aquifer will support field experimentation. Hydrologic testing to begin immediately will provide necessary insights.

An additional concern is focused on our geophysical research activity. We have recently made changes to staff and our approach, hoping to increase publication productivity and collaboration between investigators, and to facilitate greater assimilation of geophysical logging and characterization results into the site-wide IFRC hydrophysical model. The initial results of these changes have been encouraging; progress on this activity will be carefully monitored during FY 2011 to assure desired outcomes. The well-field mitigation activity will yield a substantially reduced down-hole geophysical monitoring capability. This is because the existing electrodes will not remain functional in bentonite. Consequently our ability to monitor plume behavior in the upper aquifer by geophysical methods will be limited because of significant loss in aspect ratio when the lower $2 / 3$ of the saturated zone is sealed with bentonite. During FY 2011 the project must decide whether to install a replacement geophysical monitoring system that is likely to cost approximately $\$ 300 \mathrm{~K}$. Designs and costing for several alternative plans for this system have been completed, and a research plan has been drafted that describes geophysical scientific activities that are accessible both with and without capabilities replacement. A final decision will be made on whether to proceed with geophysical monitoring capabilities replacement based on discussions with BER/SBR and other knowledgeable individuals, and the availability of requisite funding. 


\section{REFERENCES}

Archie, G. E. 1942. The electrical resistivity $\log$ as an aid in determining some reservoir characteristics. Petroleum transactions of AIME, 146:54-62.

Bjornstad, B., J. Horner, V. Vermeul, D. Lanigan, and P. Thorne. 2009. Borehole Completion and Conceptual Hydrogeologic Model for the IFRC Well Field, 300 Area, Hanford Site. Pacific Northwest National Laboratory, Richland, WA.

Bond, D. L., J. A. Davis, and J. M. Zachara. 2008. Uranium(VI) release from contaminated vadose zone sediments: Estimation of potential contributions from dissolution and desorption. In Adsorption of Metals to Geomedia II (M.O. Barnett and D. B. Kent, eds.), chapter 14, pp. 375 - 416, Elsevier, Amsterdam, Netherlands.

Chen, X., M. Haruko, M. S. Hahn, G. E. Hammond, M. Rockhold, Y. Rubin, and J. M. Zachara. 2011. Three-dimensional bayesian geostatistical aquifer characterization at the Hanford 300 Area using tracer test data. Water Resources Research (In preparation).

Davis, J. A., and D. B. Kent. 1990. Surface complexation modeling in aqueous geochemistry. In MineralWater Interface Geochemistry, Reviews in Mineralogy (M. F. Hochella and A. F. White, eds.) pp. 177260, Mineralogical Society of America, Washington, D. C.

De Barros, F., and Y. Rubin. 2011. Modeling of block-scale macrodispersion as a random function. Journal of Fluid Mechanics (Accepted).

Dong, W., and S. C. Brooks. 2006. Determination of the formation constants of ternary complexes of uranyl and carbonate with alkaline earth metal $\left(\mathrm{Mg}^{2+}, \mathrm{Ca}^{2+}, \mathrm{Sr}^{2+}\right.$, and $\left.\mathrm{Ba}^{2+}\right)$ using anion exchange method, Environ. Sci. Technol., 40:4689-4695.

Freeze, R. A., and J. A. Cherry. 1979. Groundwater. Englewood Cliffs, Prentice-Hall, Inc., New Jersey.

Gee, G., J. Keller, and A. Ward. 2005. Measurement and prediction of deep drainage from bare sediments at a semiarid site. Vadose Zone Journal, v. 4.

Herbelin, A. L., and J. C. Westall. 1999. FITEQL: A computer program for the determination of chemical equilibrium constants from experimental data. Oregon State University, Corvallis, OR.

Hoitink, D., K. Burk, J. Ramsdell, Jr., and W. Shaw. 2005. Hanford Site Climatological Summary 2004 with Historical Data. Pacific Northwest National Labotatory, Richland, WA.

Johnson, T. C., R. J. Versteeg, A. Ward, F. D. Day-Lewis, \& A. Revil. 2010. Improved hydrogeophysical characterization and monitoring through parallel modeling and inversion of time-domain resistivity and induced polarization data. Geophysics, 75(4):WA27-WA41.

Kohler, M., G. P. Curtis, D. E. Meece, and J. A. Davis. 2004. Methods for estimating adsorbed uranium (VI) and distribution coefficients of contaminated sediments. Environ. Sci. Technol., 38:240-247. 
Liu, C., J. M. Zachara, W. Yantansee, P. D. Majors, and J. P. McKinley. 2006. Microscopic reactive diffusion of uranium in the contaminated sediments at Hanford, USA. Water Resour. Res., 42:W12420, doi:10.1029/2006WR005031.

Liu, C., J. M. Zachara, N. P. Qafoku, and Z. Wang. 2008. Scale-dependent desorption of uranium from contaminated subsurface sediments. Water Resour. Res. 44:W08413, doi:10.1029/2007WR006478.

Liu, C., Z. Q. Shi, and J. M. Zachara. 2009. Kinetics of uranium(VI) desorption from contaminated sediments: Effect of geochemical conditions and model evaluation. Environ. Sci. Technol., 43:6560-6566.

Ma, R., C. Zheng, M. Tonkin, J. M. Zachara. 2011. Importance of considering intraborehole flow in solute transport modeling under highly dynamic flow conditions. J. Contam. Hydrol., doi:10.1016/j.jconhyd.2010.12.001.

McKinley, J. P., J. M. Zachara, C. T. Resch, R. A. Kaluzny, M. D. Miller, V. R. Vermeul, and D. L. Girvin. 2011. Vadose zone contributions to a contaminant aquifer plume during water table rise at the Columbia River at the Hanford Site, WA. Environmental Science \& Technology (In preparation).

Murakami, H., X. Chen, Y. Rubin. 2011. Sequential Bayesian geostatistical inversion and evaluation of combined data worth for aquifer characterization at the Hanford 300 Area. Water Resources Research (In preparation).

Murakami, H., X. Chen, M. L. Rockhold, V. R. Vermeul, and Y. Rubin. 2010. Bayesian geostatistical inversion of constant injection test data for a high-K aquifer characterization at the Hanford 300 Area. Hydrol. Earth Syst. Sci., 14, 1989-2001, doi:10.5194/hess-14-1989-2010.

Nowak, W., F. De Barros, and Y. Rubin. 2010. Bayesian geostatistical design: Optimal site investigation when the geostatistical model is uncertain. Water Resour. Res. , 46:W03535, 17 PP., 2010, doi:10.1029/2009WR008312.

Peterson, R. E., and M. P. Connelly. 2004. Water Movement in the Zone of Interaction between Groundwater and the Columbia River, Hanford Site, Washington, Medium. Pacific Northwest National Laboratory, Richland, WA.

Qafoku, N., J. M. Zachara, C. Liu, P. L. Gassman, and S. C. Smith. 2005. Kinetic desorption and sorption of U(VI) during reactive transport in a contaminated Hanford sediment. Environ. Sci. Technol., 39:31573165.

Peterson, R. E, M. L. Rockhold, R. J. Serne, P. D. Thorne, and M. D. Williams. 2008. Uranium Contamination in the Subsurface Beneath the 300 Area, Hanford Site, Washington. PNNL-17034, Pacific Northwest National Laboratory, Richland, WA.

Rubin, Y., X. Chen, H. Murakami, and M. Hahn. 2010. A Bayesian approach for inverse modeling, data assimilation, and conditional simulation of spatial random fields. Water Resour. Res. W10523, doi:10.1029/2009WR008799. 
Sinclair, K., and J. Kardouni. 2009. Surface-water/Groundwater Interactions and Near-stream Groundwater Quality along the Palouse River, South Fork Palouse River, and Paradise Creek, Environmental Assessment Program. Washington State Department of Ecology, Olympia, WA.

Stoliker, D. L., D. B. Kent, and J. M. Zachara. 2011. Application of surface complexation modeling to evaluate difference in equilibrium uranium(VI) adsorption properties of aquifer sediments.

Environmental Science Technology, (Submitted).

Vermeul, V. R., M. Williams, B. Fritz, R. Mackley, D. Mendoza, D. Newcomer, M. Rockhold, B. Williams, and D. Wellman. 2007. Treatability Test Plan for 300 Area Uranium Stabilization through Polyphosphate Injection. Pacific Northwest National Laboratory, Richland, WA.

Vermeul, V. R., J. P. McKinley, D. R. Newcomer, R. D. Mackley, and J. M. Zachara. 2010. Riverinduced flow dynamics in long-screen wells and impact on aqueous samples. Ground Water, doi: 10.1111/j.1745-6584.2010.00769.x: Ground Water, v. Online, p. 1-10.

Waichler, S. R., and S. B. Yabusaki. 2005. Flow and Transport in the Hanford 300 Area Vadose ZoneAquifer-River System. PNNL 15125, Pacific Northwest National Laboratory, Richland, WA.

Woessner, W. 2000. Stream and fluvial flood plain ground water interactions: rescaling hydrologic though. Ground Water, 38:423-429.

Yin, J., R. Haggerty, D. L. Stoliker, D. B. Kent, J. D. Istok, J. Greskowiak, and J. M. Zachara. 2011. Transient groundwater chemistry near a river: Effects on U(VI) transport in laboratory column experiments. Water Resour. Res., doi:10.1029/2010WR009369. 


\section{$\underline{2011}$}

\section{PRESENTATIONS/POSTERS}

Chen, X., H. Murakami, M. S. Hahn, G. E. Hammond, M. L. Rockhold, and Y. Rubin. 2011. "ThreeDimensional Bayesian Geostatistical Aquifer Characterization at the Hanford 300 Area using Tracer Test Data." Presented by Xingyuan Chen (Invited Speaker) at Hanford 300 Area IFRC project meeting, Richland, WA, January 19, 2011.

Christensen, J. N., M. E. Conrad, J. P. McKinley, D. L. Stoliker, D. J. DePaolo, and J. M. Zachara. 2011. "Isotopic Observations of the Spring 2009 Passive Rise Experiment." Presented by Christensen, J. N. (Invited Speaker) at IFRC All Hands meeting, Richland, WA, January 19, 2011.

Haggerty, R., and J. Yin. 2011. "Column Experiments on U(VI) Transport in Smear zone Composite: Transient Chemistry \& Transient Flow Results." Presented by R. Haggerty (Invited Speaker) at IFRC All Hands Meeting, Richland, WA, January 19, 2011.

Johnson, T. C. 2011. "Hanford 300 Area IFRC: Geophysical Monitoring System and Scientific Opportunities. "Presented by Tim Johnson (Invited Speaker) at IFRC all hand meeting, Richland, WA, January 19, 2011.

Kent, D. B., and D. L. Stoliker. 2011. "Smear-zone Geochemical \& Hydrologic Model: On-going Experiments \& Products." Presented by Doug Kent, Deb Stoliker (Invited Speaker) at IFRC All Hands Meeting, Richland, WA, January 19, 2011.

Lichtner, P. C. 2011. "IFRC Project Meeting: Adaptive Mesh Refinement and Plume Scale Modeling." Presented by Peter C. Lichtner (Invited Speaker) at IFRC All Hands Meeting, Richland, WA, January 19, 2011.

Liu, C., J. Shang, and J. M. Zachara. 2011. "Uranyl Adsorption/Desorption Kinetics." Presented by Chongxuan Liu at IFRC Project Meeting, Richland, WA, January 19, 2011.

McKinley, J. P., M. D. Miller, C. T. Resch, R. M. Kaluzny, V. R. Vermeul, and J. M. Zachara. 2011. "Aquifer Response to River Stage Fluctuations and the Resultant Uranium Contribution From the IFRC Smear Zone." Presented by James McKinley at IFRC Project Meeting, Richland, WA, January 19, 2011.

Murray, C. J., Y. J. Bott, J. P. McKinley, and J. M. Zachara. 2011. "Geostatistical Analysis of Extractable Uranium and Kd for U-233." Presented by Christopher Murray (Invited Speaker) at Hanford 300 Area IFRC Project Meeting, Richland, WA, January 19, 2011.

Rockhold, M. L. 2011. "Overview of Physical, Hydrologic, and Geophysical Data at the Hanford 300A IFRC Site." Presented by Mark L. Rockhold (Invited Speaker) at Hanford 300 Area IFRC Project Meeting, Richland, WA, January 19, 2011.

Rockhold, M. L. 2011."Observed and Simulated Results for the November 2008 Tracer Test at the Hanford 300 Area IFRC Site." Presented by Mark L. Rockhold (Invited Speaker) at Hanford 300 Area IFRC Project Meeting, Richland, WA, January 19, 2011. 
Rubin, Y. 2011. "Advanced Data Assimilation Strategies Status and Plans." Presented by Yoram Rubin (Invited Speaker) at IFRC All Hands Meeting, Richland, WA, January 19, 2011.

Vermeul, V. R., J. P. McKinley, D. R. Newcomer, B. G. Fritz, R. D. Mackley, and K. R. Parker. 2011. "River Induced Wellbore Flow Dynamics in IFRC Long-Screen Wells: Assessment of Mitigation Strategies." Presented by Vince Vermeul (Invited Speaker) at IFRC Project Meeting, Richland, WA, January 19, 2011.

Zheng, C., R. Ma, H. Prommer, J. Greskowiak, C. Liu, J. M. Zachara, and M. L. Rockhold. 2011. "Hydrologic and Tracer Experiments Simulations." Presented by Z. Chunmiao (Invited Speaker) at IFRC All Hands Meeting, WA, January 19, 2011.

\section{$\underline{2010}$}

Chen, X., H. Murakami, M. S. Hahn, G. E. Hammond, M. L. Rockhold, and Y. Rubin. 2010. "ThreeDimensional Bayesian Geostatistical Aquifer Characterization at the Hanford 300 Area using Tracer Test Data." AGU Fall Meeting, December, 2010.

Christensen, J. N., J. P. McKinley, M. E. Conrad, D. L. Stoliker, D. J. DePaolo, and J. M. Zachara. 2010. "Uranium Isotope Systematics in the 300 Area U Plume and the IFRC Plot: Progress Towards a Site U Isotopic Model." Presented by John N. Christensen at DOE-ERSP 5th Annual PI Meeting, Washington DC, March 31, 2010.

Christensen, J. N., J. P. McKinley, M. E. Conrad, D. L. Stoliker, P. E. Dresel, D. J. DePaolo, and J. M. Zachara. 2010. "Uranium Isotopic Systematics of the 300 Area (Hanford, WA) Groundwater Plume and U-contaminated Sediments." Presented by John N. Christensen at Goldschmidt 2010, Knoxville, TN, June 15, 2010.

de Barros, F. and Y. Rubin. 2010. "Modeling of Block-Scale Effective Macrodispersion Tensors as Space Random Functions.” AGU Fall Meeting, December, 2010.

Fredrickson, J. K. 2010. "Hanford 300 Area Subsurface Microbiology \& Biogeochemistry: Findings \& Scientific Opportunities." Presented by Jim K. Fredrickson (Invited Speaker) at DOE-ERSP 5th Annual PI Meeting, Washington DC, March 31, 2010.

Fredrickson, J, K., J. P. McKinley, C. T. Resch, J. H. Lee, X. Lin, A. Konopka, D. W. Kennedy, M. J. Marshall, C. I. Pearce, K. M. Rosso, B. N. Bjornstad, T. Peretyazhko, E. E. Roden, E. S. Shelobolina, and J. M. Zachara. 2010. "Biogeochemical Redox Transition with Depth in the Hanford 300 Area IFRC Subsurface." Presented by Jim K. Fredrickson (Invited Speaker) at DOE-ERSP 5th Annual PI Meeting, Washington DC, March 29, 2010.

Greskowiak, J., M. B. Hay, H. Prommer, C. Liu, V. Post, J. A. Davis. 2010. “Comparison of Chemical and Physical Non-equilibrium Models to Simulate Multi-scale Kinetic Mass-transfer and Surface Complexation of U(VI) in Porous media." Presented at Ground Water Summit, Denver, CO, 2010. 
Haggerty, R., D. B. Kent, C. Liu, J. Yin, D. L. Stoliker, C. Zheng, R. Ma, J. Greskowiak, G. E. Hammond, P. C. Lichtner, J. D. Istok, and J. M. Zachara. 2010. "Conceptual Model Development: Site Geochemical Reaction and Mass Transfer Model for U(VI) Transport and Field Validation for the Hanford IFRC." Presented by John M. Zachara (Invited Speaker) at DOE-ERSP 5th Annual PI Meeting, Washington DC, March 31, 2010.

Liu, C, and J. M. Zachara. 2010. "Scale-Dependency of Geochemical and Biogeochemical Reaction Rates: The Role of Pore-Scale Mass Transfer." Presented by Chongxuan Liu (Invited Speaker) at Seventh International Conference on Remediation of Chlorinated and Recalcitrant Compounds, Monterey, California, May 24-27, 2010.

Liu, C., S. N. Kerisit, J. M. Zachara, and R. P. Ewing. 2010. "Matrix Diffusion in Subsurface Porous Media." Presented by Chongxuan Liu (Invited Speaker) at 2010 International Groundwater Forum, Beijing, China, July 8, 2010.

Liu, C. and J. M. Zachara. 2010. "Scale-Dependent Rates of Geochemical and Biogeochemical Reactions." Presented by Chongxuan Liu (Invited speaker) at Chinese Academy of Science, Beijing, China, July 12, 2010,

Liu C., J. M, Zachara, and C. Zhang. 2010. "The Role of Pore-Scale Reactive Mass Transport in the Scale-Dependency of Geochemical and Biogeochemical Reaction Rates: A Uranyl Desorption Case." Presented by Chongxuan Liu (Invited Speaker) at DOE 5th Annual ERSP PI Meeting, Washington DC, March 29, 2010.

Liu, C., J. M. Zachara, S. N. Kerisit, and Z. Wang. 2010. "Multi-Scale Investigation on Mass Transfer Processes in Subsurface Porous Media." Presented by Chongxuan Liu (Invited Speaker) at 2010 CMSDDRC Poster Session, Richland, WA, June 15, 2010.

Liu, C., J. Shang, S. N. Kerisit, Z. Wang, and J. M. Zachara. 2010. "Intra-grain Reactive Diffusion of Uranium and Upscaling in Subsurface Sediments." Presented by Chongxuan Liu at 2010 Annual AGU Fall Meeting, San Francisco, CA, December 17, 2010.

Ma, R., C. Zheng, C. Liu, J. Zachara, H. Prommer, J. Greskowiak. 2010. “A Multi-rate Mass Transfer Model for Field-scale Uranium Transport in a Physically and Chemically Heterogeneous Aquifer.” Presented at Ground Water Summit, Denver, CO, 2010.

Ma, R., C. Zheng, M. Tonkin, J. M. Zachara. 2010. "Importance of Considering Intraborehole Flow in Solute Transport Modeling under Highly Dynamic Flow Conditions." Abstract H52C-05, presented at 2010 Fall Meeting, AGU, San Francisco, CA, December 13-17, 2010.

Ma, R., C. Zheng, C. Liu, J. Zachara, H. Prommer, J. Greskowiak. 2010 "Coupled Process Modeling of Hanford IFRC Site, USA." Presented at the International Groundwater Forum, Beijing, China, July 8-9, 2010.

McKinley, J. P., J. M. Zachara, C. T. Resch, D. C. Girvin, R. M. Kaluzny, V. R. Vermeul, and J. N. Christensen. 2010. "The Deep Vadoze Zone as a Source of Uranium to the Unconfined Aquifer at the 
Hanford Site IFRC." Presented by James P. McKinley (Invited Speaker) at DOE-ERSP 5th Annual PI Meeting, Washington DC, March 28, 2010.

McKinley, J. P., J. M. Zachara, C. T. Resch, D. C. Girvin, R. M. Kaluzny, V. R. Vermeul, and J. N. Christensen. 2010. "The Deep Vadoze Zone as a Source of Uranium to the Near-shore Aquifer at the Hanford Site, Washington." Presented by John N. Christensen at Goldschmidt 2010, Knoxville , TN, June $15,2010$.

Murakami, H., X. Chen, M. S. Hahn, M. W. Over, M. L. Rockhold, V. Vermeul, G. E. Hammond, J. M. Zachara, and Y. Rubin. 2010. "Sequential Bayesian Geostatistical Inversion and Evaluation of Combined DataWorth for Aquifer Characterization at the Hanford 300 Area." AGU Fall Meeting, December, 2010.

Murray, C. J., J. M. Zachara, J. P. McKinley, Y. J. Bott, and D. A. Moore. 2010. "Establishing a Geochemical Heterogeneity Model for a Contaminated Vadose Zone - Aquifer System.” Presented by Chris Murray (Invited Speaker) at DOE-ERSP 5th Annual PI Meeting, Washington DC, March 29, 2010.

Murray, C. J., J. M. Zachara, J. P. McKinley, and Y. J. Bott. 2010. "Establishing a Geochemical Heterogeneity Model for a Contaminated Vadose Zone-Aquifer System." Presented by Chris Murray at AGU - American Geophysical Union Fall Meeting 2010, San Francisco, CA, December 15, 2010.

Over, M. W., H. Murakami, M. S. Hahn, Y. Yang, and Y. Rubin. 2010. "Multi-dimensional Likelihood Estimation Techniques in Conjunction with the Method of Anchored Distributions (MAD)." AGU Fall Meeting, December, 2010.

Rockhold, M. L., V. R. Vermeul, C. J. Murray, and J. M. Zachara. 2010. "Hydrogeologic Characterization of the Hanford 300 Area IFRC Site, Observed and Simulated Tracer Test Results, and Plans for Future Refinements." Presented by Mark L. Rockhold (Invited Speaker) at Fifth Annual DOE ERSP-PI Meeting, Washington DC, March 30, 2010.

Rockhold, M. L., V. R. Vermeul, C. J. Murray, and J. M. Zachara. 2010. "Geohydrology of the Hanford 300 Area IFRC Site." Presented by Mark L. Rockhold (Invited Speaker) at Fifth Annual DOE ERSP-PI Meeting, Washington DC, March 29, 2010.

Rockhold, M., V. Vermeul, R. Mackley, D. Newcomer, B. Fritz, D. Mendoza, E. Newcomer, T. Wietsma, M. Oostrom, P. Thorne, C. Murray, and J. Zachara. 2010. "Geohydrology of the Hanford 300 Area IFRC Site." Oral Presentation for IFRC Project Review at the $5^{\text {th }}$ Annual DOE-ERSP PI Meeting, Washington DC, March 29-April 1, 2010.

Rockhold, M. L., M. Oostrom, T. W. Wietsma, and J. M. Zachara. 2010. "Correlations Between Physical and Hydraulic Properties and Uranium Desorption in Contaminated, Intact Sediment Cores." Presented by Mark L. Rockhold at AGU, San Francisco, CA, December 17, 2010.

Rubin, Y., W. Nowak, and F. de Barros. 2010. “A Task-oriented Approach for Hydrogeological Site Characterization.” AGU Fall Meeting, December, 2010.

Rubin, Y., X, Chen, H, Murakami, M. S. Hahn, M. L. Rockhold, V. R. Vermeul, G. E. Hammond, and 
P. C. Lichtner. 2010. "Data Assimilation for Saturated Zone Hydraulic Conductivity Model and Future Plans." Presented by John M. Zachara at DOE-ERSP 5th Annual PI Meeting, Washington DC, March 31, 2010.

Rubin, Y., X. Chen, H. Murakami, M. S. Hahn, M. L. Rockhold, V. R. Vermeul, G. E. Hammond, P. C. Lichtner, M. D. Freshley, and J. M. Zachara. 2010. "Modeling and Data Assimilation at the Hanford Site." Presented by Yoram Rubin at DOE-ERSP 5th Annual PI Meeting, Washington DC, March 29, 2010.

Stoliker, D. L., D. B. Kent, J. Yin, R. Haggerty, M. B. Hay, J. A. Davis, and J. M. Zachara. 2010. "Geochemical Controls and Grain-scale Modeling of U(VI) Mass-transfer in the Hanford 300-Area Aquifer." 240 ${ }^{\text {th }}$ American Chemical Society National Meeting, Boston, MA, 2010.

Vermeul, V. R., J. P. McKinley, D. R. Newcomer, B. G. Fritz, R. D. Mackley, and J. M. Zachara. 2010. "River Induced Wellbore Flow Dynamics in Hanford IFRC Monitoring Wells: Evidence, Implications, and Mitigation." Presented by John M. Zachara (Invited Speaker) at DOE-ERSP 5th Annual PI Meeting, Washington DC, March 31, 2010.

Zachara, J. M., M. D. Freshley, B. N. Bjornstad, J. N. Christensen, M. S. Conrad, J. K. Fredrickson, G. E. Hammond, R. Haggerty, T. C. Johnson, D. B. Kent, A. Konopka, P. C. Lichtner, C. Liu, J. P. McKinley, C. J. Murray, M. L. Rockhold, Y. Rubin, V. R. Vermeul, R. J. Versteeg, A. L. Ward, C. Zheng, and K. M. Thompson. 2010. "Integrated Field Research Challenge Site Hanford 300 Area ." Presented by John M. Zachara (Invited Speaker) at DOE-ERSP 5th Annual PI Meeting, Washington DC, March 29, 2010.

Zachara, J. M. 2010. "Multi-Scale Mass Transfer Processes Controlling Natural Attenuation and Engineered Remediation: An IFRC Focused on Hanford's 300 Area Uranium Plume." Presented by John M. Zachara (Invited Speaker) at DOE-ERSP 5th Annual PI Meeting, Washington DC, March 31, 2010.

Zachara, J. M., B. N. Bjornstad, C. Zheng, D. B. Kent, J. K. Fredrickson, M. D. Freshley, G. E. Hammond, J. N. Christensen, A. Konopka, C. Liu, M. S. Conrad, J. P. McKinley, P. C. Lichtner, M. L. Rockhold, R. J. Versteeg, R. Haggerty, T. C. Johnson, V. R. Vermeul, A. L. Ward, and Y. Rubin. 2010. "Laboratory \& Field Studies of Uranium Migration in a Linked Groundwater-River System: Hydrologic \& Geochemical Interactions." Presented by John M. Zachara (Invited Speaker) at China University of Geosciences-Beijing, Beijing, China, July 14, 2010.

Zachara, J. M. 2010. "Environmental Geochemistry of Uranium in a Coupled Vadose Zone-GroundwaterRiver System." Presented by John M. Zachara (Invited Speaker) at Washington State University Seminar Series, Pullman, WA, September 13, 2010.

Zachara, J. M. 2010. "Environmental Geochemistry of Uranium in a Coupled Vadose Zone-GroundwaterRiver System." Presented by John M. Zachara (Invited Speaker) at Evergreen State College, Olympia, WA, November 30, 2010.

Zheng, C., R. Ma, Y. Fang, J. Greskowiak, H. Prommer, J. M .Zachara, M. L. Rockhold, and A. L. Ward. 2010. "Coupled Process Modeling of the IFRC Site: Approaches, Insights, and Future Plans ." 
Presented by John M. Zachara (Invited Speaker) at DOE-ERSP 5th Annual PI Meeting, Washington DC, March 31, 2010. 


\section{$\underline{2011}$}

\section{PUBLICATIONS}

Chen, X., H. Murakami, M. S. Hahn, G. E. Hammond, M. L. Rockhold, Y. Rubin and J. M. Zachara.

2011. Three-dimensional Bayesian geostatistical aquifer characterization at the Hanford 300 Area using tracer test data. Water Resources Research. (In preparation).

de Barros, F. and Y. Rubin. 2011. Modelling of block-scale macrodispersion as a random function, Journal of Fluid Mechanics (Accepted).

Ewing, R. P., C. Liu, and Q. Hu. 2011. Modeling intragranular diffusion starting from nonequilibrium, Water Resources Research (Submitted).

Fang Y., J. M. Zachara, and C. Liu. 2011. Uranium(VI) mass transfer under various injection conditions at Hanford Integrated Field Research challenge site. Water Resources Research (In preparation).

Greskowiak, J., M. B. Hay, H. Prommer, C. Liu, V. E. Post, R. Ma, J. A. Davis, C. Zheng, and J. M. Zachara. 2011. Simulating adsorption of U(VI) under transient groundwater flow and hydrochemistry physical versus non-equilibrium model. Water Resources Research (Submitted).

Hammond, G. E., P. C. Lichtner, and M. L. Rockhold. 2011. Stochastic simulation of uranium migration at the Hanford 300 Area. J. Contam. Hydrol.120-121, (115-128).

Hay, M. B., D. L. Stoliker, J. A. Davis, and J. M. Zachara. 2011. Characterization of the intragranular water regime within subsurface sediments: Pore volume, surface area, and mass transfer limitations. Water Resources Research (Submitted).

Liu, C., J. M. Zachara, and A. Reed. 2011. Scale dependent rates of uranyl desorption from contaminated sediments: Role of pore-scale reactive mass transfer. Environmental Science and Technology (In revision).

Liu, C., J. Shang, and J. M. Zachara. 2011. Multi-species diffusion models: A study of uranyl species diffusion. Water Resources Research (In preparation).

Liu C., S. Kerisit, J. Shang, and J. M. Zachara. 2011. Pore size effect on the rate of diffusive mass transfer of uranyl species. Environmental Science and Technology (In preparation).

Long, P., K. Williams, M. Freshley, J. Zachara, J. Davis, S. Yabusaki, and M. Rockhold. 2011. Persistence of uranium groundwater plumes: Contrasting mechanisms at two contaminated DOE sites. Journal Contaminant Hydrology (In preparation).

Ma, R., C. Zheng, M. Tonkin, and J. M. Zachara. 2011. Importance of intra-borehole flow in solute transport modeling under highly dynamic flow conditions. Journal Contaminant Hydrology. doi:10.1016/j.jconhyd.2010.12.001. 
Ma, R., J. Greskowiak, H. Prommer, C. Liu, C. Zheng, and J. Zachara. 2011. Model-based quantification of the influence of calcite on uranium mobility at the groundwater/surface water interface. Environmental Science and Technology (In preparation).

Ma, R., C. Zheng, J. M. Zachara, and M. Tonkin. 2011. Utility of bromide and heat tracers for aquifer characterization in a highly dynamic environment. Water Resources Research (In preparation).

McKinley, J. P., J. M. Zachara, C. T. Resch, D. L. Girvin, M. D. Miller, J. L. Phillips, V. R. Vermeul, and T. A. Beck. 2011. Vadose zone contributions to groundwater U plume driven by water table fluctuations in a riparian aquifer at the Columbia River, Washington. Environmental Science and Technology (In preparation).

Murakami, H., X. Chen, and Y. Rubin. 2011. Sequential Bayesian geostatistical inversion and evaluation of combined data worth for aquifer characterization at the Hanford 300 Area. (In preparation).

Murray, C., J. M. Zachara, J. P. McKinley, Y. Bott, and D. Moore. 2011. A geochemical heterogeneity model for a contaminated vadose zone - aquifer system with dynamic water table fluctuation. Journal of Contaminant Hydrology (In preparation).

Revil, A., M. Karaoulis, T. C. Johnson, and A. Kemna. 2011. A review of low-frequency electrical methods for subsurface characterization and monitoring in hydrogeology. Hydrogeology Journal (Submitted).

Rockhold, M. L., X. Chen, T. C. Johnson, V. R. Vermeul, and J. M. Zachara. 2011. Geophysical data assimilation for facies delineation and application to inverse modeling of a field tracer test. Water Resources Research (In preparation).

Rockhold, M. L., V. R. Vermeul, R. Mackley, B. Fritz, D. Mendoza, E. Newcomer, D. Newcomer, C. J. Murray, and J. M. Zachara. 2011. Hydrogeologic characterization of the Hanford 300 Area Integrated Field Research Challenge Site and numerical modeling of the first aquifer tracer test. Groundwater (Submitted).

Shang J., C. Liu, and J. M. Zachara. 2011. Grain-size dependent kinetics of uranium(VI) adsorption and desorption and rate additivity (In preparation).

Stoliker, D. L., D. B. Kent, and J. M. Zachara. 2011. Application of surface complexation modeling to evaluate difference in equilibrium uranium(VI) adsorption properties of aquifer sediments.

Environmental Science and Technology (Submitted).

Wang, Z., J. M. Zachara, J. -F. Boily, D. Moore, Y. Xia, and K. Draper. 2011. Unraveling U(VI) surface speciation at low concentration by CLIFS spectroscopy: Application to contaminated aquifer sediments. Geochimica Cosmochimica Acta (Submitted).

Yin, J., D. R. Haggerty, D. L. Stoliker, D. B. Kent, J. D. Istok, J. Greskowiak, and J. M. Zachara. 2011. Transient groundwater chemistry and groundwater flow near a river: Effects on U(VI) transport. Water Resources Research (Accepted). 
Zachara, J. M., C. Liu, M. Oostrom, J. P. McKinley, T. Wietsma, and C. T. Resch. 2011. Mass transfer limited adsorption and desorption of $\mathrm{U}$ in intact sediment cores retrieved from a contaminated aquifer. Environmental Science and Technology (In preparation).

\section{$\underline{2010}$}

Ewing, R. P., Q. Hu, and C. Liu. 2010. Scale dependence of intragrain porosity, tortuosity, and diffusivity, Water Resour. Res. 46, W06513.

Greenwood, W. J. 2010. Characterizing anisotropy and heterogeneity in a fluvial aquifer with azimuthal resistivity soundings. Journal Applied Physics (Submitted).

Greskowiak, J., H. Prommer, C. Liu, V. E. A. Post, R. Ma, C. Zheng, and J. M. Zachara. 2010.

Comparsion of parameter sensitivities between a laboratory and field scale model of uranium transport in a dual-domain, distributed-rate reactive system. Water Resour. Res. 46 (W09509).

Hammond, G. E. and P. C. Lichtner. 2010. Field-scale model for the natural attenuation of uranium at the Hanford 300 area using high performance computing. Water Resources Research (Accepted).

Harrington, S. J., B. D. Wood, and R. Haggerty. 2010. Effects of equilibrium pH and inorganic carbon on uranium transport in Hanford sediment. Environmental Science and Technology (Submitted).

Ilton, E. S., J. M. Zachara, D. A. Moore, J. P. McKinley, A. D. Eckberg, C. L. Cahill, and A. R. Felmy. 2010. A dissolution study of metatorbernite: Thermodynamic properties and the effect of $\mathrm{pH}$ and phosphate. Environ. Sci. and Technol. es101619f_webrelease.

Johnson, T., R. Versteeg, A. Ward, F. Day-Lewis, and A. Revil. 2010. Improved hydrogeophysical characterization and monitoring through parallel modeling and inversion of time-domain resistivity and induced polarization data. Geophysics. J. 75(4), 27-41.

Johnson, T. C., R. J. Versteeg, A. Ward, J. Greenwood, and C. Strickland. 2010. Electrical geophysical characterization of the Hanford 300 Area Integrated Field Research Challenge well-field using high performance DC resistivity inversion geostatistically constrained by borehole conductivity logs. Geostatistics (Submitted).

Kerisit, S. and C. Liu. 2010. Molecular simulation of the diffusion of uranyl carbonate species in aqueous solution. Geochim. Cosmochim. Acta. 74: 4937-4952.

Ma, R., C. Zheng, H. Prommer, J. Greskowiak, C. Liu, J. Zachara, and M. Rockhold. 2010. A field-scale reactive transport model for $\mathrm{U}(\mathrm{VI})$ migration influenced by coupled multi-rate mass transfer and surface complexation reactions. Water Resour. Res. 46 (W05509):1-17.

Ma, R., and C. Zheng. 2010. Effects of density and viscosity in modeling heat as a groundwater tracer. Groundwater. doi:10.1111/j.1745-6584.2009.00660.x. 
Murakami, H., X. Chen, M. S. Hahn, Y. Liu, M. L. Rockhold, V. R. Vermeul, and Y. Rubin. 2010. Bayesian approach for three-dimensional aquifer characterization at the Hanford 300 Area. Hydrol. Earth Syst. Sci. 14;1989-2001.

Newcomer, D. R., B. N. Bjornstad, and V. R. Vermeul. 2010. Vertical wellbore flow monitoring for assessing spatial and temporal flow relationships with a dynamic river boundary. Groundwater Monitoring and Remediation (In press).

Nowak, W., F. de Barros, and Y. Rubin. 2010. Bayesian geostatistical design: Optimal site investigation when the geostatistical model is uncertain. Water Resour. Res. 46 (W03535).

Rubin, Y., X. Chen, H. Murakami, and M. Hahn. 2010. A Bayesian approach for inverse modeling, data assimilation, and conditional simulation of spatial random fields. Water Resourc. Res. 46 (W10523), doi:10.1029/2009WR008799.

Spane, F. A. and R. D. Mackley. 2010. Removal of river-stage fluctuations from unconfined aquifer well response using a multiple-regression deconvolution approach. Groundwater (In press)

Um, W., J. M. Zachara, C. Liu, and D. Moore. 2010. Resupply mechanism to a contaminated aquifer: A laboratory study of U(VI) desorption from capillary fringe sediments. Geochim. Cosmochim. Acta. 74(18):5155-5170.

Vermeul, V. R., J. P. McKinley, D. R. Newcomer, R. D. Mackley, and J. M. Zachara. 2010. River induced wellbore flow dynamics in long-screen wells and their impact on aqueous sampling results. Groundwater. doi:10.1111/j.1745-6584.2010.00769. 


\section{REPORTS}

2011

Zachara, J. M. Hanford IFRC Quarterly Report, January 2011. PNNL-20126, Pacific Northwest National Laboratory, Richland, WA.

\section{$\underline{2010}$}

Zachara, J. M., B. N. Bjornstad, J. N. Christensen, M. E. Conrad, J. K. Fredrickson, M. D. Freshley, R. Haggerty, G. Hammond, D. B. Kent, A. Konopka, P. C. Lichtner, C. Liu, J. P. McKinley, C. J. Murray, M. L. Rockhold, Y. Rubin, V. R. Vermeul, R. J. Versteeg, A. L. Ward, and C. Zheng. 2010. Multi-Scale Mass Transfer Processes Controlling Natural Attenuation and Engineered Remediation: An IFRC Focused on Hanford's 300 Area Uranium Plume. PNNL-19209, Pacific Northwest National Laboratory, Richland, WA.

Zachara, J. M., Hanford IFRC Quarterly Report, January 2010. PNNL-SA-70422, Pacific Northwest National Laboratory, Richland, WA.

Zachara, J. M. Hanford IFRC Quarterly Report, July 2010. PNNL-SA-74316, Pacific Northwest National Laboratory, Richland, WA.

Zachara J. M. IFRC FY10 First Quarter Performance Measure. PNNL-SA-75592, Pacific Northwest National Laboratory, Richland, WA.

Zachara J. M. IFRC FY10 Second Quarter Performance Measure. PNNL-SA-75593, Pacific Northwest National Laboratory, Richland, WA.

Zachara, J. M. IFRC FY10 Third Quarter Performance Measure. PNNL-SA-75589, Pacific Northwest National Laboratory, Richland, WA.

Zachara, J. M. IFRC FY10 Fourth Quarter Performance Measure. PNNL-SA-7559, Pacific Northwest National Laboratory, Richland, WA.

Zachara J. M. Hanford IFRC Quarterly Report \& Well Field Mitigation Plan, October 2010. PNNL-SA75653, Pacific Northwest National Laboratory, Richland, WA. 